\title{
Review Article \\ Recent Applications of Mass Spectrometry in the Study of Grape and Wine Polyphenols
}

\author{
Riccardo Flamini \\ Consiglio per la Ricerca e la Sperimentazione in Agricoltura-Centro di Ricerca per la Viticoltura (CRA-VIT), \\ Viale XXVIII Aprile 26, 31015 Conegliano, Italy \\ Correspondence should be addressed to Riccardo Flamini; riccardo.flamini@entecra.it
}

Received 24 September 2012; Accepted 12 October 2012

Academic Editors: D.-A. Guo, T. Stafilov, and M. Valko

Copyright (C) 2013 Riccardo Flamini. This is an open access article distributed under the Creative Commons Attribution License, which permits unrestricted use, distribution, and reproduction in any medium, provided the original work is properly cited.

Polyphenols are the principal compounds associated with health benefic effects of wine consumption and in general are characterized by antioxidant activities. Mass spectrometry is shown to play a very important role in the research of polyphenols in grape and wine and for the quality control of products. The soft ionization of LC/MS makes these techniques suitable to study the structures of polyphenols and anthocyanins in grape extracts and to characterize polyphenolic derivatives formed in wines and correlated to the sensorial characteristics of the product. The coupling of the several MS techniques presented here is shown to be highly effective in structural characterization of the large number of low and high molecular weight polyphenols in grape and wine and also can be highly effective in the study of grape metabolomics.

\section{Principal Polyphenols of Grape and Wine}

Polyphenols are the principal compounds associated to health benefic effects of wine consumption. A French epidemiological study performed in the end of 1970s reported that in France, despite the high consumption of foods rich in saturated fatty acids, the incidence of mortality from cardiovascular diseases was lower than that in other comparable countries. This phenomenon was called "the French paradox" and was related to the beneficial effects of red wine consumption [1]. In general; polyphenols have antioxidant activities. Their activity as peroxyl radical scavengers and in the formation of complexes with metals $(\mathrm{Cu}, \mathrm{Fe}$, etc.) has been shown by in vitro studies. Moreover, the ability of polyphenols to cross the intestinal wall of mammals confers their biological properties.

Flavan-3-ols are one of the principal classes of grape polyphenols which include $(+)$-catechin and $(-)$-epicatechin, and their oligomers called procyanidins, proanthocyanidins, and prodelphinidins. B-type and A-type procyanidins and proanthocyanidins (the latter are condensed tannins) are present in the grape skin and seeds; tannins are mainly present in seeds, and prodelphinidins are polymeric tannins composed of gallocatechin units (structures in Figure 1).
During winemaking the condensed (or nonhydrolyzable) tannins are transferred to the wine and contribute strongly to the sensorial characteristic of the product. In the mouth, the formation of complexes between tannins and saliva proteins confers to the wine the sensorial characteristic of astringency: bitterness and astringency of wine is linked to tannins structure, in particular galloylation degree (DG) and polymerization degree (DP) of flavan-3-ols [2,3]. Grape tannins are used as active ingredients in medicinal products characterized by antioxidant plasma activity and for the treatment of circulatory disorders (capillary fragility, microangiopathy of the retina, reducing of platelet aggregation, decreasing of the susceptibility of healthy cells towards toxic and carcinogenic agents, and antioxidant activity toward human low density lipoprotein) (see [4], and references cited herein).

Flavonols are another important class of grape polyphenols. These compounds are mainly present in the skin of berry; the principal are quercetin, kaempferol, and myricetin present in glycoside forms such as glucoside, glucuronide, and rutin. Recently, also isorhamnetin, laricitrin, and syringetin were identified in grape $[5,6]$. The structures of flavonols are reported in Figure 2(b). The main biological activity of quercetin is to block human platelets aggregation, and it seems that it inhibits carcinogens and the cancer 


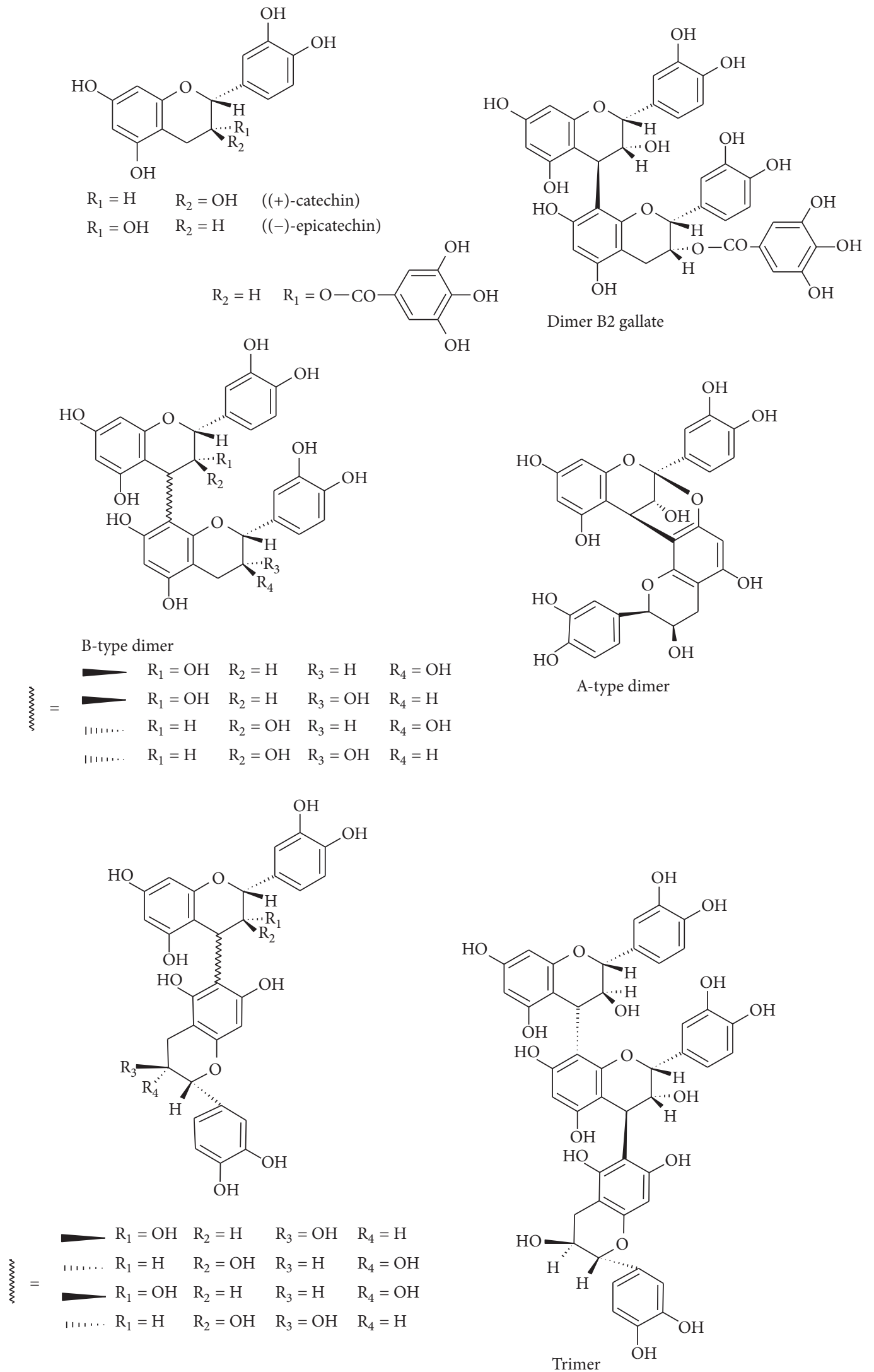

FIGURE 1: B-type and A-type flavan-3-ol dimers and trimers present in the grape seeds. 


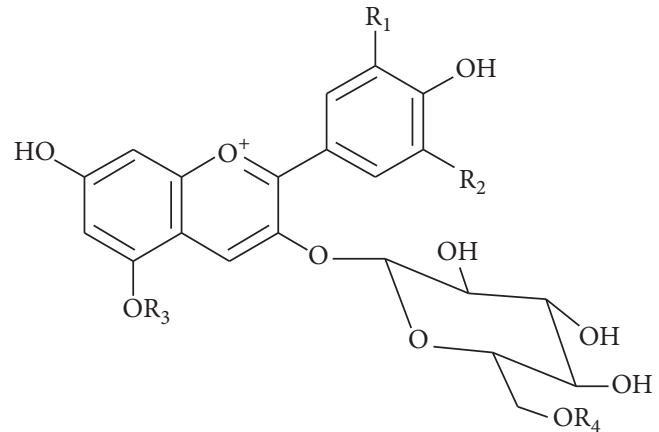

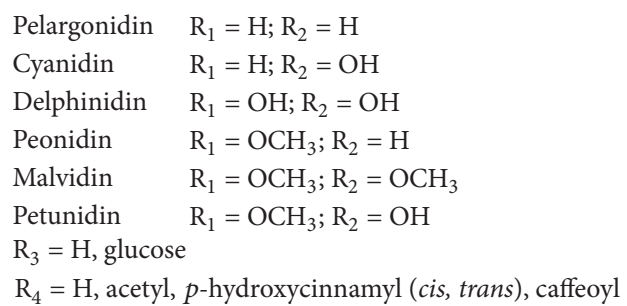

(a)<smiles>[R]c1cc(-c2oc3cc(O)cc(O)c3c(=O)c2[R])cc([R2])c1O</smiles>

$\mathrm{R}$ = glucose; glucuronic acid

Kaempferol $\quad \mathrm{R}_{1}=\mathrm{H} ; \mathrm{R}_{2}=\mathrm{H}$

Quercetin $\quad \mathrm{R}_{1}=\mathrm{OH} ; \mathrm{R}_{2}=\mathrm{H}$

Myricetin $\quad \mathrm{R}_{1}=\mathrm{OH} ; \mathrm{R}_{2}=\mathrm{OH}$

Isorhamnetin $\mathrm{R}_{1}=\mathrm{H} ; \mathrm{R}_{2}=\mathrm{OCH}_{3}$

Laricitrin $\quad \mathrm{R}_{1}=\mathrm{OH} ; \mathrm{R}_{2}=\mathrm{OCH}_{3}$

Syringetin $\quad \mathrm{R}_{1}=\mathrm{OCH}_{3} ; \mathrm{R}_{2}=\mathrm{OCH}_{3}$

(b)

FIGURE 2: (a) The principal monomer anthocyanins of grape: the glucose residue can be linked to an acetyl, coumaroyl, or caffeoyl group. (b) The principal flavonols of grape.

cell growth in human tumors (see [4] and references cited herein).

Stilbene compounds are the principal phytoalexins of grape: they include cis- and trans-resveratrol (3,5,4'-trihydroxystilbene) and their glucoside derivatives (cis- and transpiceid), piceatannol $\left(3,4,3^{\prime}, 5^{\prime}\right.$-tetrahydroxy-trans-stilbene), and stilbene oligomers (viniferins). A number of studies evidenced anticancer, cardioprotection, anti-inflammatory and antioxidant activities, and platelet aggregation inhibition of trans-resveratrol [7-13]. Grapevine synthesizes viniferins in different parts of the plant (roots, clusters, and stems) in particular $\mathcal{E}$-viniferin, two $\delta$-viniferin glucosides, and pallidol $[14,15]$. Moreover, viniferins can arise from the oligomerisation of trans-resveratrol in grape tissues as active defense of the plant against exogenous attacks or could be produced from resveratrol by extracellular enzymes released from the pathogen in an attempt to eliminate undesirable toxic compounds $[16,17]$. Structures of the principal vine viniferins are showed in Figure 3.

Anthocyanins are the compounds responsible for the red color of grapes and wines. Principal anthocyanins of Vitis vinifera varieties are delphinidin (Dp), cyanidin (Cy), petunidin $(\mathrm{Pt})$, peonidin $(\mathrm{Pn})$, and malvidin $(\mathrm{Mv})$, present in the skins as 3-O-monoglucoside, 3-O-acetylmonoglucoside, and 3-O-(6-O-p-coumaroyl)monoglucoside. Often, also Mv3-O-(6-O-caffeoyl)monoglucoside is present. More recently, pelargonidin ( $\mathrm{Pg}$ ) 3-O-monoglucoside was found in grape [24]. Often the not $V$. vinifera (hybrid) red grapes also contain diglucoside anthocyanins with the second glucose molecule linked to the C-5 hydroxyl group (structures showed in Figure 2(a)).
The anthocyanin profile is also determined for the study of grape chemotaxonomy; for example, the presence of 3,5O-diglucoside anthocyanins is used to distinguish between $V$. vinifera and hybrid grape varieties, the former being characterized by low presence or practical absence of these compounds. Moreover, grape anthocyanins are antioxidant and natural colorants used in the nutraceutical, food, and pharmaceutical industries [26-28].

During the wine aging, anthocyanins are undergone reactions with other matrix compounds, and new molecules with different chromatic characteristics, with respect to their precursors, are formed [29]. As a consequence, the anthocyanic profile of wine changes dramatically during aging; for example, the LC-chromatogram of a 4-month aged wine recorded at $520 \mathrm{~nm}$ shows as main signals the grape anthocyanins, and after 2-year aging, these signals disappear completely, and a broad peak due to the new anthocyanin derivatives overlaps the latter part of the chromatogram $[30,31]$. Reaction of anthocyanins with flavan-3-ols, procyanidins, and tannins shifts the wine from purple-red to brick-red hue, and the formation of pyranoanthocyanins, stable structures formed by reaction between anthocyanins and acetaldehyde, pyruvic acid, vinylphenol, vinylcatechol, vinylguaiacol, or vinyl(epi)catechin, toward orange hue [20, 21, 32-35].

More than hundred structures belonging the pigment families of anthocyanins, pyranoanthocyanins, direct flavanol-anthocyanin condensation products and acetaldehydemediated flavanol-anthocyanin condensation products (anthocyanin linked to flavan-3-ol either directly or by ethyl bridge), were identified in red wines. Structures of principal anthocyanin-derivatives are showed in Figure 4, [30]. 
<smiles>Oc1ccc(/C=C/c2ccc(O)c(/C=C/c3cc(O)cc4c3[C@H](c3cc(O)cc(O)c3)[C@H](c3ccc(O)cc3)O[C@H]4c3cc(O)cc4c3[C@@H](c3cc(O)cc(O)c3)[C@H](c3ccc(O)cc3)O4)c2)cc1</smiles><smiles>Oc1ccc(/C=C\c2cc(O)cc3c2[C@@H](c2cc(O)cc(O)c2)[C@@H](c2ccc(O)cc2)O3)cc1</smiles>

5<smiles>Oc1ccc([C@H]2c3cc(O)cc(O)c3[C@@H](c3ccc(O)cc3)[C@H]2c2ccc(O)cc2)cc1</smiles>

6<smiles>Oc1ccc(/C=C2/c3cc(O)cc(O)c3[C@@H](c3cc(O)cc(O)c3)[C@H]2c2ccc(O)cc2)cc1</smiles><smiles>Oc1ccc(C=C2c3cc(O)cc(O)c3[C@H](c3ccc(O)cc3)[C@H]2c2ccc(O)cc2)cc1</smiles><smiles></smiles>

$\mathrm{HO}$<smiles>Oc1ccccc1</smiles><smiles>Oc1ccc(/C=C/c2cc(O)cc3c2[C@H](c2cc(O)cc4c2[C@H](c2ccc(O)cc2)[C@H](c2ccc(O)cc2)O4)[C@H]3c2ccc(O)cc2)cc1</smiles>

11

12

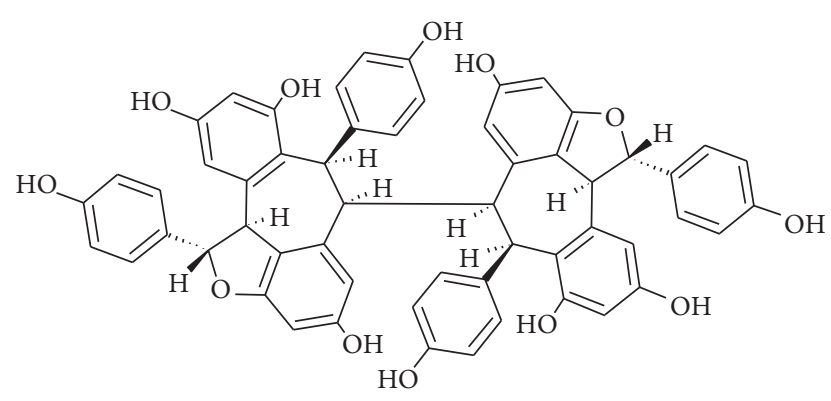

13

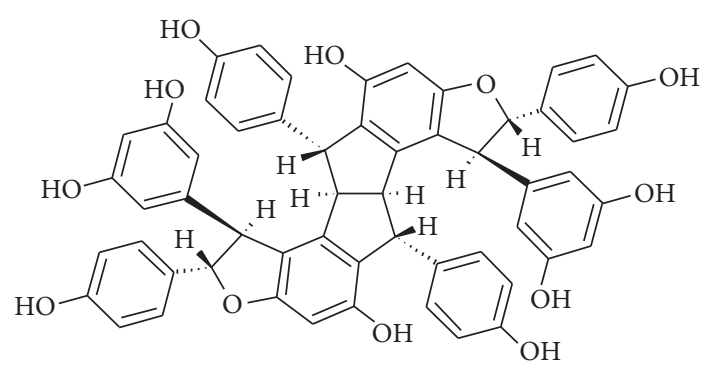

14

Figure 3: Continued. 


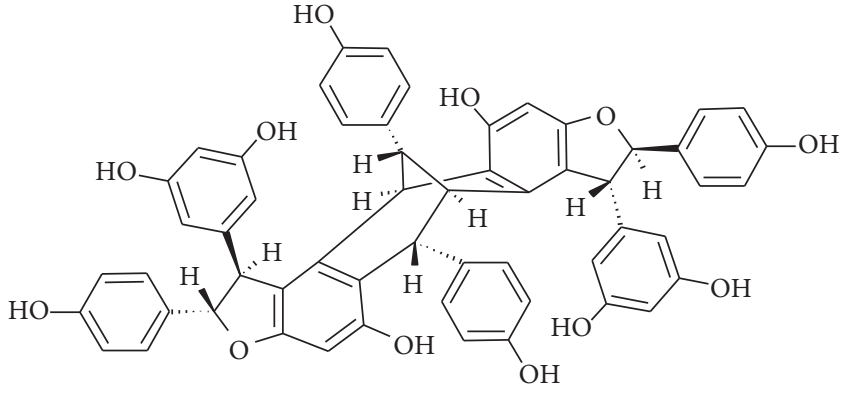

15

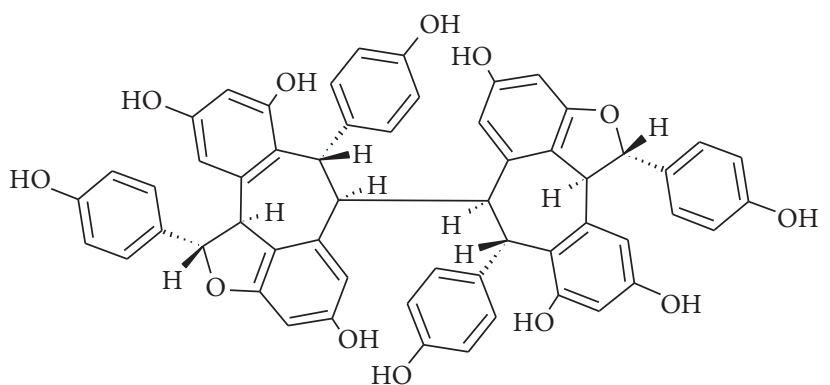

16

FIGURE 3: trans-resveratrol (1) and principal viniferins of the vine: $Z$ - $\varepsilon$-viniferin (2), $E$ - $\varepsilon$-viniferin (3), $E$ - $\omega$-viniferin (4), $Z$ - $\omega$-viniferin (5), pallidol (6), $E$-ampelopsin D (7), E-quadrangularin A (8), $\alpha$-viniferin (9), E-cis-miyabenol C (10), Z-miyabenol C (11), E-miyabenol C (12), isohopeaphenol (13), ampelopsin H (14), vaticanol C isomer (15), and hopeaphenol (16).

TABLE 1: LC retention times (RTs), maximum adsorption UV-Vis wavelengths, and mass spectra data of flavonols identified in Petit Verdot grape skins.

\begin{tabular}{lccc}
\hline Flavonol & HPLC RT (min) & $\lambda_{\max }(\mathrm{nm})$ & {$[\mathrm{M}-\mathrm{H}]^{+}$and product ion $(\mathrm{m} / z)$} \\
\hline Myricetin-3-glucuronide & 13.9 & $257(\mathrm{sh}), 261,301(\mathrm{sh}), 353$ & 495,319 \\
Myricetin-3-glucoside & 14.5 & $257(\mathrm{sh}), 262,298(\mathrm{sh}), 355$ & 481,319 \\
Quercetin-3-glucuronide & 18.0 & $257,265(\mathrm{sh}), 299(\mathrm{sh}), 354$ & 479,303 \\
Quercetin-3-glucoside & 18.8 & $256,265(\mathrm{sh}), 295(\mathrm{sh}), 354$ & 465,303 \\
Laricitrin-3-glucoside & 19.9 & $256,265(\mathrm{sh}), 301(\mathrm{sh}), 357$ & 495,333 \\
Kaempferol-3-glucoside & 22.6 & $265,298(\mathrm{sh}), 320(\mathrm{sh}), 348$ & 449,287 \\
Isorhamnetin-3-glucoside & 24.3 & $255,265(\mathrm{sh}), 297(\mathrm{sh}), 354$ & 479,317 \\
Syringetin-3-glucoside & 24.9 & $255,265(\mathrm{sh}), 300(\mathrm{sh}), 357$ & 509,347 \\
Laricitrin-3-galactoside & 19.4 & $256,265(\mathrm{sh}), 302(\mathrm{sh}), 357$ & 495,333 \\
Kaempferol-3-galactoside & 21.1 & $266,292(\mathrm{sh}), 320(\mathrm{sh}), 348$ & 449,287 \\
Kaempferol-3-glucuronide & 21.9 & $265,290(\mathrm{sh}), 320(\mathrm{sh}), 348$ & 463,287 \\
Quercetin-3-(6-acetyl)glucoside & 22.9 & $257,265(\mathrm{sh}), 295(\mathrm{sh}), 352$ & 517,303 \\
Syringetin-3-(6-acetyl)glucoside & 30.4 & $255,265(\mathrm{sh}), 298(\mathrm{sh}), 358$ & 517,347 \\
\hline
\end{tabular}

\section{Liquid Chromatography/Mass Spectrometry Analysis of Nonanthocyanic Polyphenols in Grape and Wine}

Liquid Chromatography/Mass Spectrometry (LC/MS) coupled with Multiple Mass Spectrometry (MS/MS and $\mathrm{MS}^{n}$ ) is the most effective tool for the structural characterization of low molecular weight (MW) polyphenols in grape extracts and wine. It is also widely used to characterize high-MW compounds, such as procyanidins, proanthocyanidins, prodelphinidins, and tannins [37-40]. In general, these methods require minor sample purification, and MS/MS allows characterization of both aglycone and sugar moiety.

A study of flavonols in different $V$. vinifera red grape extracts showed, in addition to myricetin and quercetin 3$\mathrm{O}$-glucosides and 3-glucuronides, and to kaempferol and isorhamnetin 3-O-glucosides, the presence of laricitrin and syringetin 3-glucosides. Also, minor flavonols, such as kaempferol and laricitrin 3-galactosides, kaempferol-3-glucuronide, and quercetin and syringetin 3-(6-acetyl)glucoside, were identified [5]. Table 1 reports the flavonols identified in
Petit Verdot grape skins extract. Extraction was performed by using a methanol/ $\mathrm{H}_{2} \mathrm{O} /$ formic acid $50: 48.5: 1.5(\mathrm{v} / \mathrm{v} / \mathrm{v})$, and the analytes were separated from anthocyanins by performing solid-phase extraction (SPE) using a combined reverse-phase and cationic-exchanger commercial cartridge. After sample loading, the cartridge was washed with $\mathrm{HCl}$ $0.1 \mathrm{M}$ solution, and the flavonol fraction containing neutral and acidic polyphenols was recovered with methanol. LC analysis was performed by using a reverse-phase $\mathrm{C}_{18}$ column with elution gradient with water/acetonitrile/formic acid $87: 3: 10 \mathrm{v} / \mathrm{v} / \mathrm{v}$ and $40: 50: 10 \mathrm{v} / \mathrm{v} / \mathrm{v}$. Flavonols were detected by performing analysis with the mass spectrometer operating in positive ion mode.

Usually, LC/MS analysis of resveratrol (3,5,4 -trihydroxystilbene) and piceatannol $\left(3,4,3^{\prime}, 5^{\prime}\right.$-tetrahydroxy transstilbene) in grape is performed in negative-ion mode. Chromatographic separation can be performed by using a reverse-phase $\mathrm{C}_{18}$ column and elution gradient program with a binary solvent composed of water $/ 0.1 \%$ formic acid and methanol (e.g., 33\% methanol for $40 \mathrm{~min}, 33 \% \rightarrow 100 \%$ methanol in $15 \mathrm{~min}, 100 \%$ methanol for $5 \mathrm{~min}$ ) [42]. 
<smiles>COc1cc(-c2[o+]c3cc(O)cc(O)c3c(-c3c(O)cc(O)c4c3OC(c3ccc(O)c(O)c3)C(O)C4)c2Cl)cc(OC)c1O</smiles>

(a)<smiles>[R][CH]Oc1c(-c2cc([R2])c(O)c([R3])c2)[o+]c2cc(O)cc3c2c1C=C([R1])O3</smiles>

$\mathrm{R}_{1}=\mathrm{H} ; \mathrm{R}_{2}=\mathrm{OCH}_{3} ; \mathrm{R}_{3}=\mathrm{OCH}_{3} ; \mathrm{R}_{4}=\mathrm{H}$ (vitisin $\mathrm{B}$ )

$\mathrm{R}_{1}=\mathrm{H} ; \mathrm{R}_{2}=\mathrm{OCH}_{3} ; \mathrm{R}_{3}=\mathrm{OCH}_{3} ; \mathrm{R}_{4}=$ acetyl

$\mathrm{R}_{1}=\mathrm{H} ; \mathrm{R}_{2}=\mathrm{OCH}_{3} ; \mathrm{R}_{3}=\mathrm{OCH}_{3} ; \mathrm{R}_{4}=$ coumaroyl

$\mathrm{R}_{1}=\mathrm{CH}_{3} ; \mathrm{R}_{2}=\mathrm{OCH}_{3} ; \mathrm{R}_{3}=\mathrm{OCH}_{3} ; \mathrm{R}_{4}=\mathrm{H}$

$\mathrm{R}_{1}=\mathrm{OH} ; \mathrm{R}_{2}=\mathrm{OCH}_{3} ; \mathrm{R}_{3}=\mathrm{OCH}_{3} ; \mathrm{R}_{4}=\mathrm{H}$

$\mathrm{R}_{1}=\mathrm{COOH} ; \mathrm{R}_{2}=\mathrm{OCH}_{3} ; \mathrm{R}_{3}=\mathrm{OH} ; \mathrm{R}_{4}=\mathrm{H}$

$\mathrm{R}_{1}=\mathrm{COOH} ; \mathrm{R}_{2}=\mathrm{OCH}_{3} ; \mathrm{R}_{3}=\mathrm{H} ; \mathrm{R}_{4}=\mathrm{H}$

$\mathrm{R}_{1}=\mathrm{COOH} ; \mathrm{R}_{2}=\mathrm{OCH}_{3} ; \mathrm{R}_{3}=\mathrm{OCH}_{3} ; \mathrm{R}_{4}=\mathrm{H}$

$\mathrm{R}_{1}=\mathrm{COOH} ; \mathrm{R}_{2}=\mathrm{OCH}_{3} ; \mathrm{R}_{3}=\mathrm{OCH}_{3} ; \mathrm{R}_{4}=$ acetyl

$\mathrm{R}_{1}=\mathrm{COOH} ; \mathrm{R}_{2}=\mathrm{OCH}_{3} ; \mathrm{R}_{3}=\mathrm{OCH}_{3} ; \mathrm{R}_{4}=$ coumaroyl

$\mathrm{R}_{1}=\mathrm{COOH} ; \mathrm{R}_{2}=\mathrm{OCH}_{3} ; \mathrm{R}_{3}=\mathrm{H} ; \mathrm{R}_{4}=$ coumaroyl

$\mathrm{R}_{1}=\mathrm{COOH} ; \mathrm{R}_{2}=\mathrm{OH} ; \mathrm{R}_{3}=\mathrm{OH} ; \mathrm{R}_{4}=\mathrm{H}$<smiles>[R]COc1c(-c2cc([R4])c(O)c([R2])c2)[o+]c2cc(O)cc3c2c1C=C(c1c(O)cc(O)c2c1OC(c1ccc(O)c(O)c1)C(O)C2[R3])O3</smiles>

$\mathrm{R}_{1}=\mathrm{OCH}_{3} ; \mathrm{R}_{2}=\mathrm{OCH}_{3} ; \mathrm{R}_{3}=\left(\right.$ epi)catechin; $\mathrm{R}_{4}=\mathrm{H}$

$\mathrm{R}_{1}=\mathrm{OCH}_{3} ; \mathrm{R}_{2}=\mathrm{H} ; \mathrm{R}_{3}=\mathrm{H} ; \mathrm{R}_{4}=\mathrm{H}$

$\mathrm{R}_{1}=\mathrm{OCH}_{3} ; \mathrm{R}_{2}=\mathrm{OCH}_{3} ; \mathrm{R}_{3}=\mathrm{H} ; \mathrm{R}_{4}=\mathrm{H}$

$\mathrm{R}_{1}=\mathrm{OCH}_{3} ; \mathrm{R}_{2}=\mathrm{OCH}_{3} ; \mathrm{R}_{3}=\mathrm{H} ; \mathrm{R}_{4}=$ coumaroyl<smiles>COc1cc(-c2[o+]c3c(C(C)(C)c4c(O)cc(O)c5c4OC(c4ccc(O)c(O)c4)C(O)C5)c(O)cc(O)c3cc2OC(C)=O)cc(OC)c1O</smiles>

(b)<smiles>[R][CH]Oc1c(-c2cc([R2])c(O)c([R3])c2)[o+]c2cc(O)cc3c2c1C=C(c1cc([R3])c(O)c([R])c1)O3</smiles>

$\mathrm{R}_{1}=\mathrm{H} ; \mathrm{R}_{2}=\mathrm{OCH}_{3} ; \mathrm{R}_{3}=\mathrm{OCH}_{3} ; \mathrm{R}_{4}=\mathrm{H} ; \mathrm{R}_{5}=\mathrm{H}$ (pigment $\mathrm{A}$ )

$\mathrm{R}_{1}=\mathrm{H} ; \mathrm{R}_{2}=\mathrm{OCH}_{3} ; \mathrm{R}_{3}=\mathrm{OCH}_{3} ; \mathrm{R}_{4}=\mathrm{H} ; \mathrm{R}_{5}=\mathrm{OH}$

$\mathrm{R}_{1}=\mathrm{H} ; \mathrm{R}_{2}=\mathrm{OCH}_{3} ; \mathrm{R}_{3}=\mathrm{OCH}_{3} ; \mathrm{R}_{4}=$ acetyl; $\mathrm{R}_{5}=\mathrm{H}$

$\mathrm{R}_{1}=\mathrm{H} ; \mathrm{R}_{2}=\mathrm{OCH}_{3} ; \mathrm{R}_{3}=\mathrm{OCH}_{3} ; \mathrm{R}_{4}=$ coumaroyl $\mathrm{R}_{5}=\mathrm{H}$

$\mathrm{R}_{1}=\mathrm{H} ; \mathrm{R}_{2}=\mathrm{OCH}_{3} ; \mathrm{R}_{3}=\mathrm{OCH}_{3} ; \mathrm{R}_{4}=$ acetyl; $\mathrm{R}_{5}=\mathrm{OCH}_{3}$

$\mathrm{R}_{1}=\mathrm{H} ; \mathrm{R}_{2}=\mathrm{OCH}_{3} ; \mathrm{R}_{3}=\mathrm{OCH}_{3} ; \mathrm{R}_{4}=$ coumaroyl; $\mathrm{R}_{5}=\mathrm{OCH}_{3}$

$\mathrm{R}_{1}=\mathrm{OCH}_{3} ; \mathrm{R}_{2}=\mathrm{OCH}_{3} ; \mathrm{R}_{3}=\mathrm{OCH}_{3} ; \mathrm{R}_{4}=\mathrm{H} ; \mathrm{R}_{5}=\mathrm{OCH}_{3}$

$\mathrm{R}_{1}=\mathrm{H} ; \mathrm{R}_{2}=\mathrm{OCH}_{3} ; \mathrm{R}_{3}=\mathrm{OH} ; \mathrm{R}_{4}=\mathrm{H} ; \mathrm{R}_{5}=\mathrm{H}$

$\mathrm{R}_{1}=\mathrm{H} ; \mathrm{R}_{2}=\mathrm{OCH}_{3} ; \mathrm{R}_{3}=\mathrm{OH} ; \mathrm{R}_{4}=$ acetyl; $\mathrm{R}_{5}=\mathrm{H}$

$\mathrm{R}_{1}=\mathrm{H} ; \mathrm{R}_{2}=\mathrm{OCH}_{3} ; \mathrm{R}_{3}=\mathrm{OH} ; \mathrm{R}_{4}=$ coumaroyl; $\mathrm{R}_{5}=\mathrm{H}$

$\mathrm{R}_{1}=\mathrm{H} ; \mathrm{R}_{2}=\mathrm{OCH}_{3} ; \mathrm{R}_{3}=\mathrm{H} ; \mathrm{R}_{4}=$ coumaroyl $\mathrm{R}_{5}=\mathrm{H}$

$\mathrm{R}_{1}=\mathrm{H} ; \mathrm{R}_{2}=\mathrm{OCH}_{3} ; \mathrm{R}_{3}=\mathrm{H} ; \mathrm{R}_{4}=\mathrm{H} ; \mathrm{R}_{5}=\mathrm{H}$

$\mathrm{R}_{1}=\mathrm{H} ; \mathrm{R}_{2}=\mathrm{OCH}_{3} ; \mathrm{R}_{3}=\mathrm{H} ; \mathrm{R}_{4}=\mathrm{H} ; \mathrm{R}_{5}=\mathrm{OH}$

$\mathrm{R}_{1}=\mathrm{H} ; \mathrm{R}_{2}=\mathrm{OCH}_{3} ; \mathrm{R}_{3}=\mathrm{H} ; \mathrm{R}_{4}=$ coumaroyl; $\mathrm{R}_{5}=\mathrm{OH}$

$\mathrm{R}_{1}=\mathrm{H} ; \mathrm{R}_{2}=\mathrm{OCH}_{3} ; \mathrm{R}_{3}=\mathrm{OCH}_{3} ; \mathrm{R}_{4}=$ coumaroyl; $\mathrm{R}_{5}=\mathrm{OH}$

$\mathrm{R}_{1}=\mathrm{H} ; \mathrm{R}_{2}=\mathrm{OCH}_{3} ; \mathrm{R}_{3}=\mathrm{H} ; \mathrm{R}_{4}=\mathrm{H} ; \mathrm{R}_{5}=\mathrm{OCH}_{3}$

$\mathrm{R}_{1}=\mathrm{H} ; \mathrm{R}_{2}=\mathrm{OCH}_{3} ; \mathrm{R}_{3}=\mathrm{OCH}_{3} ; \mathrm{R}_{4}=\mathrm{H} ; \mathrm{R}_{5}=\mathrm{OCH}_{3}$

FIGURE 4: Above: compounds formed in wines during aging: (a) structure with direct linkage between anthocyanin and flavan-3-ol proposed by Somers [18] and (b) anthocyanin-flavan-3-ol structure by ethyl bridge proposed by Timberlake and Bridle [19]. Below: structures of C-4 substituted anthocyanins identified in aged red wines formed by reaction with pyruvic acid, vinylphenol, vinylcatechol, vinylguaiacol, and vinyl(epi)catechin [20-23]. 


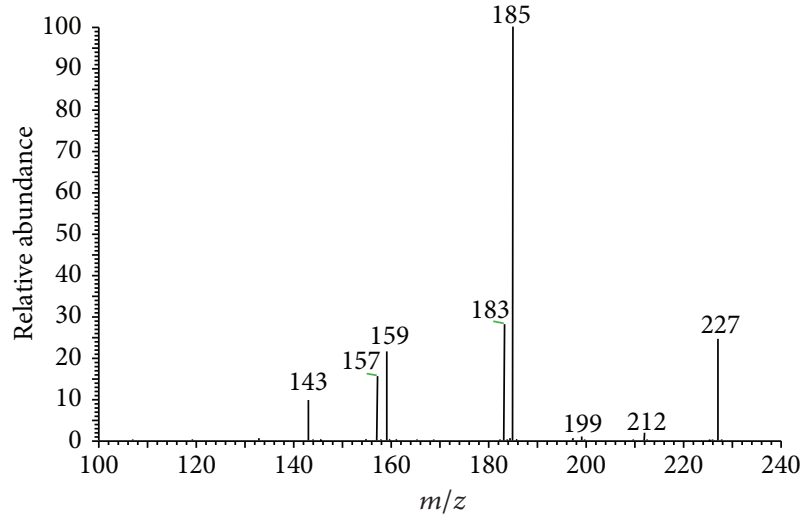

(a)

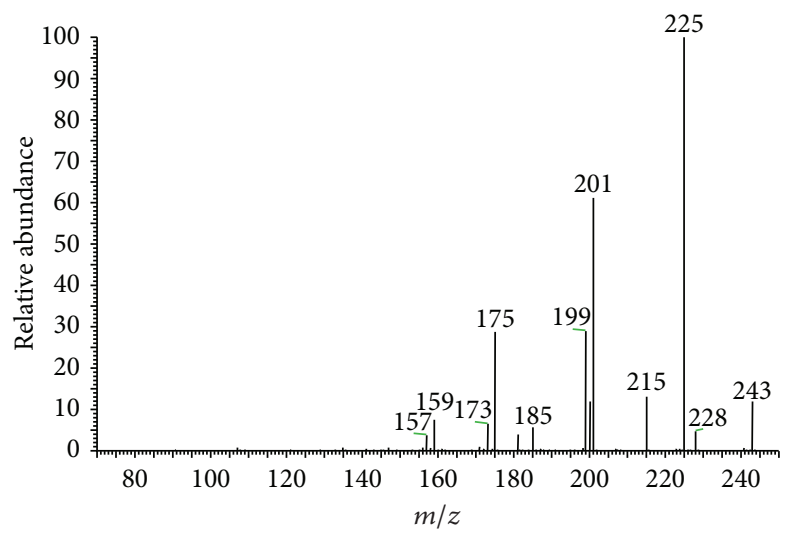

(b)

Figure 5: Product negative-ion spectrum of direct infusion ESI-generated [M-H] $]^{-}$species of trans-resveratrol (a) and piceatannol (b) [25].

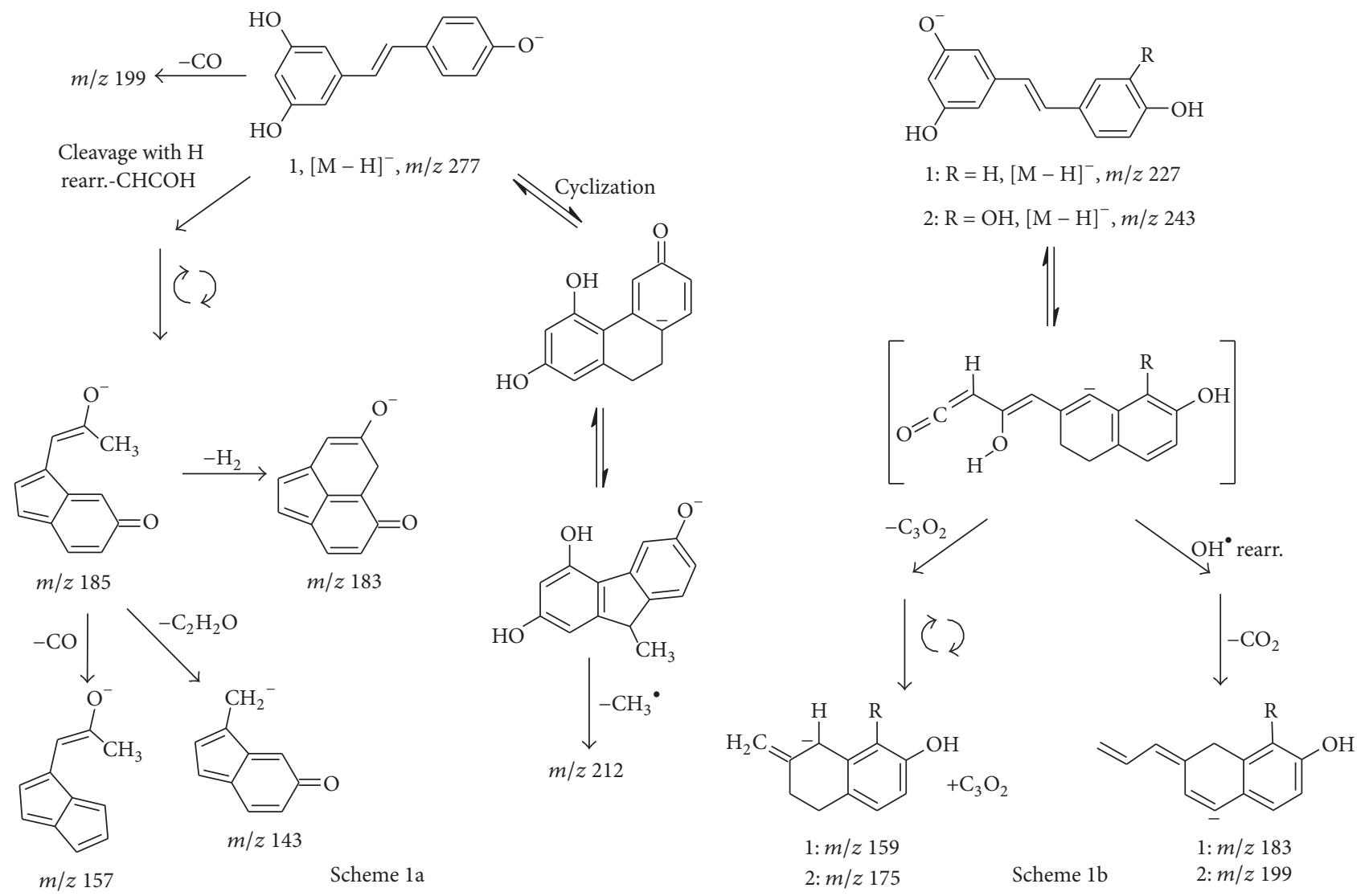

FIgURE 6: Collisionally induced fragmentation patterns of $[\mathrm{M}-\mathrm{H}]^{-}$ions of trans-resveratrol at $m / z 227$ (compound $\mathbf{1}$ ) considering that the deprotonation reaction occurred on the phenol moiety (Scheme 1a), and of $[\mathrm{M}-\mathrm{H}]^{-}$ions of trans-resveratrol $(\mathrm{R}=\mathrm{H}$, compound $\mathbf{1})$ and piceatannol at $m / z 243(\mathrm{R}=\mathrm{OH}$, compound 2) considering that the deprotonation reaction occurred on the resorcinol moiety (Scheme $1 \mathrm{~b})$, [25].

Recently, the mechanisms of the fragmentation of transresveratrol and piceatannol were studied by $\mathrm{MS}^{n}$ and deuterium exchange experiments and performing accurate mass measurements [25]. The product ion spectra of transresveratrol $[\mathrm{M}-\mathrm{H}]^{-}$ion at $m / z 227$ and of piceatannol at $m / z 243$ are reported in Figure 5. Fragmentation patterns of the two compounds are reported in Figure 6. Fragmentations were confirmed by deuterium labeling experiments by dissolving the standard compounds in deuterated methanol: the deprotonated molecules of trans-resveratrol and piceatannol were shifted at $m / z 229$ and $m / z 246$, respectively, proving the occurrence of $\mathrm{OH}$ hydrogen exchanges. 


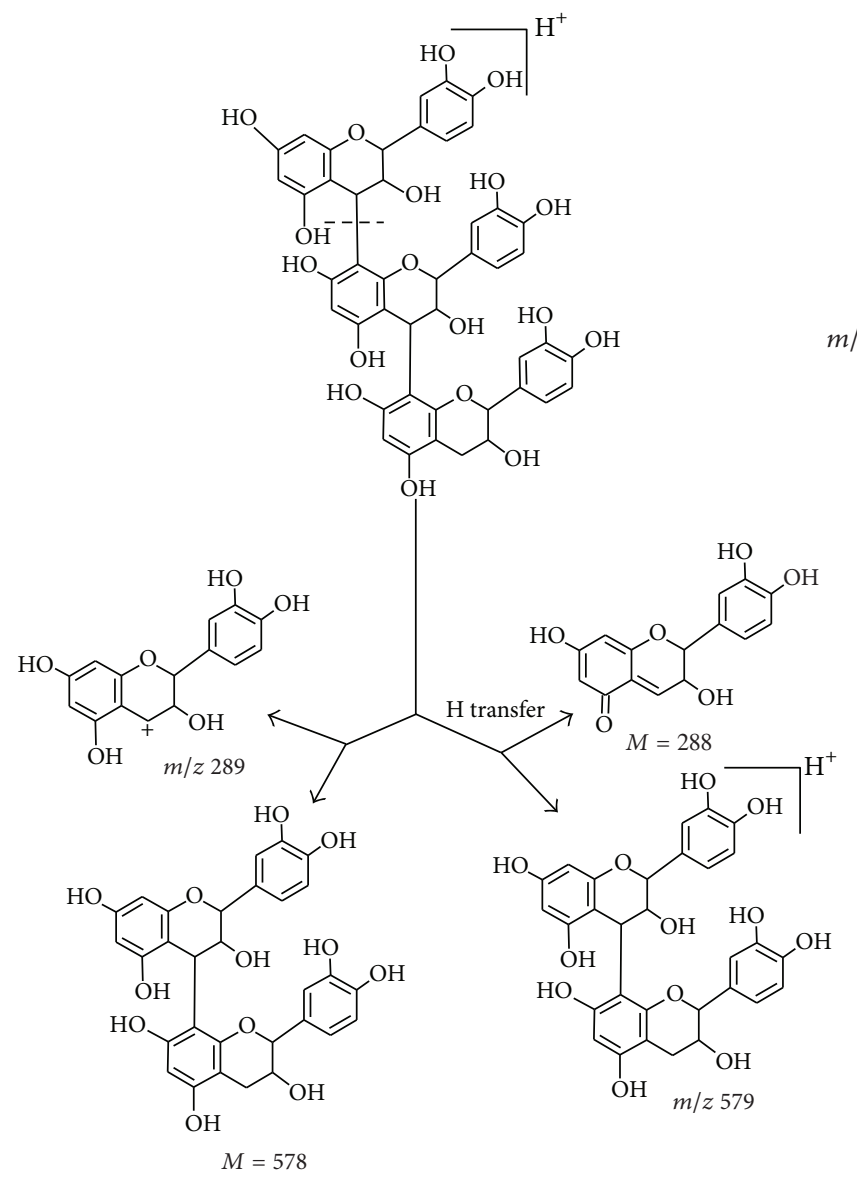

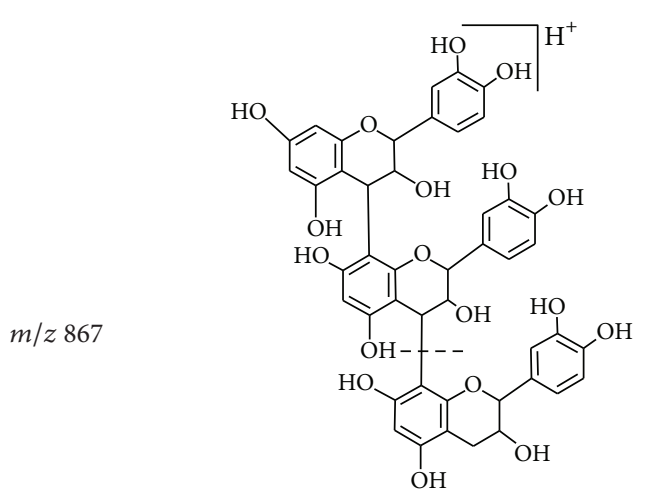

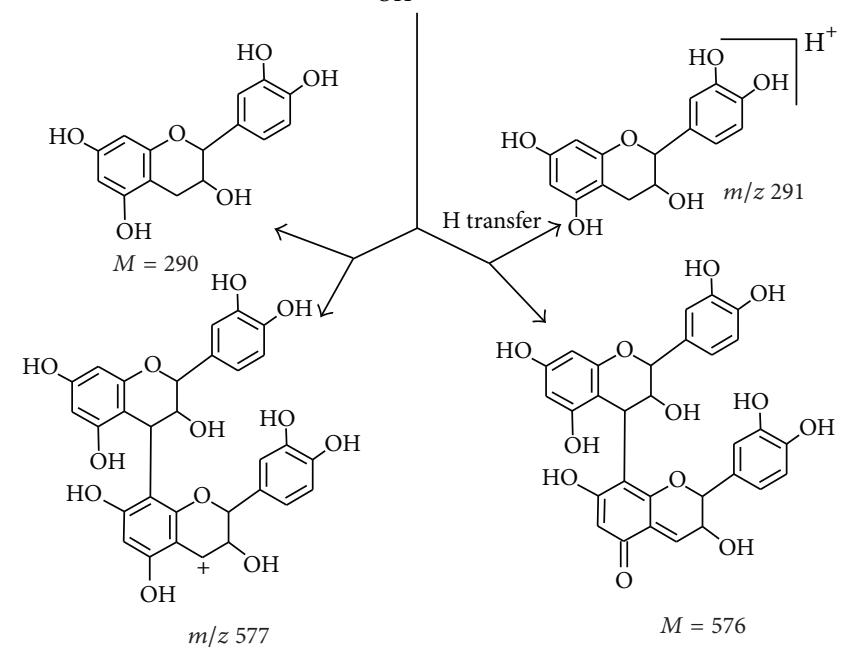

FIGURE 7: Fragmentation patterns of $m / z 867$ trimeric procyanidins studied in ESI-MS positive-ion mode [36].

Extraction of proanthocyanidins (PAs) and tannins from seeds and skins can be performed from the powder produced by grinding frozen material using a methanol/ $\mathrm{H}_{2} \mathrm{O} 25: 75$ (v/v) solution (e.g., three consecutive extractions for $15 \mathrm{~min}$ under stirring at room temperature using ultrasounds [44, 45] or with an acetone $/ \mathrm{H}_{2} \mathrm{O} 60: 40(\mathrm{v} / \mathrm{v})$ solution [3]. After removing of organic solvent, the aqueous residue has to be washed with hexane in order to eliminate lipophilic substances. The extract can be then fractionated on a column for gel filtration of natural products Sephadex LH-20 by eluting different fractions with ethanol and acetone aqueous solutions [44, 45]. Alternatively, purification of aqueous extract can be done by performing chromatography on a methacrylic size-exclusion resin and elution from the column of two fractions with ethanol/ $\mathrm{H}_{2} \mathrm{O} / \mathrm{TFA} 55: 45: 0.02$ $\mathrm{v} / \mathrm{v} / \mathrm{v}$ and acetone $/ \mathrm{H}_{2} \mathrm{O} 30: 70 \mathrm{v} / \mathrm{v}$ [3]. The two solutions are pooled, concentrated under vacuum, and freeze dried. Further purification of the residue can be performed on divinylbenzene-polystyrene resin: flavan-3-ol monomers are recovered with water and ether, then PAs with polymerization degree of 3 units (DP3) with methanol. Finally, the fraction containing DP10 is recovered with acetone/ $\mathrm{H}_{2} \mathrm{O}$ $60: 40 \mathrm{v} / \mathrm{v}$. Seed extract, or grape juice, can be also purified by SPE using a reverse-phase $\mathrm{C}_{18}$ cartridge. Extract is suspended in water, and the solution is passed through the cartridge previously conditioned by passage of methanol and water, and after sample loading, the cartridge is rinsed with water, and the fraction containing PAs is eluted with acetone $/ \mathrm{H}_{2} \mathrm{O} /$ acetic acid $70: 29.5: 0.5 \mathrm{v} / \mathrm{v} / \mathrm{v}[46,47]$.

Extraction of tannins from skins is performed by preliminary removing the low MW phenolics (in particular anthocyanins) immerging the skins in a $12 \% \mathrm{v} / \mathrm{v}$ ethanol solution for $72 \mathrm{~h}$ at $4^{\circ} \mathrm{C}$. Then, skins are ground in methanol, and the solution is kept in immersion for other two hours at $4^{\circ} \mathrm{C}$. Solid parts are extracted again with acetone/ $\mathrm{H}_{2} \mathrm{O}$ $60: 40 \mathrm{v} / \mathrm{v}$ at $4^{\circ} \mathrm{C}$ overnight. The two extracts are concentrated under vacuum and fractionated separately on a size-exclusion resin. After removing of sugars and phenolic acids by washing the column with ethanol/ $\mathrm{H}_{2} \mathrm{O} / \mathrm{TFA} 55: 45: 0.02(\mathrm{v} / \mathrm{v} / \mathrm{v})$ and acetone $/ \mathrm{H}_{2} \mathrm{O} 30: 70(\mathrm{v} / \mathrm{v})$, the fraction containing PAs with DP 12-20 is recovered with acetone $/ \mathrm{H}_{2} \mathrm{O} 60: 40 \mathrm{v} / \mathrm{v}$ [3].

LC/ESI-MS analysis of PAs is usually performed by reverse-phase chromatography, even if normal phase chromatography using silica columns provided a satisfactory separation of oligomers based on their MW [46, 47]. The LC/ESI-MS positive-ion chromatogram of a grape seeds extract (analysis performed by a reverse-phase column and gradient elution with a binary solvent composed of aqueous 


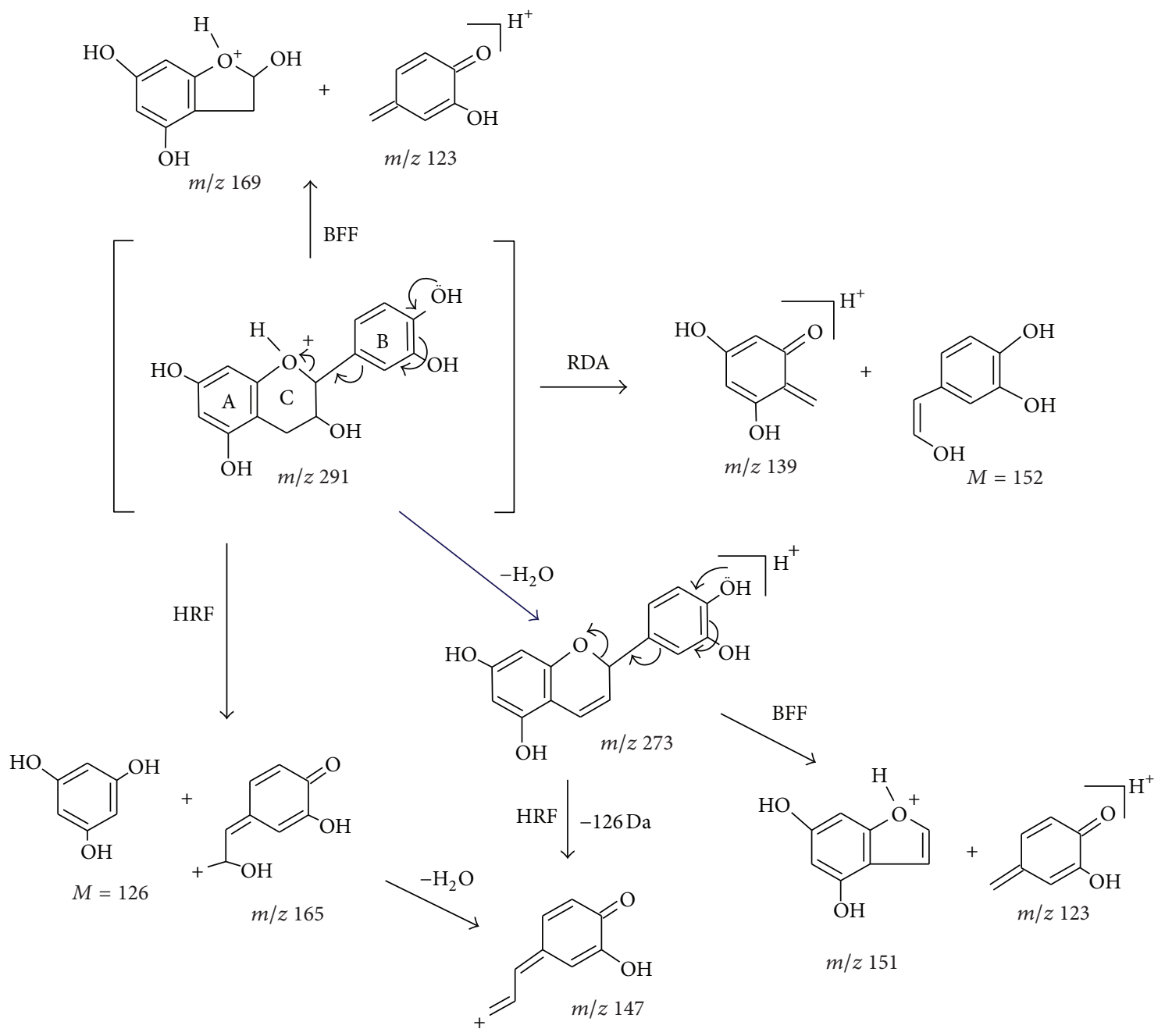

FIGURE 8: Fragmentation pathways of monomer catechin in positive-ion mode: retro-Diels-Alder fission (RDA), heterocyclic ring fission (HRF), benzofuran forming fission (BFF), and loss of water molecule [41].

$0.1 \%$ formic acid and acetonitrile/0.1\% formic acid) shows the signals of protonated catechin and epicatechin at $m / z 291$, protonated catechin/epicatechin gallate at $\mathrm{m} / z 443$, protonated catechin/epicatechin dimer at $m / z 579$, and protonated catechin/epicatechin gallate dimers and trimers at $m / z 731$, $m / z 883$ and $m / z 867$, respectively [48].

PAs were also characterized by direct-infusion ESI-MS without performing chromatographic separation. Negativeion analysis of the extract dissolved in methanol/acetonitrile showed the highest intensity of ions including multiplied charged species [50]. Moreover, simpler mass spectra were recorded due to the absence of intense adduct ion species and to the production of more multiply charged ions with respect to the positive ionization mode. The $[\mathrm{M}-\mathrm{H}]^{-}$and $[\mathrm{M}-2 \mathrm{H}]^{2-}$ species of PAs with DP3 and DP9 are reported in Table 2. Abundant $[\mathrm{M}-\mathrm{H}]^{-}$singly charged ions separated by $288 \mathrm{Da}$ in the ranges $m / z 289-2017$ and $m / z 441-1881$, were observed, corresponding to procyanidins (PCs) with DP 1-7 and procyanidin monogallates (PC1Gs) with DP $1-6$, respectively. PAs with DP9 show the additional larger $[\mathrm{M}-\mathrm{H}]^{-}$ ions derived from PC1G with DP7, PC2Gs (procyanidin digallates) with DP6 and DP7, and PC3Gs (trigallates) with DP4 and DP5.

The fragmentation pathways of $[\mathrm{M}-\mathrm{H}]^{-}$and $[\mathrm{M}-3 \mathrm{H}]^{-}$ ions at $m / z 577,575,729,727$, and $m / z 441$ are probably due to the cleavage of the interflavanic bond, Retro-DielsAlder (RDA) fission on the $\mathrm{C}$ ring followed by the elimination of water with formation of $[\mathrm{M}-\mathrm{H}-152]^{-}(\mathrm{m} / z$ 713, 425, 865 , and 577) and $\left[\mathrm{M}-\mathrm{H}-152-\mathrm{H}_{2} \mathrm{O}\right]^{-}(\mathrm{m} / z$ 695, 407, 847, and 559) ions, and $[\mathrm{M}-\mathrm{H}-126]^{-}$ions at $m / z 739$ and 451 formed by elimination of a phloroglucinol molecule. The ion at $m / z 881$ corresponds to a epicatechin-gallate dimer or a epicatechin-epicatechin-epigallocatechin trimer (two isobaric compounds). Doubly charged ions showed a series of abundant ions separated by $144 \mathrm{Da}$ from $\mathrm{m} / z 652.4$ to 1948.8 , which correspond to the $[\mathrm{M}-2 \mathrm{H}]^{2-}$ ions of PC1Gs with DP 4-13. Increase of the orifice voltage showed two different fragmentation patterns of trimeric species: formation of two ions at $m / z 575$ and 573 from the ions at $m / z 863$ (A-type) and formation of ions at $m / z 711$ due to RDA fragmentation. 


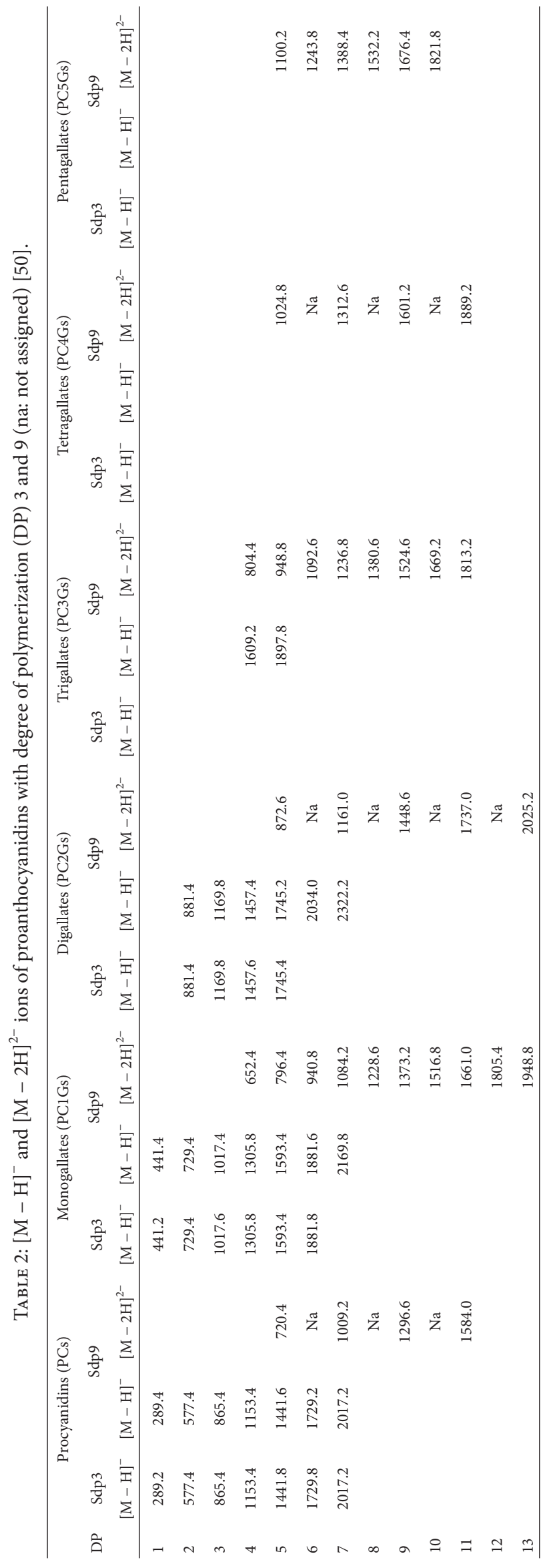




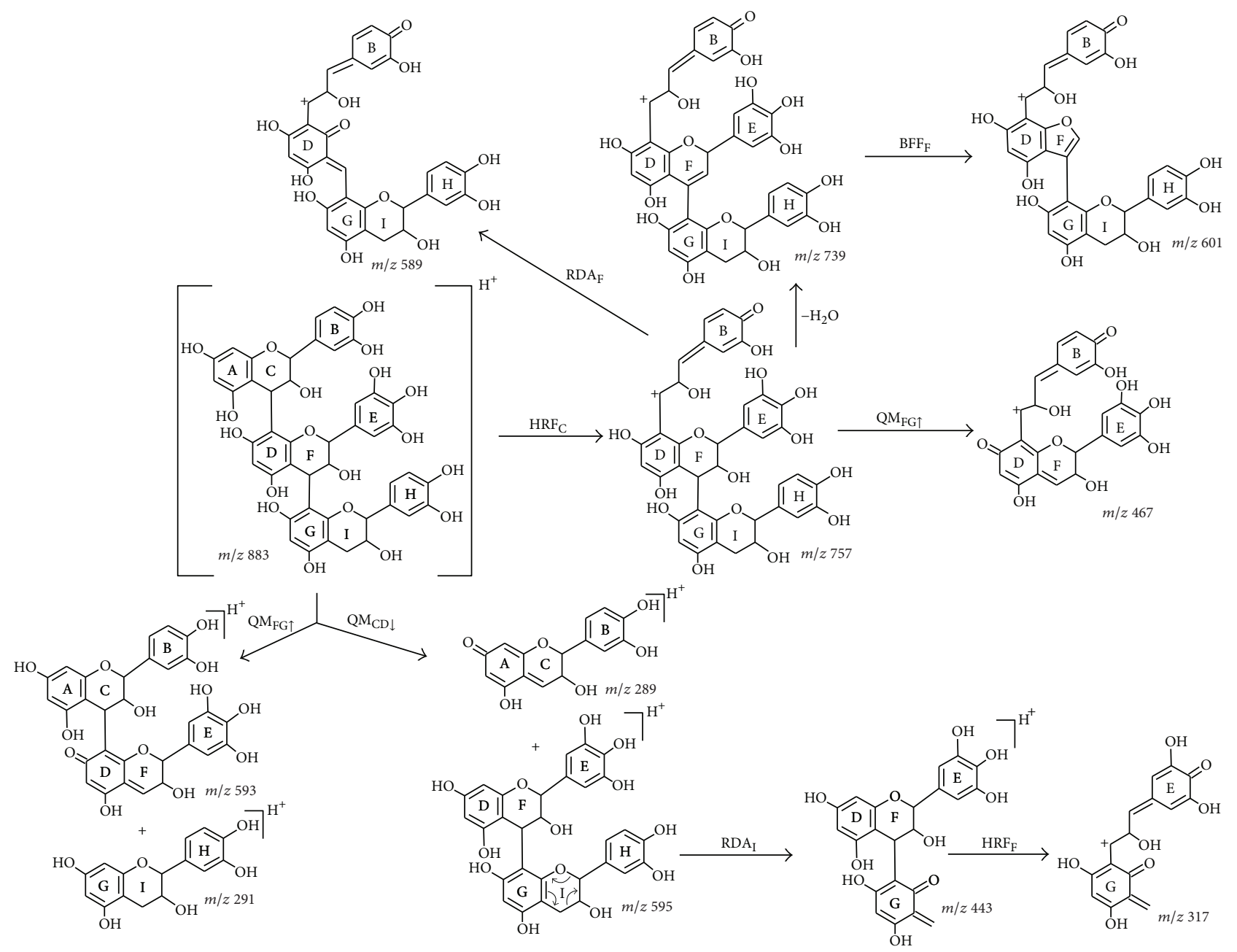

FIGURE 9: Positive-ion mode fragmentation pathways of B-type trimer $m / z$ 883: retro-Diels-Alder fission (RDA), heterocyclic ring fission (HRF), benzofuran forming fission (BFF), quinone methide fission $(\mathrm{QM})$, and loss of water molecule. $\mathrm{QM}_{\mathrm{CD}}$ : the ion derived from the $\mathrm{QM}$ fission of ring-C/ring-D linkage bond by the loss of upper unit and $\mathrm{QM}_{\mathrm{FG} \uparrow}$ : the ion derived from the QM fission of ring-F/ring-G linkage bond by the loss of lower unit [41].

Neutral loss of $152 \mathrm{Da}$ (corresponding to 3,4-dihydroxy- $\alpha$ hydroxystyrene) induces formation of two fragments at $\mathrm{m} / \mathrm{z}$ 285 and 289 generated by cleavage of the A-type interflavanic linkage [51].

Operating in positive ionization mode provides also the signals of PCs and PAs protonated molecules: $[\mathrm{M}+\mathrm{H}]^{+}$ion of catechin dimers, trimers, and tetramers at $m / z 579,867$, and 1155 , of their mono- and digalloyl derivatives at $m / z 731$, $883,1019,1171,1307$, and 1459 , of trimers and tetramers trigalloyl derivatives at $\mathrm{m} / z 1323$ and 1611 , together with those of $[\mathrm{M}+\mathrm{H}]^{+}$ions of flavan-3-ols pentamers, hexamers, and heptamers $(m / z 1443,1731,2019)$, their monogalloyl derivatives $(m / z 1595,1883,2171)$, pentamers and hexamers digalloyl derivatives $(\mathrm{m} / z 1747$ and 2035), and pentamers and hexamers trigalloyl derivatives $(m / z 1899$ and 2187) are observed [45].

In another study, the presence of galloylated A-type procyanidins in grape seeds was evidenced [52]. Procyanidins were extracted from seeds with methanol and fractionated using graded methanol/chloroform precipitation in order to obtain the oligomers with lower MW. ESI-MS spectra recorded in positive mode showed the presence of $[\mathrm{M}+\mathrm{H}]^{+}$ ions of A-type and B-type nongalloylated and monogalloylated procyanidins with DP $2-5$, and of digalloylated oligomers with DP 2-3. A-type procyanidins occurred with abundance $60 \%-80 \%$ with respect to the corresponding type- $\mathrm{B}$ species, the abundance of monogalloylated dimers was $20 \%$ of the abundance of the corresponding nongalloylated ones. For higher DP, the abundance of nongalloylated oligomers was higher of the corresponding galloylated oligomers. The type-A interflavanic linkages were present in the terminal units, whereas the type-B interflavanic linkages were extension units.

Figure 7 shows the positive-ion $\mathrm{MS}^{3}$ fragmentations of the most intense trimeric procyanidins signals in the spectra at $m / z 867$ [36]. The schemes of positive fragmentation patterns for monomer catechin and of a B-type trimer at $\mathrm{m} / \mathrm{z}$ 883 are reported in Figures 8 and 9, respectively [41]. Table 3 


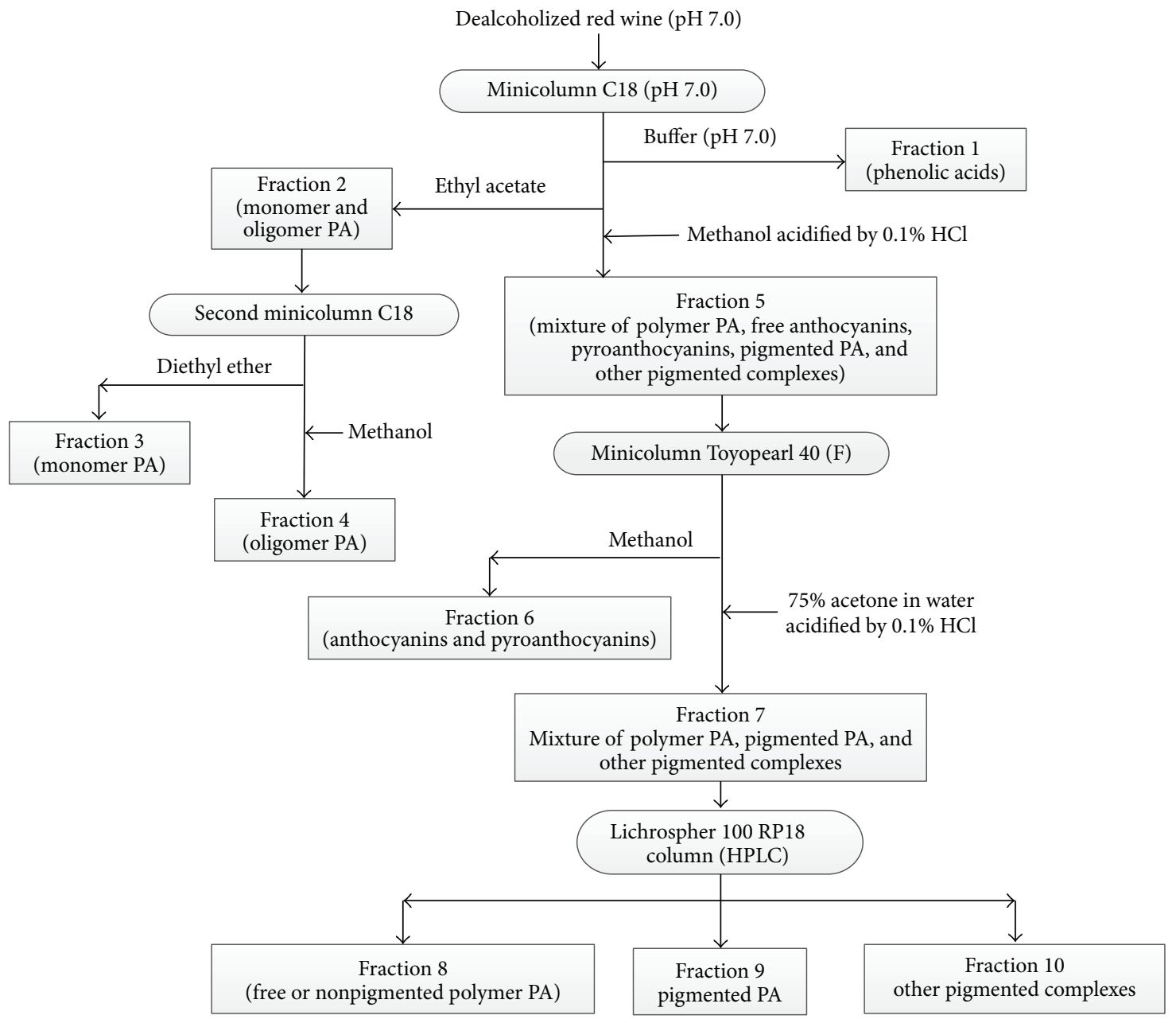

FIGURE 10: Fractionation of polyphenols in red wine (PA, proanthocyanidins) [43].

reports the positive-ion LC/ESI-MS ${ }^{n}$ product ions of flavan3-ol monomers and PAs dimers, trimers, and oligomers.

A recent study reports the identification of fourteen flavan-3-ol monoglycosides in Merlot grape seeds and wine extracts [53]. Analyses were performed using an ESIquadrupole time of flight mass spectrometry system operating in negative-ion mode. Compounds were identified on the basis of their exact masses and specific fragmentation patterns and as aglycones showed (+)-catechin, (-)-epicatechin, (-)-epigallocatechin, and epicatechin gallate monomeric units.

Several methods of sample preparation were proposed to perform analysis of polyphenols in wine. The nonanthocyanic polyphenols identified in four different wine varieties (Tempranillo, Graciano, Cabernet Sauvignon, and Merlot) by performing LC/ESI-MS analysis are reported in Table 4. The analytes were extracted from $50 \mathrm{~mL}$ of wine previously reduced to $15 \mathrm{~mL}$ under vacuum in order to eliminate ethanol. Two consecutive extractions were performed by using diethyl ether and ethyl acetate. The two organic phases were combined, the solvent removed, and the residue was dissolved in a methanol $/ \mathrm{H}_{2} \mathrm{O}$ solution. LC analyses were performed using a reverse-phase $\mathrm{C}_{18}$ column performing the gradient elution with a binary solvent composed of $\mathrm{H}_{2} \mathrm{O}$ /acetic acid $98: 2 \mathrm{v} / \mathrm{v}$ and $\mathrm{H}_{2} \mathrm{O}$ /acetonitrile/acetic acid $78: 20: 2 \mathrm{v} / \mathrm{v} / \mathrm{v}$ [54]. The compounds were identified on the basis of their fragment ions and maximum absorption wavelengths recorded in the mass and UV-Vis spectra, respectively. Table 4 reports a number of compounds included in different classes of phenols, such as flavonols, hydroxycinnamoyltartaric acids, stilbene compounds (cisand trans-resveratrol, piceid), phenolic acids, flavan-3-ols, and dimeric (B1, B3, B4, and B5) and trimeric (C1, T2 and T3) procyanidins.

Two different purification methods by using sizeexclusion and reverse-phase chromatography were used to perform sample preparation for the analysis of PCs and PAs in wine. A volume of dealcoholized wine was passed through a size-exclusion resin, the stationary phase was washed with water, and the fraction containing simple polyphenols was eluted with ethanol $/ \mathrm{H}_{2} \mathrm{O} / \mathrm{TFA} 55: 45: 0.005 \mathrm{v} / \mathrm{v} / \mathrm{v}$. The fraction containing dimers and trimers was recovered with acetone $/ \mathrm{H}_{2} \mathrm{O} 60: 40 \mathrm{v} / \mathrm{v}$ [55]. Sample preparation by reverse-phase chromatography was instead performed using 


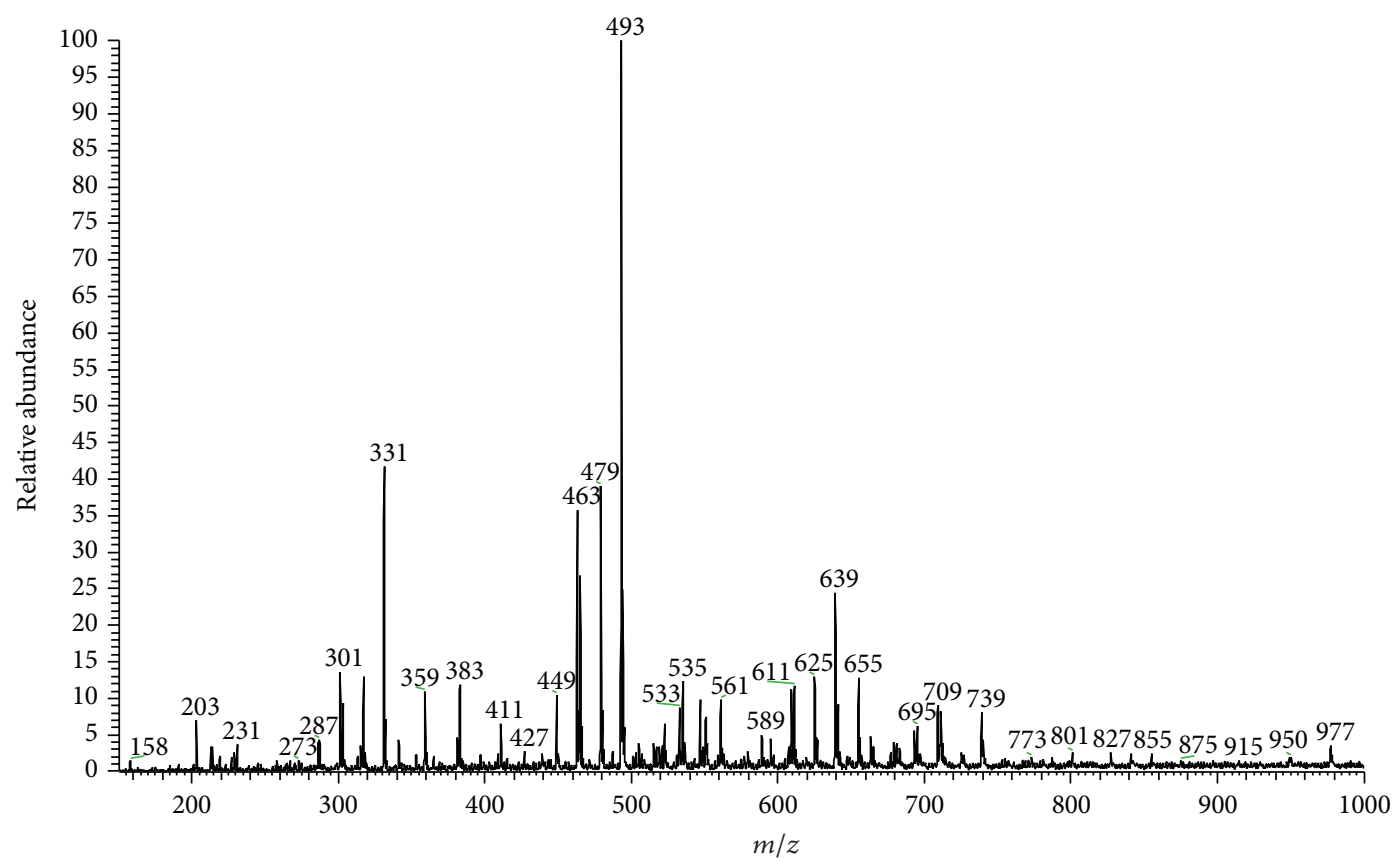

FIGURE 11: Profile of anthocyanins in Clinton skin extract recorded by direct-injection positive-ion ESI/MS.

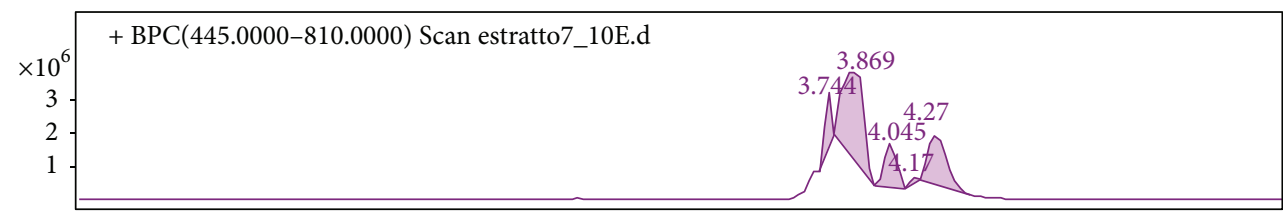

(a)

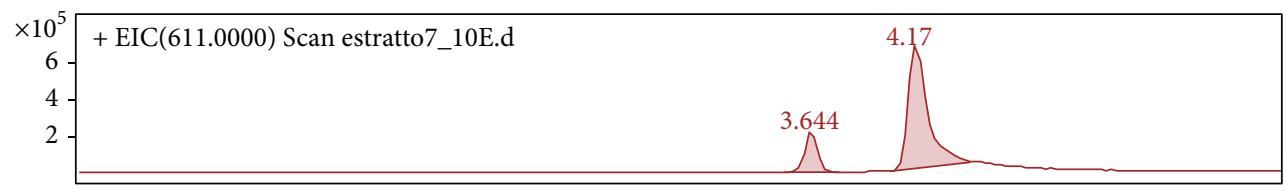

(b)

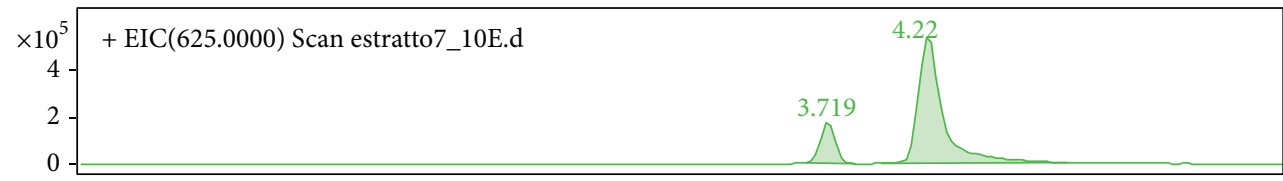

(c)

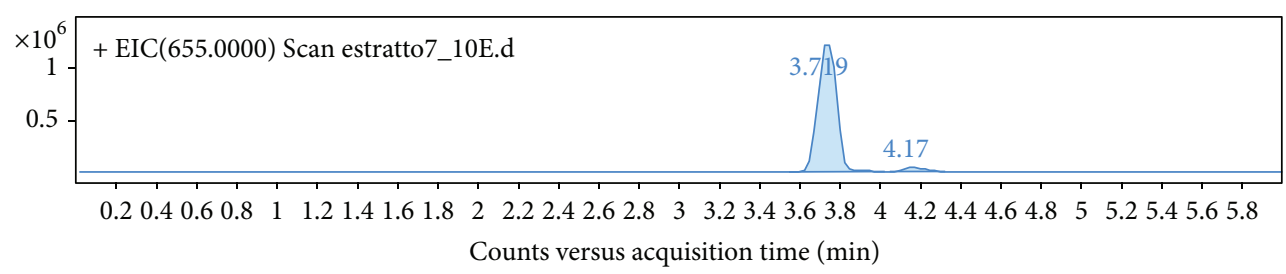

(d)

FIGURE 12: LC-Chip/ESI-QTOF-MS analysis of Clinton grape skins extract: (a) total ion chromatogram (TIC); (b) extracted ion chromatogram (EIC) of the signal at $m / z$ 611; (c) EIC of the signal at $m / z$ 625; (d) EIC of the signal at $m / z 655$ [49]. 


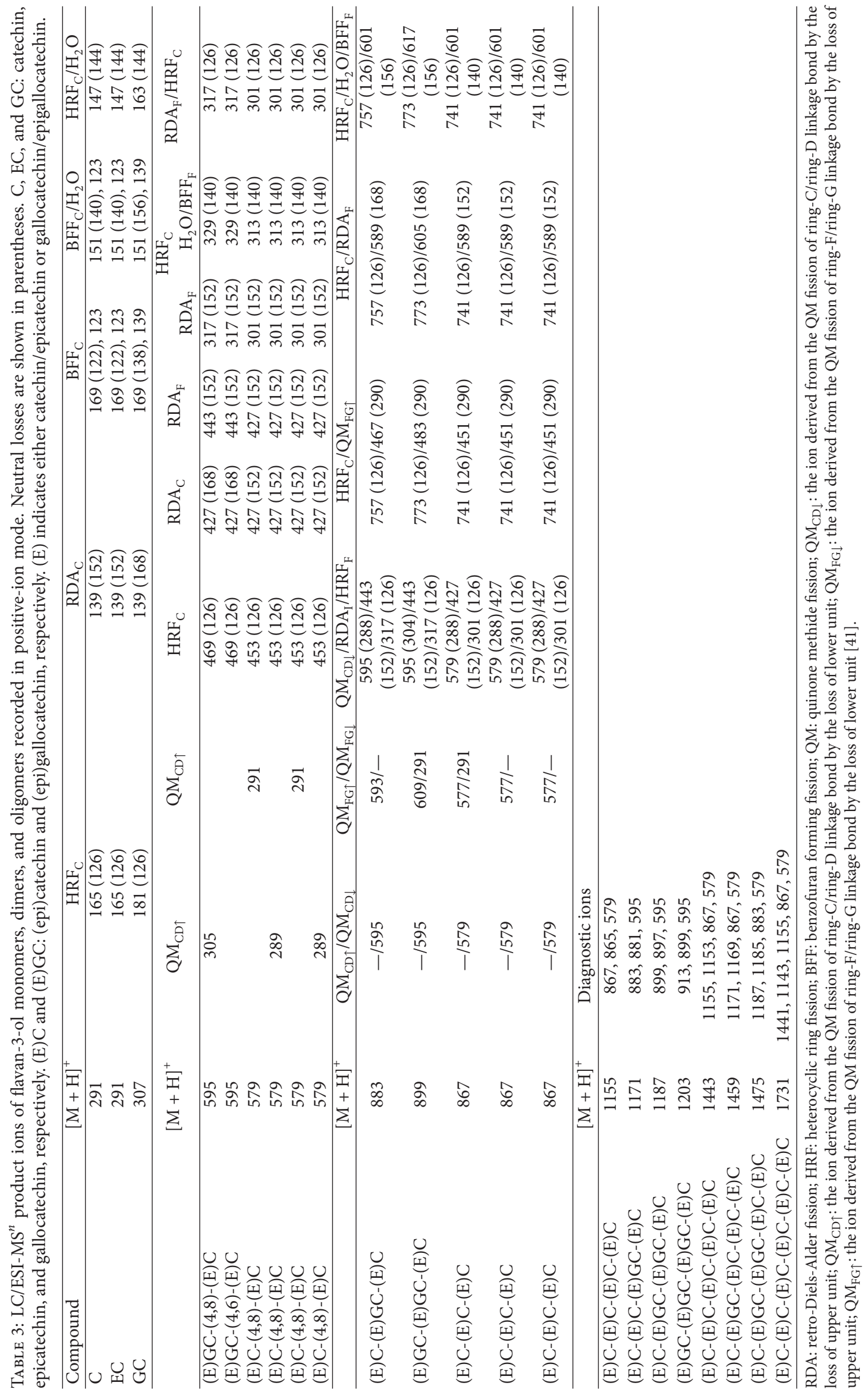


TABLE 4: Nonanthocyanin phenolic compounds identified by LC/ESI-MS in wines from Vitis vinifera varieties Tempranillo, Graciano, Cabernet Sauvignon, and Merlot. Principal mass fragments and maximum UV-Vis absorption wavelengths are reported. (s): shoulder [54].

\begin{tabular}{|c|c|c|c|c|}
\hline \multirow{2}{*}{$\mathrm{RT}(\min )$} & \multirow{2}{*}{ Compound } & \multicolumn{2}{|c|}{$(m / z)$} & \multirow{2}{*}{$\lambda_{\max }(\mathrm{nm})$} \\
\hline & & {$[\mathrm{M}-\mathrm{H}]^{-}$} & Fragments & \\
\hline 7.6 & Gallic acid & 169 & 125 & 272 \\
\hline 14.0 & Protocatechuic acid & 153 & 109 & 294,260 \\
\hline 15.7 & Dihydroxyphenylethanol & 153 & & 280 \\
\hline 16.7 & trans-caffeoyltartaric acid & 311 & 179 & $330,298(s)$ \\
\hline 19.2 & 2,3-Dihydroxy-1-(4-hydroxy-3-methoxyphenyl)-propan-1-one & 211 & & 310,280 \\
\hline 19.5 & Methyl gallate & 183 & 169,125 & 272 \\
\hline 20.5 & Tyrosol & 137 & & 275 \\
\hline 22.3 & (epi)gallocatechin-(epi)catechin dimer & 593 & 425 & 276 \\
\hline 22.7 & Procyanidin B3 & 577 & 425,289 & 280 \\
\hline 23.0 & Procyanidin B1 & 577 & 425,289 & 280 \\
\hline 24.2 & trans-coumaroyl-tartaric acid & 295 & 163 & 313 \\
\hline 27.3 & $(+)$-catechin & 289 & & 279 \\
\hline 28.0 & Procyanidin T2 & 865 & $713,577,289$ & 280 \\
\hline 28.3 & trans-feruryltartaric acid & 325 & 193 & $329,301(\mathrm{~s})$ \\
\hline 28.7 & Hexose ester of vanillic acid & 329 & 167 & nd \\
\hline 29.0 & Procyanidin T3 & 865 & $713,577,289$ & 280 \\
\hline 29.7 & Vanillic acid & 167 & & 289,262 \\
\hline 30.5 & Procyanidin B4 & 577 & 425,289 & 283 \\
\hline 31.3 & trans-caffeic acid & 179 & 135 & 323 \\
\hline 33.0 & Hexose ester of trans-p-coumaric acid (1) & 325 & 163,145 & 311 \\
\hline 33.6 & Procyanidin B2 & 577 & 425,289 & 280 \\
\hline 34.6 & Syringic acid & 197 & & 277 \\
\hline 37.0 & Hexose ester of trans-p-coumaric acid (2) & 325 & 163,145 & 312 \\
\hline 38.7 & $(-)$-epicatechin & 289 & & 279 \\
\hline 40.2 & Trimeric procyanidin & 865 & $713,577,289$ & 280 \\
\hline 41.3 & Ethyl gallate & 197 & 169,125 & 273 \\
\hline 42.2 & Procyanidin C1 & 865 & $713,577,289$ & 282 \\
\hline 43.2 & trans-p-coumaric acid & 163 & 119 & 309 \\
\hline 43.5 & Trimeric procyanidin & 865 & $713,577,289$ & 280 \\
\hline 43.8 & Procyanidin dimer gallate & 729 & 577 & 278 \\
\hline 44.0 & Procyanidin B5 & 577 & 425,289 & 280 \\
\hline 48.5 & Myricetin-3-O-glucuronide & 493 & 317 & $349,300(s), 261$ \\
\hline 50.1 & Myricetin-3-O-glucoside & 479 & 317 & $349,300(\mathrm{~s}), 261$ \\
\hline 51.3 & Epicatechin-3-O-gallate & 441 & 289,169 & 277 \\
\hline 53.2 & trans-resveratrol-3-O-glucoside & 389 & 227 & 306(s), 319 \\
\hline 55.2 & Ellagic acid & 301 & & 368 \\
\hline 57.2 & Quercetin-3-O-galactoside & 463 & 301 & $354,300(\mathrm{~s}), 256$ \\
\hline 57.7 & Quercetin-3-O-glucuronide & 477 & 301 & $354,300(\mathrm{~s}), 256$ \\
\hline 58.2 & Astilbin & 449 & 303 & 288 \\
\hline 58.7 & Quercetin-3-O-glucoside & 463 & 301 & $354,300(\mathrm{~s}), 256$ \\
\hline 60.6 & Tryptophol & 160 & & 279 \\
\hline 62.4 & Kaempferol-3-O-glucoside & 447 & 285 & $346,300(\mathrm{~s}), 265$ \\
\hline 67.6 & Myricetin & 317 & & $371,300(\mathrm{~s}), 254$ \\
\hline 68.9 & cis-resveratrol-3-O-glucoside & 389 & 227 & 285 \\
\hline 71.9 & trans-resveratrol & 227 & & $306,319(\mathrm{~s})$ \\
\hline 92.7 & Quercetin & 301 & & $369,300(\mathrm{~s}), 255$ \\
\hline 95.7 & cis-resveratrol & 227 & & 284 \\
\hline
\end{tabular}




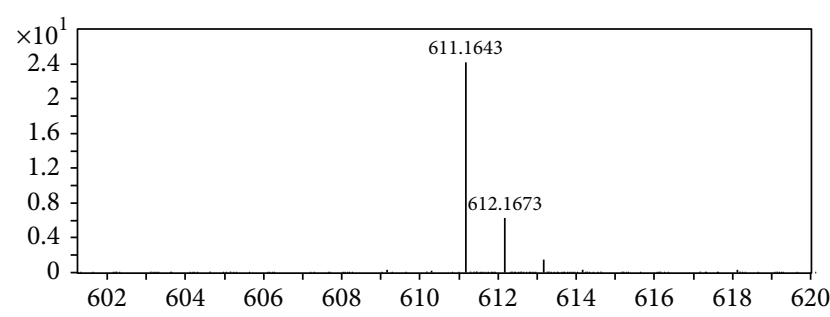

(a)

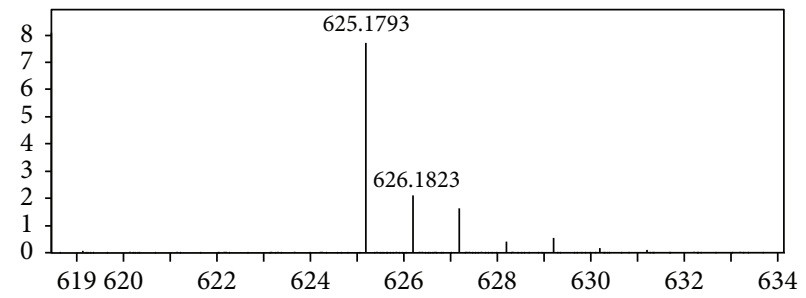

(c)

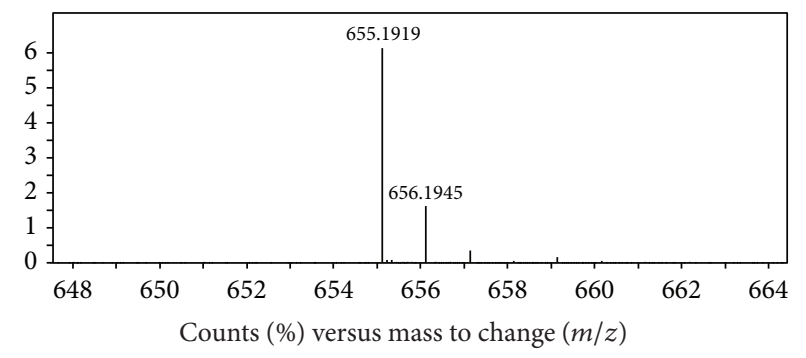

(e)

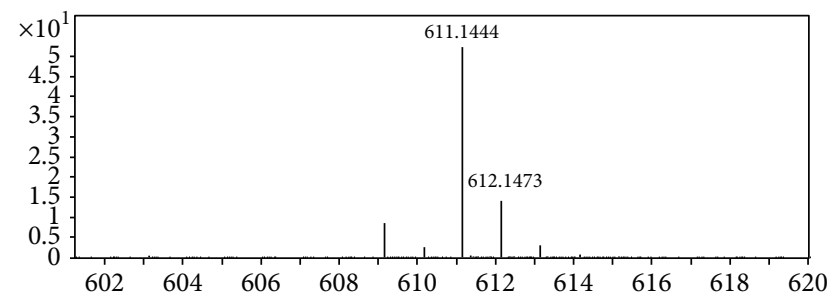

(b)

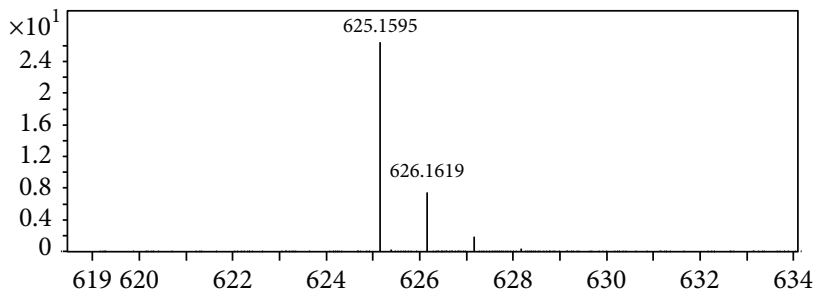

(d)

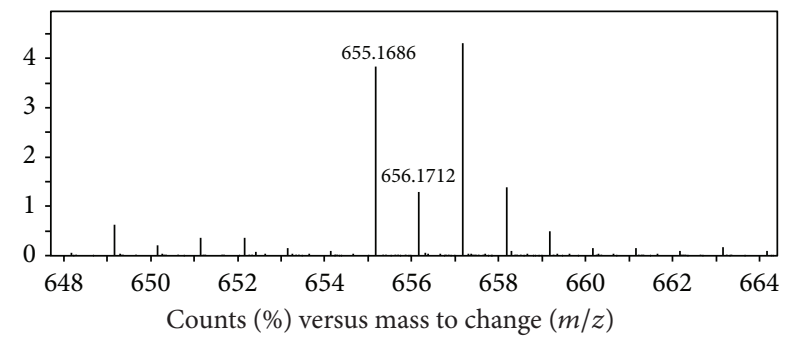

(f)

FIgURE 13: $\mathrm{M}^{+}$signals recorded by LC-Chip-QTOF of isobaric pairs of anthocyanins at $\mathrm{m} / z$ 611 (Cy-diglucoside (a) and Dp- $p$ coumaroylmonoglucoside (b)), at $\mathrm{m} / z 625$ (Pn-diglucoside (c) and Pt-p-coumaroylmonoglucoside (d)), and at $\mathrm{m} / z 655$ (Mv-diglucoside (e) and Mv-caffeoylmonoglucoside (f)) [49].

a $\mathrm{C}_{18}$ cartridge. A volume of dealcoholized wine was loaded onto the cartridge, and PAs were recovered with $10 \mathrm{~mL}$ of acetone $/ \mathrm{H}_{2} \mathrm{O} /$ acetic acid $70: 29.5: 0.5 \mathrm{v} / \mathrm{v} / \mathrm{v}$ solution [46].

The flow diagram in Figure 10 shows a method for fractionation of wine polyphenols by reverse-phase chromatography [43]. The more complex polyphenols recovered in the fractions $8-10$ were characterized by LC/ESIMS and $\mathrm{MS}^{n}$ negative-ion mode analysis and reported in Table 5, [57].

\section{LC/MS of Grape Anthocyanins}

Liquid chromatography mass spectrometry (LC/MS) coupled with multiple mass spectrometry (MS/MS and $\mathrm{MS}^{n}$ ) has been widely used for structural characterization of grape anthocyanins [59] and to study the structure of new anthocyanin derivatives formed during wine aging $[22,23,30,36$, 60-63]. LC analysis of anthocyanins is usually performed by a reverse-phase $\mathrm{C}_{18}$ column by performing gradient elution of compounds using a binary solvent composed of $\mathrm{H}_{2} \mathrm{O} /$ formic acid $90: 10 \mathrm{v} / \mathrm{v}$ and methanol/ $\mathrm{H}_{2} \mathrm{O} /$ formic acid $50: 40: 10 \mathrm{v} / \mathrm{v} / \mathrm{v}$. The analytes are detected by recording the chromatogram at $520 \mathrm{~nm}$. Due to the lack of standards commercially available, the identification of compounds is usually performed on the basis of their column elution sequence.

A study showed that; nonacidified methanol is a solvent suitable for extraction of anthocyanins from grape skins reducing the risk of hydrolysis of acetylated compounds [64]. Alternatively, extraction by methanol $/ \mathrm{H}_{2} \mathrm{O} /$ formic acid solution $(50: 48.5: 1.5 \mathrm{v} / \mathrm{v} / \mathrm{v})$ was proposed [65]. Anthocyanins can be then purified by passing through a $\mathrm{C}_{18}$ cartridge: after sample loading, the nonanthocyanic phenols are eluted from the cartridge with ethyl acetate, then anthocyanins are recovered with methanol. A fast direct-injection ESI-MS/MS analysis in positive-ion mode provides structural characterization and semiquantitative data of the anthocyanins in the extract [66]. As may be seen in the ESI-direct injection spectrum of Clinton grape skins extract in Figure 11, all anthocyanins show evident signal of the $\mathrm{M}^{+}$ion.

MS/MS and collision-induced-dissociation (CID) provide characterization of compounds. Experiments are performed by applying a supplementary radio frequency field to the endcaps of the ion trap $(1-15 \mathrm{~V})$ in order to make the selected ions collide with He. Precursor ions and the fragments recorded for the sample in Figure 11 are reported 


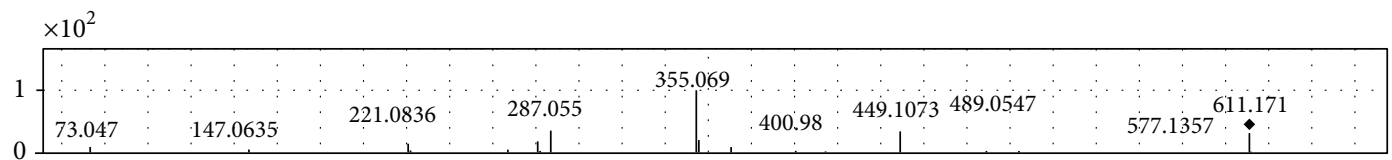

(a)

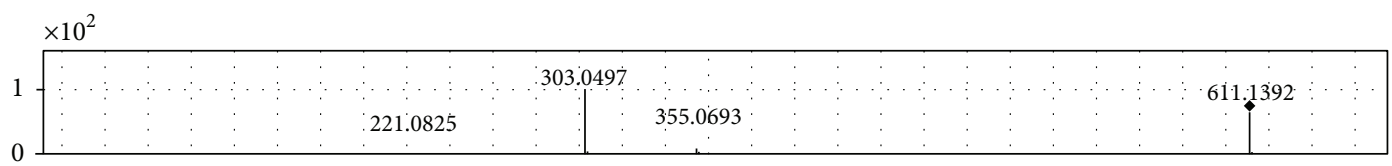

(b)

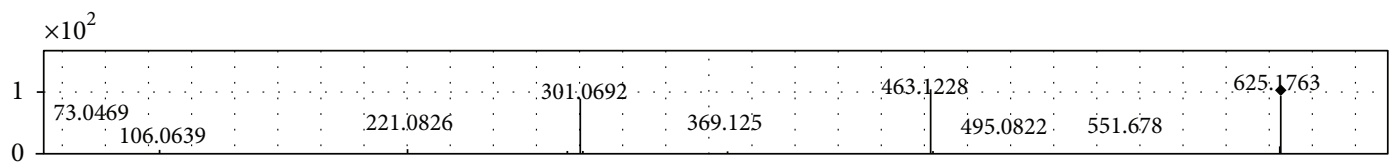

(c)

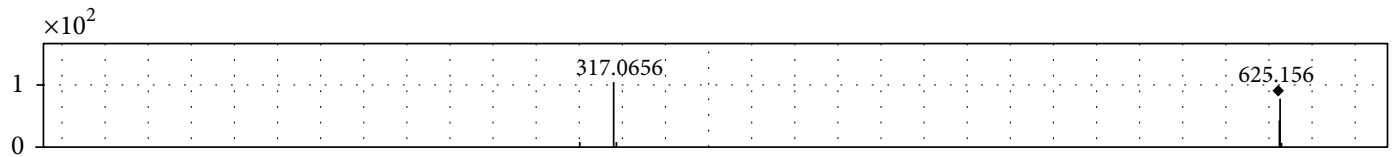

(d)

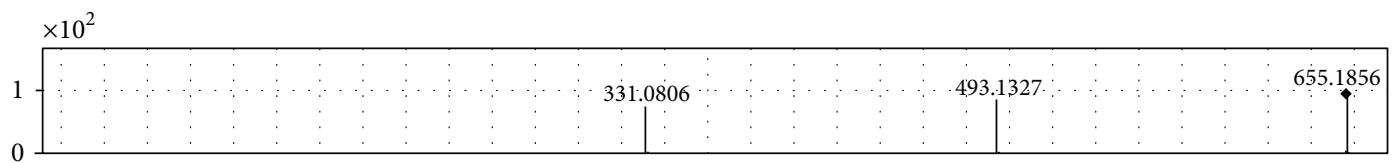

(e)

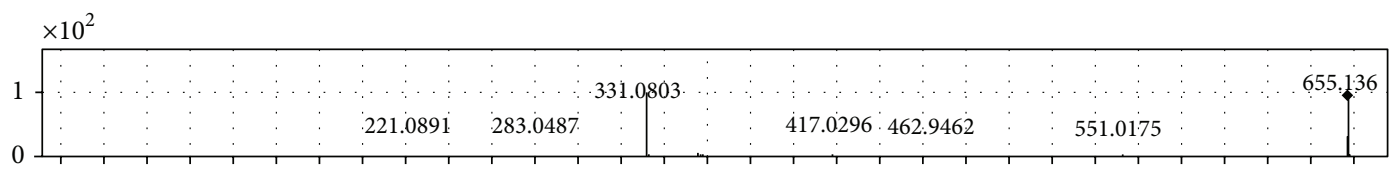

6080100120140160180200220240260280300320340360380400420440460480500520540560580600620640660

Counts (\%) versus mass to change $(\mathrm{m} / \mathrm{z})$

(f)

FIGURE 14: MS/MS spectra of isobaric anthocyanin pairs recorded by LC-Chip/Q-TOF: Cy-diglucoside (a) and Dp- $p$-coumaroylmonoglucoside (b) with $\mathrm{M}^{+}$at $m / z$ 611, Pn-diglucoside (c) and Pt-p-coumaroylmonoglucoside (d) with $\mathrm{M}^{+}$at $m / z$ 625, and $\mathrm{Mv}$ diglucoside (e) and Mv-caffeoylmonoglucoside (f) with $\mathrm{M}^{+}$at $m / z 655$ [49].

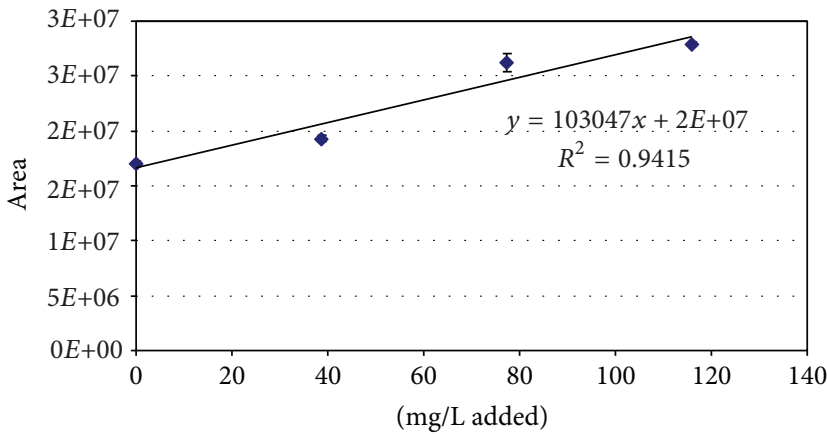

FIGURE 15: Calibration curve calculated by spiking the Clinton grape skins extract with Mv-3,5-O-diglucoside standard at three different concentration. Mean data of the $\mathrm{M}^{+}$signal area at $\mathrm{m} / z 655$ extrapolated from EIC of two replicated analyses and variability bars are shown [49]. 


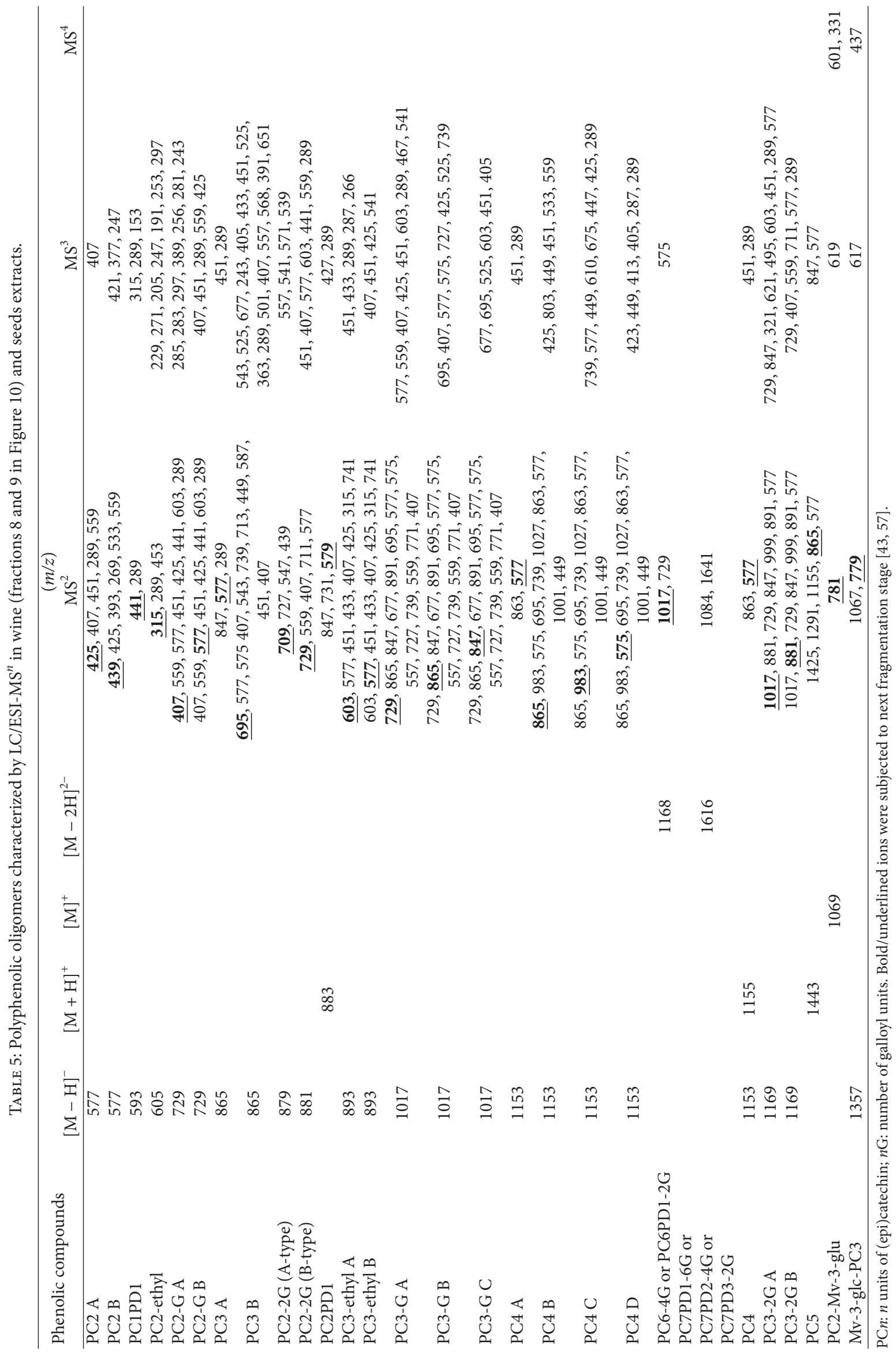




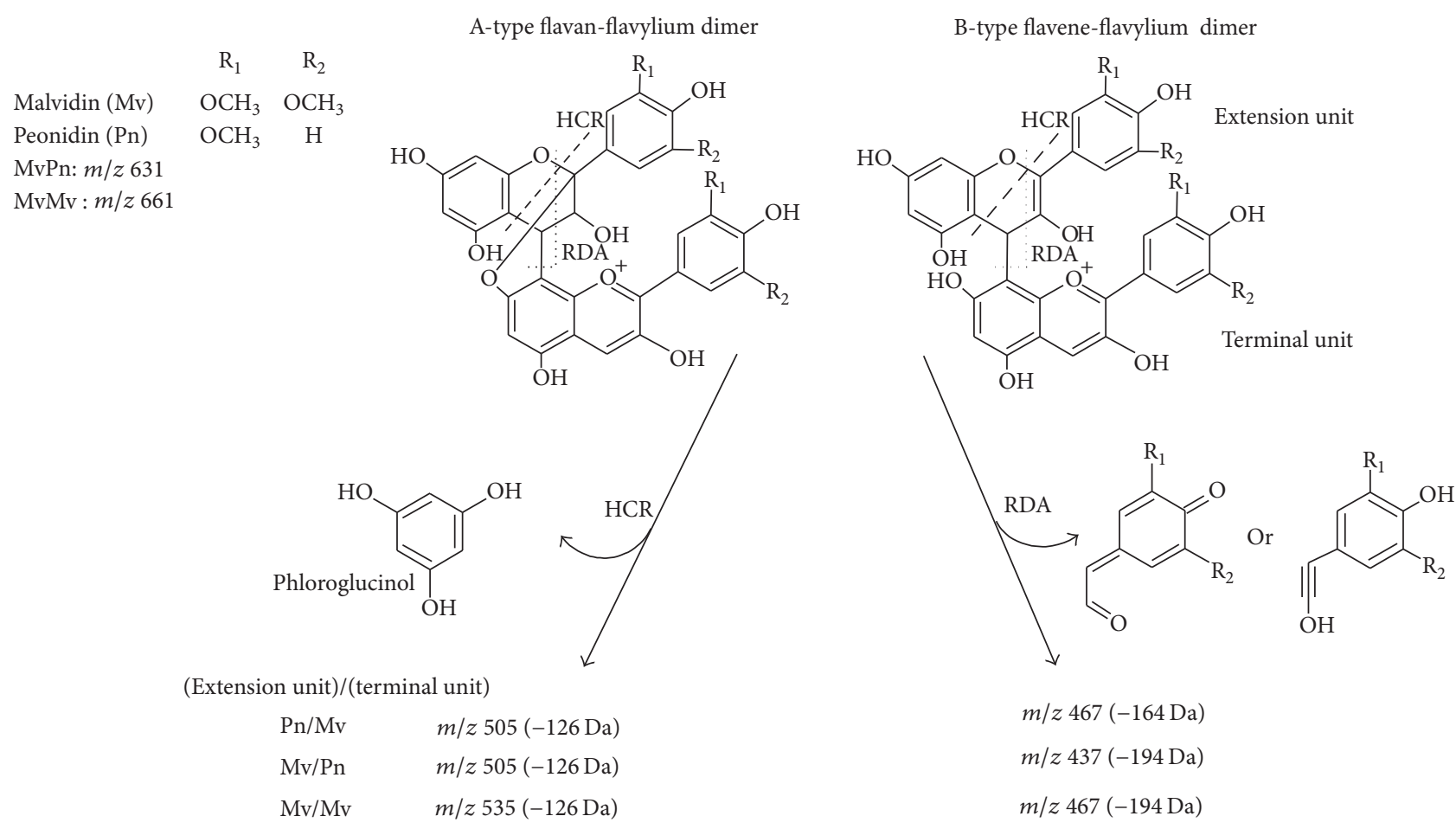

FIGURE 16: Fragmentation scheme proposed for two anthocyanin dimers. HCR: heterocyclic ring fission and RDA: retro-Diels-Alder fission [56].

in Table 6. A list of other monomer anthocyanins identified in extracts of other grape varieties is reported in Table 7, [66].

In general, $\mathrm{MS}^{n}$ is highly effective in differentiation also of isobaric anthocyanins. The fragment ions $[\mathrm{M}-162]^{+}$, $[\mathrm{M}-324]^{+}$(formed by two consecutive losses of sugar residue), $[\mathrm{M}-204]^{+},[\mathrm{M}-308]^{+}$, and $[\mathrm{M}-470]^{+}$(consecutive losses of $p$-coumaroylglucose and glucose) allow characterization of both monoglucoside and diglucoside compounds. Of course, the collision energy applied affects the relative abundance of diagnostic fragments. In the case of Mv-3,5O-diglucoside and Mv-3-O-(6-caffeoyl)monoglucoside, to distinguish between two compounds by performing $\mathrm{MS}^{n}$ experiments is not possible because they have identical molecular mass and aglycone. For identification of two compounds, dissolution of the extract in deuterated water was performed to observe the different mass shifts in agreement with the different number of exchangeable acidic proton present in each molecule [66]. Direct-ESI/MS also provided semiquantitative data of anthocyanins in the extract. Quantification of compounds was performed on the calibration curves of $\mathrm{Mv}$-3-O-glucoside for monoglucosides $\left(\mathrm{M}^{+}\right.$at $\mathrm{m} / \mathrm{z}$ 493) and of $\mathrm{Mv}-3,5-\mathrm{O}$-diglucoside for diglucosides $\left(\mathrm{M}^{+}\right.$at $m / z 655$ ) being standard commercially available compounds. An Mv-3-O-glucoside 40-ppm solution in water/acetonitrile $95: 5 \mathrm{v} / \mathrm{v}$ was used to optimize the ESI parameters in order to maximize the signals $[36,66]$.

Also, the capabilities of quadrupole-time-of-flight (QTOF) MS coupled with LC-Chip were used to distinguish between $\mathrm{Mv}-3,5-\mathrm{O}$-diglucoside and Mv-3-O-(6-O-caffeoyl)monoglucoside in Clinton extract, and the method was compared with direct-infusion ESI/IT-MS [49]. LCChip analyses were performed using a chromatographic system composed of an enrichment column Zorbax 300 $\mathrm{SB}_{-\mathrm{C}_{18}}(40 \mathrm{~nL}, 5 \mu \mathrm{m})$ and analytical column Zorbax 300 SB-C ${ }_{18}(75 \mu \mathrm{m} \times 43 \mathrm{~mm}, 5 \mu \mathrm{m})$. Elution of compounds from the column was performed by a binary solvent mixture composed of aqueous $0.1 \%$ formic acid and methanolic $0.1 \%$ formic acid working at a flow rate of $400 \mathrm{~nL} / \mathrm{min}$. Before analysis, the grape skins extract was diluted with a loading solution (aqueous $5 \%$ methanol containing $0.1 \%$ formic acid), and $1 \mu \mathrm{L}$ of the sample was injected. LCChip/ESI-QTOF MS provided the complete anthocyanin fingerprint of the sample in less than 5 minutes with practically no solvent consumption. Neither MS/MS was necessary for identification of isobaric compounds, nor deuterium exchange experiments to distinguish between compounds having the same aglycone. The fast separation bypassed also the problem of Pt-3-O-(6-O-acetyl)monoglucoside and Dp3,5-O-diglucoside quantification of direct-infusion ESI/IT MS due to overlapping of their signals with matrix interferences. The high specificity of LC-Chip/Q-TOF-MS was due to highly reproducible retention times (Chip-chromatography reduces the problems arising from dead volumes, eluent flow constancy, and ESI condition stabilities), highly effective and reproducible collisional experiments, accurate mass measurements, and consequent elemental formula determination of the precursor and fragment ions. Total ion chromatogram (TIC) and extracted ion chromatogram (EIC) of the three isobaric compound pairs at $m / z 611,625$, and 655 identified 
TABLE 6: Fragments from $\mathrm{M}^{+}$ions of anthocyanins in Clinton grape skin extract produced by direct-ESI and MS ${ }^{n}$ [66].

\begin{tabular}{|c|c|c|c|c|}
\hline \multirow[t]{2}{*}{ Anthocyanin } & \multicolumn{4}{|c|}{$m / z$} \\
\hline & $\mathrm{M}^{+}$ & {$\left[\mathrm{M}-\mathrm{C}_{6} \mathrm{H}_{10} \mathrm{O}_{5}\right]^{+}$} & & \\
\hline Malvidin-3-O-monoglucoside & 493 & 331 & & \\
\hline Petunidin-3-O-monoglucoside & 479 & 317 & & \\
\hline Delphinidin-3-O-monoglucoside & 465 & 303 & & \\
\hline Peonidin-3-O-monoglucoside & 463 & 301 & & \\
\hline \multirow[t]{2}{*}{ Cyanidin-3-O-monoglucoside } & 449 & 287 & & \\
\hline & $\mathrm{M}^{+}$ & {$\left[\mathrm{M}-\mathrm{C}_{8} \mathrm{H}_{12} \mathrm{O}_{6}\right]^{+}$} & & \\
\hline Malvidin-3-O-(6-O-acetyl)monoglucoside & 535 & 331 & & \\
\hline Petunidin-3-O-(6-O-acetyl)monoglucoside & 521 & 317 & & \\
\hline Delphinidin-3-O-(6-O-acetyl)monoglucoside & 507 & 303 & & \\
\hline Peonidin-3-O-(6-O-acetyl)monoglucoside & 505 & 301 & & \\
\hline \multirow[t]{2}{*}{ Cyanidin-3-O-6-O-(acetyl)monoglucoside } & 491 & 287 & & \\
\hline & $\mathrm{M}^{+}$ & {$\left[\mathrm{M}-\mathrm{C}_{15} \mathrm{H}_{16} \mathrm{O}_{7}\right]^{+}$} & & \\
\hline Malvidin-3-O-(6-O-p-coumaroyl)monoglucoside & 639 & 331 & & \\
\hline Petunidin-3-O-(6-O-p-coumaroyl)monoglucoside & 625 & 317 & & \\
\hline Delphinidin-3-O-(6-O-p-coumaroyl)monoglucoside & 611 & 303 & & \\
\hline Peonidin-3-O-(6-O-p-coumaroyl)monoglucoside & 609 & 301 & & \\
\hline \multirow[t]{2}{*}{ Cyanidin-3-O-(6-O-p-coumaroyl)monoglucoside } & 595 & 287 & & \\
\hline & $\mathrm{M}^{+}$ & {$\left[\mathrm{M}-\mathrm{C}_{6} \mathrm{H}_{10} \mathrm{O}_{5}\right]^{+}$} & {$\left[\mathrm{M}-2\left(\mathrm{C}_{6} \mathrm{H}_{10} \mathrm{O}_{5}\right)\right]^{+}$} & \\
\hline Malvidin-3,5-O-diglucoside & 655 & 493 & 331 & \\
\hline Petunidin-3,5-O-diglucoside & 641 & 479 & 317 & \\
\hline Delphinidin-3,5-O-diglucoside & 627 & 465 & 303 & \\
\hline Peonidin-3,5-O-diglucoside & 625 & 463 & 301 & \\
\hline \multirow[t]{2}{*}{ Cyanidin-3,5-O-diglucoside } & 611 & 449 & 287 & \\
\hline & $\mathrm{M}^{+}$ & {$\left[\mathrm{M}-\mathrm{C}_{6} \mathrm{H}_{10} \mathrm{O}_{5}\right]^{+}$} & {$\left[\mathrm{M}-\mathrm{C}_{15} \mathrm{H}_{16} \mathrm{O}_{7}\right]^{+}$} & {$\left[\mathrm{M}-\mathrm{C}_{15} \mathrm{H}_{16} \mathrm{O}_{7}-\mathrm{C}_{6} \mathrm{H}_{10} \mathrm{O}_{5}\right]^{+}$} \\
\hline Malvidin-3-(6-O-p-coumaroyl),5-O-diglucoside & 801 & 639 & 493 & 331 \\
\hline Petunidin-3-(6-O-p-coumaroyl),5-O-diglucoside & 787 & 625 & 479 & 317 \\
\hline Delphinidin-3-(6-O-p-coumaroyl),5-O-diglucoside & 773 & 611 & 465 & 303 \\
\hline \multirow[t]{2}{*}{ Cyanidin-3-(6-O-p-coumaroyl),5-O-diglucoside } & 757 & 595 & 449 & 287 \\
\hline & $\mathrm{M}^{+}$ & {$\left[\mathrm{M}-\mathrm{C}_{15} \mathrm{H}_{16} \mathrm{O}_{8}\right]^{+}$} & & \\
\hline Malvidin-3-O-(6-O-caffeoyl)monoglucoside & 655 & 331 & & \\
\hline
\end{tabular}

TABLE 7: Monomer anthocyanins identified by LC/ESI-MS/MS analysis in skin extract and juice of different grape cultivars [24, 69].

\begin{tabular}{lcc}
\hline Anthocyanin & $m / z[\mathrm{M}]^{+}$ & Cultivar \\
\hline Cy-3-O-pentoside & 419 & Casavecchia \\
Pg-3-O-glucoside & 433 & Concord, Salvador, Rubired \\
Cy-3-O-(6-O-acetyl)pentoside & 461 & Casavecchia \\
Cy-3-O-(6-O-p-coumaryl)pentoside & 565 & Casavecchia \\
Dp-3-O-glucoside-pyuvic acid & 533 & Isabelle \\
Dp-3-O-(6-O-p-coumaryl)glucoside-pyruvic acid & 679 & Isabelle \\
Pn-3-O-glucoside-acetaldehyde & 487 & Isabelle, Pallagrello \\
Mv-3-O-glucoside-acetaldehyde & 517 & Isabelle \\
Pt-3-O-(6-O-p-caffeoyl)-5-O-diglucoside & 803 & Isabelle, Casavecchia \\
Dp-3-O-(6-O-acetyl)-5-O-diglucoside & 669 & Isabelle \\
Dp-3-O-(6-O-feruloyl)-5-O-diglucoside & 803 & Isabelle, Casavecchia \\
Pn-3-O-(6-O-p-coumaryl)-5-O-diglucoside & 771 & Concord, Salvador, Isabelle, Casavecchia \\
\hline
\end{tabular}

Pg: pelargonidin; Dp: delphinidin; Cy: cyanidin; Pt: petunidin; Pn: peonidin; Mv: malvidin. 


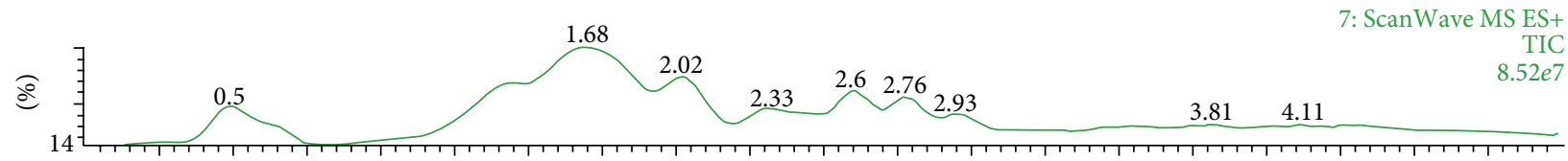

(a)

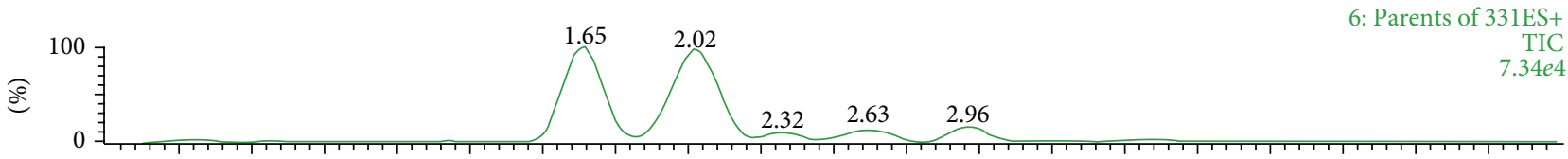

(b)

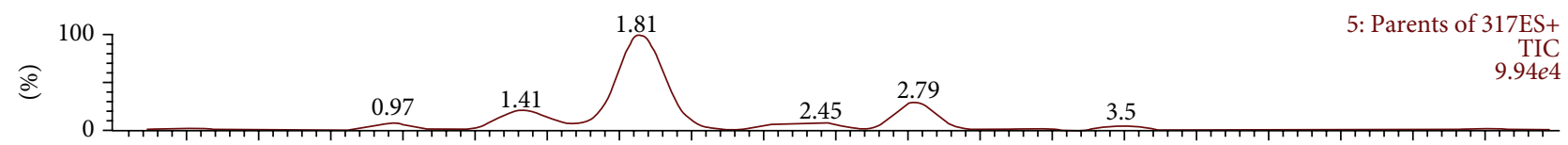

(c)

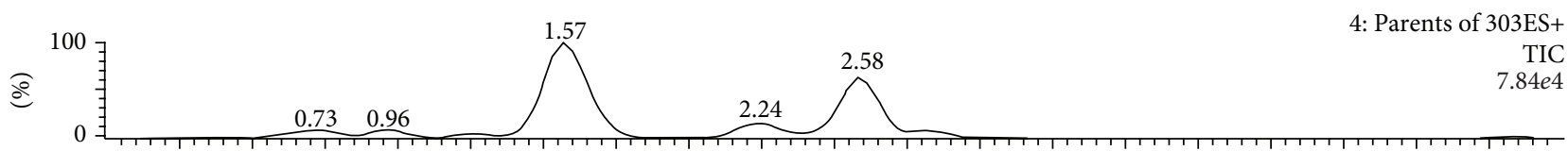

(d)

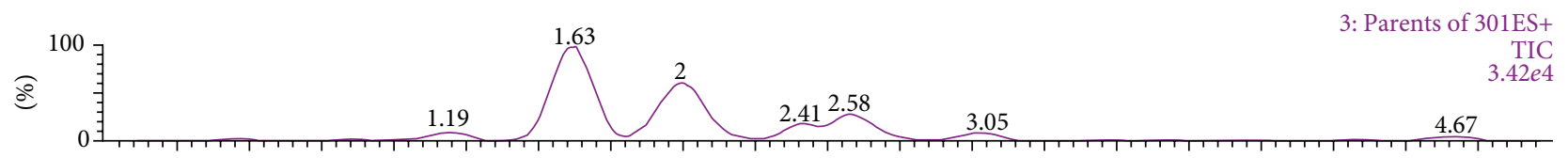

(e)

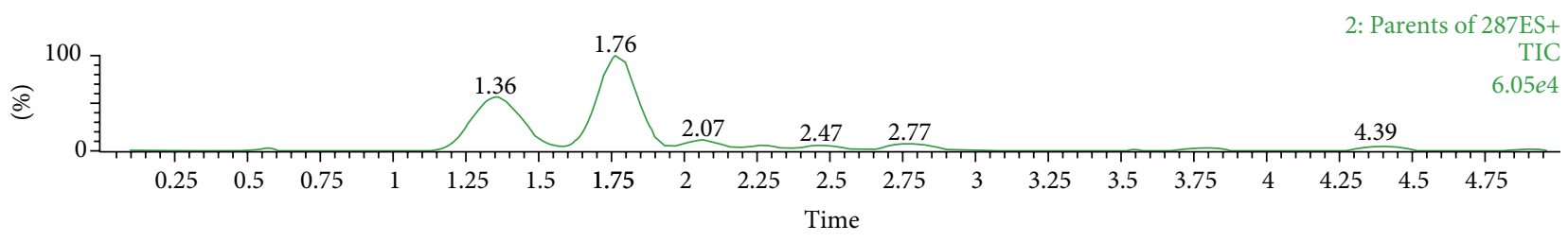

(f)

FIGURE 17: UPLC/MS total ion chromatogram (TIC) (a) and precursor-ion chromatograms from anthocyanin analysis of Bacò 30-12 grape skins extract. (b) Precursor-ion chromatogram of fragment at $\mathrm{m} / z 331$ (corresponding to $\mathrm{Mv}$ ); (c) precursor-ion chromatogram of fragment at $m / z 317(\mathrm{Pt})$; (d) precursor-ion chromatogram of fragment at $m / z 303(\mathrm{Dp})$; (e) precursor-ion chromatogram of fragment at $m / z 301$ (Pn); (f) precursor-ion chromatogram of fragment at $m / z 287$ (Cy) [58].

in the analysis of Clinton grape skins extract are showed in Figure 12.

Reverse-phase LC-Chip allowed the separation of all the isobaric pairs of compounds with an elution sequence from the column linked to the polarity of compounds: first elute the more polar diglucosides, followed by monoglucosides, and finally the less polar acylated monoglucosides (acetates and $p$ coumarates, resp.). The anthocyanins identified in the Clinton extract by LC-Chip/Q-TOF and direct-ESI/IT-MS analysis are reported in Table 8.

To distinguish between isobaric pairs of anthocyanins, also accurate mass measurements were performed. Figure 13 shows the Q-TOF signals recorded after LC-Chip separation of isobaric pairs at nominal mass $\mathrm{m} / z 611$ (Cy-diglucoside and Dp-p-coumaroylmonoglucoside), $m / z 625$ (Pn-diglucoside and Pt-p-coumaroylmonoglucoside), and $m / z 655$ (Mv-diglucoside and Mv-caffeoylmonoglucoside). For these ions, the Q-TOF system used did not provide sufficient resolution to distinguish between $\mathrm{Cy}-3,5-\mathrm{O}$-diglucoside $\left(\mathrm{C}_{27} \mathrm{H}_{31} \mathrm{O}_{16}\right.$, MW 611.1612) and Dp-3-O-(6-O-p-coumaroyl)monoglucoside $\left(\mathrm{C}_{30} \mathrm{H}_{27} \mathrm{O}_{14}\right.$, MW 611.1401), Pn-3,5-Odiglucoside $\left(\mathrm{C}_{28} \mathrm{H}_{33} \mathrm{O}_{16}\right.$, MW 625.1769) and Pt-3-O-(6-Op-coumaroyl)monoglucoside $\left(\mathrm{C}_{31} \mathrm{H}_{29} \mathrm{O}_{14}, \mathrm{MW}\right.$ 625.1557), or Mv-3,5-O-diglucoside $\left(\mathrm{C}_{29} \mathrm{H}_{35} \mathrm{O}_{17}, \mathrm{MW}\right.$ 655.1874) and Mv-3-O-(6-O-caffeoyl)monoglucoside $\left(\mathrm{C}_{32} \mathrm{H}_{31} \mathrm{O}_{15}, \quad \mathrm{MW}\right.$ 655.1663 ) because a resolution at least 30.000 is necessary. MS/MS allowed to confirm identi-fication of the compounds with $\mathrm{M}^{+}$at $m / z 611$ and $m / z 625$ (on the basis of their 


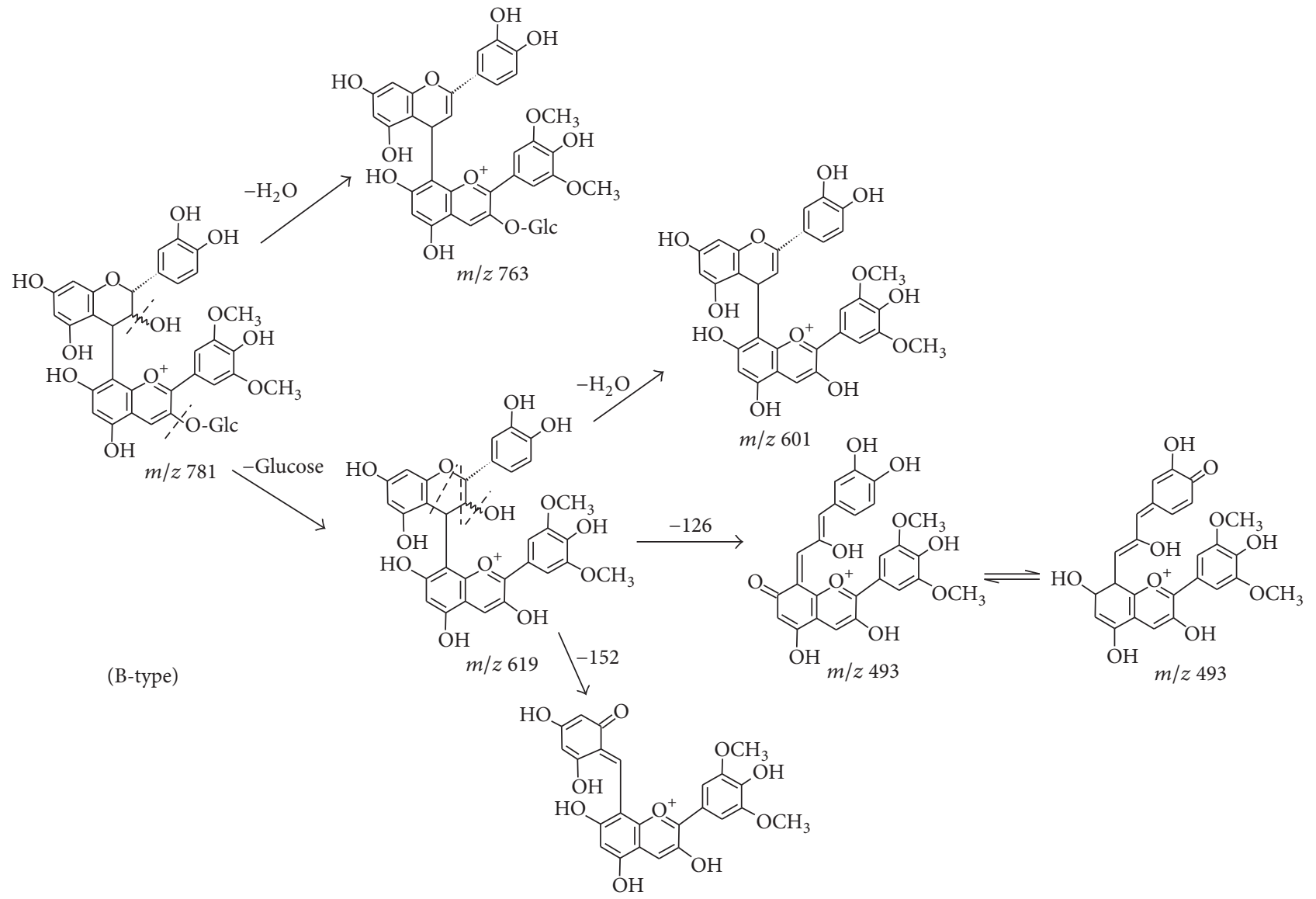<smiles>COc1cc(C2Oc3cc(O)cc(O)c3C23Oc2c(O)cc(O)c(c2OC)CC3O)cc(OC)c1O</smiles>

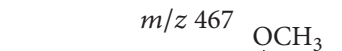

(A-type)

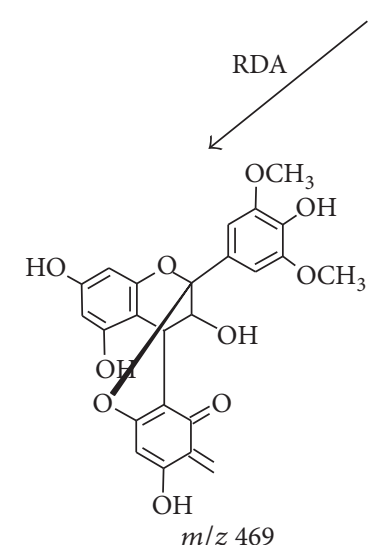

$-\mathrm{H}_{2}^{m / z} \mathrm{O}$<smiles>COC1=CC(C2Oc3cc(O)c4c(c3OC2C=CC(C)C)C(O)CC(O)C4c2ccc(O)c(O)c2)C=C(OC)C1=O</smiles>

FIgURE 18: MS/MS fragmentation scheme proposed for (epi)catechin-Mv-3-glu B-type linkage $\left(\mathrm{M}^{+}\right.$at $m / z$ 781) and for Mv-3-glu(epi)catechin A-type linkage $\left(\mathrm{M}^{+}\right.$at $m / z$ 783) [67, 68]. RDA: retro-Diels-Alder fission. 
<smiles>COc1cc(C2=C(OCl)C(c3c(O)cc(O)c4cc(OC5CCCCC5)c(-c5cc(OC)c(O)c(OC)c5)[o+]c34)c3c(O)cc(O)c(C4c5c(O)cc(O)cc5OC(c5ccc(O)c(O)c5)C4O)c3O2)cc(OC)c1O</smiles>

(a)

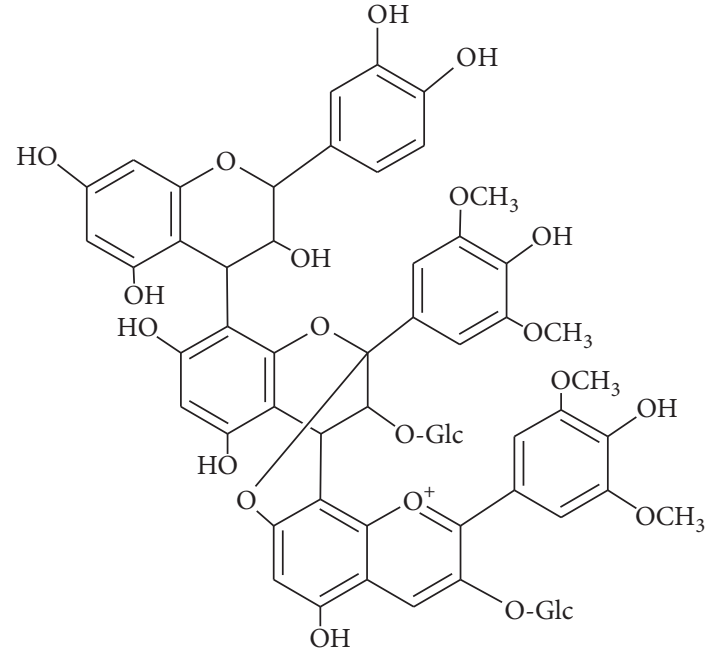

(b)

FIgURE 19: Possible structures proposed for the $\mathrm{M}^{+}$species at $m / z$ 1273: (a) (E)C-MvG-Mv+G trimer in flavene-flavylium form (B-type linkage) and (b) (E)C-MvG-Mv+G trimer in flavan-flavylium form (A-type linkage) [60].

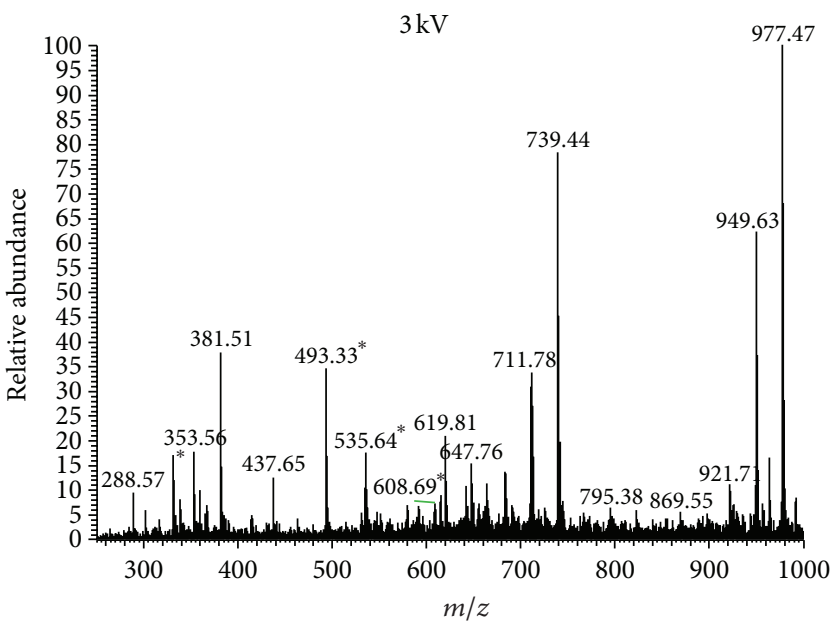

(a)

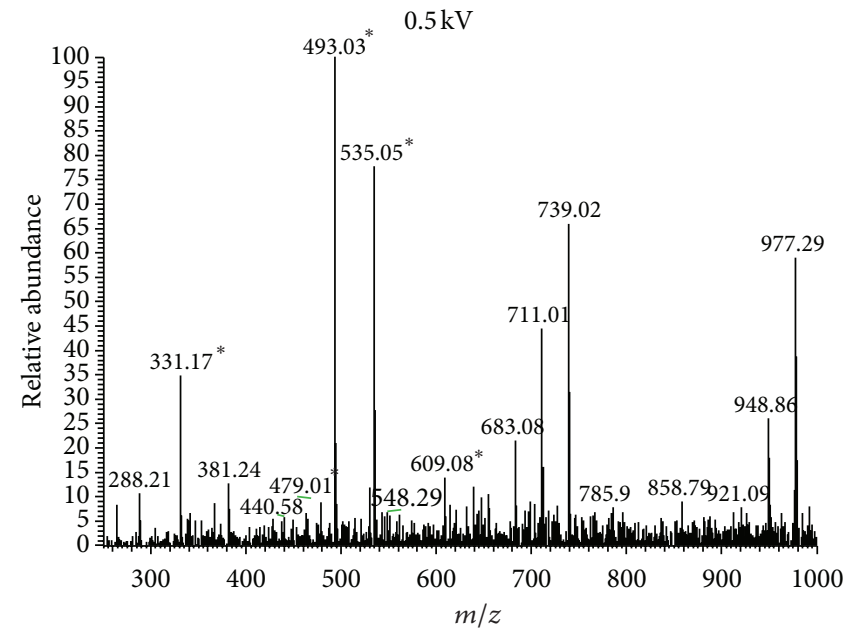

(b)

FIGURE 20: Mass spectra of a Cabernet Sauvignon wine recorded by application of spray capillary voltage $3 \mathrm{kV}$ (a) and $0.5 \mathrm{kV}$ (b). ${ }^{*}:$ main anthocyanin signals [70].

different aglycone ions), but only chip separation allowed differentiation of two isobaric compounds with the same aglycone moiety (nominal mass $655 \mathrm{Da}$ ).

Figure 14 shows the MS/MS mass spectra of the isobaric anthocyanin pairs Cy-diglucoside and Dp-p-coumaroylmonoglucoside $\left(\mathrm{M}^{+}\right.$at $m / z$ 611), Pn-diglucoside and $\mathrm{Pt}$ - $\mathrm{p}$-coumaroylmonoglucoside $\left(\mathrm{M}^{+}\right.$at $\left.m / z 625\right)$, and $\mathrm{Mv}$ diglucoside and $\mathrm{Mv}$-caffeoylmonoglucoside $\left(\mathrm{M}^{+}\right.$at $\left.m / z 655\right)$. The spectra (a), (c), and (e) are characteristic of diglucoside compounds and show the ions formed by $162 \mathrm{Da}$ loss corresponding to glucose residue at $m / z 449,463$, and 493 for Cy-diglucoside, Pn-diglucoside, and Mv-diglucoside, respectively, and the aglycone ions at $m / z 287,301$, and $m / z$
331. The spectra (b), (d), and (f), characteristic of cinnamoylmonoglucoside derivatives, show the aglycones of Dp- $p$-coumaroylmonoglucoside, Pt- $p$-coumaroylmonoglucoside, and Mv-caffeoylmonoglucoside at $m / z$ 303, 317, and $m / z$ 331, respectively.

Concentration of anthocyanins in the extract was determined on the calibration curve calculated by spiking the sample with $\mathrm{Mv}$-3,5-O-diglucoside standard at three different concentrations. The resulting calibration curve is showed in Figure 15.

Quantitative percentage data of LC-Chip/ESI-QTOF-MS and ESI/IT-MS analysis of Clinton extract are reported in Table 8 . The two methods showed good agreement, except 


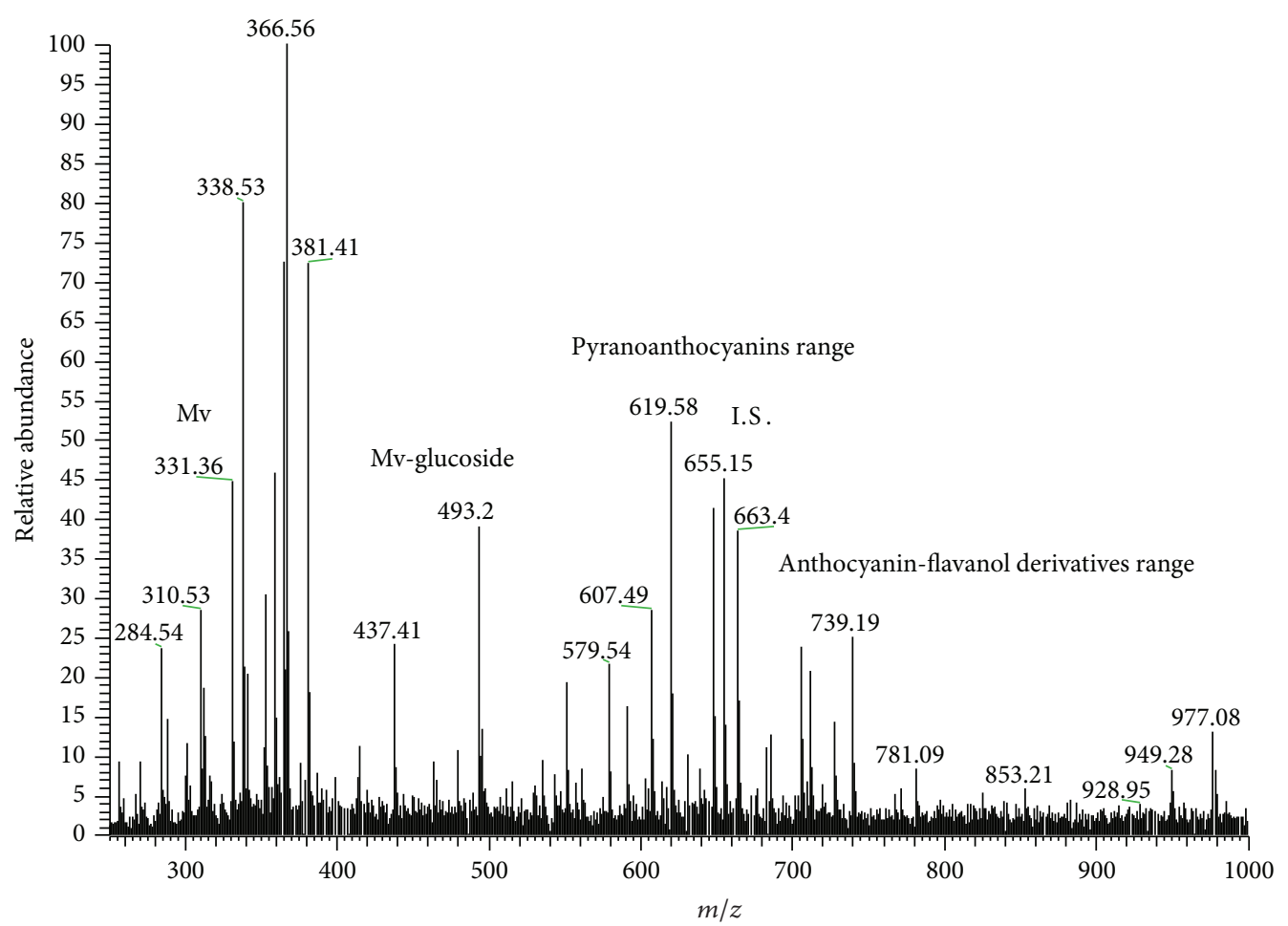

FIGURE 21: Direct-infusion pneumatic spray (DIPS with capillary voltage $0.5 \mathrm{kV}$ ) of a Cabernet Sauvignon wine aged several years. Mv: malvidin; IS: internal standard Mv-3,5-diglucoside [70].

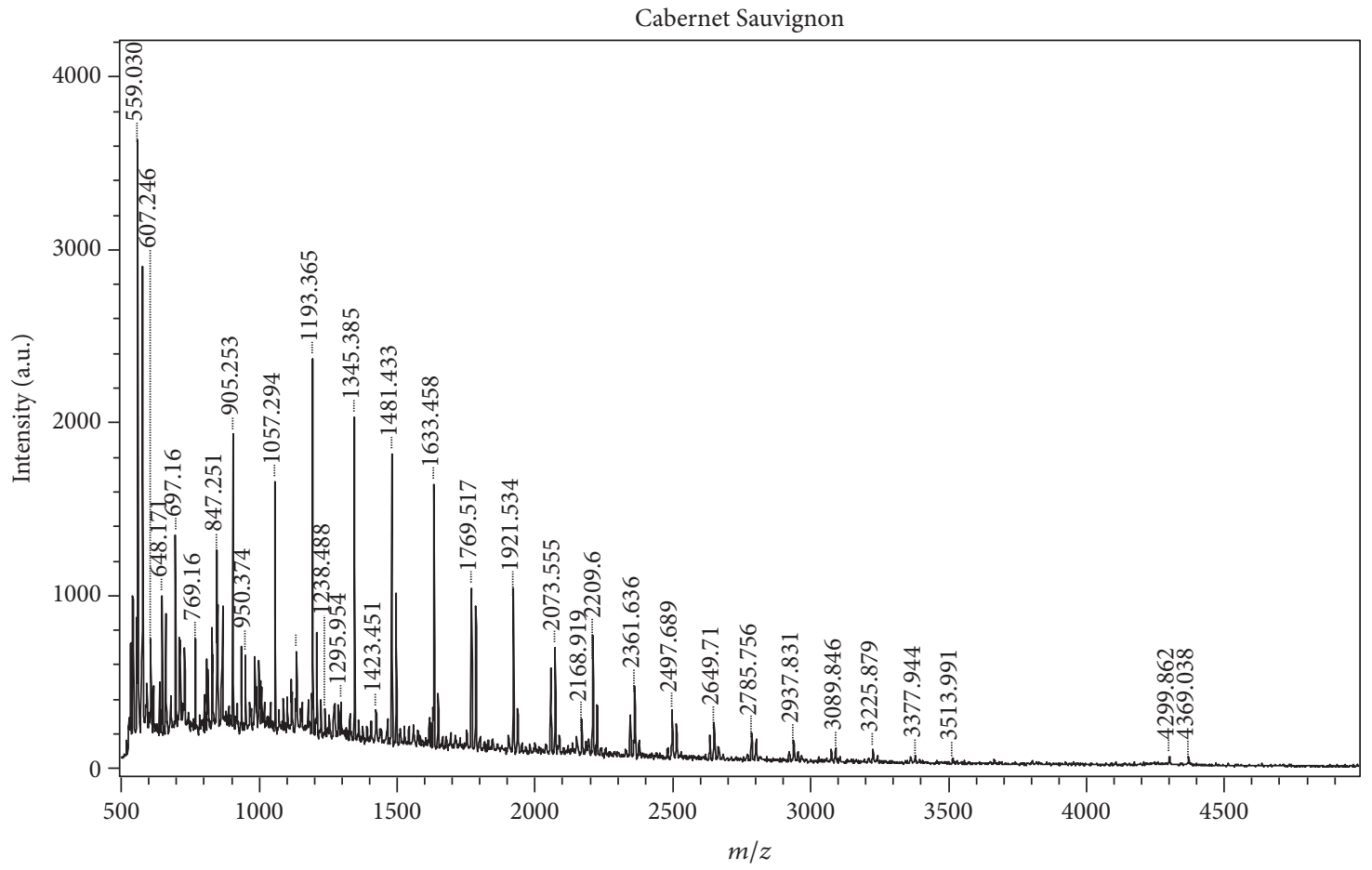

FIGURE 22: Signals of PAs in the MALDI-TOF spectrum of a Cabernet Sauvignon grape seeds extract. 
TABLE 8: Anthocyanins identified in Clinton grape skins extract by direct-ESI/IT-MS and LC-Chip/ESI-QTOF-MS analysis performed in positive-ion mode (LC-Chip retention times are reported). Data are expressed as relative percentage of $\mathrm{M}^{+}$signal of compound with respect to $\mathrm{M}^{+}$signal of Mv-3-O-monoglucoside at $m / z 611$ and $m / z 493$.

\begin{tabular}{|c|c|c|c|c|}
\hline \multirow[b]{2}{*}{ Compound } & \multirow[b]{2}{*}{ MW } & \multirow{2}{*}{$\begin{array}{c}\text { Direct-ESI/IT-MS } \\
\mathrm{M}^{+} \text {height } \% \\
\text { Relative to Mv monoglucoside }\end{array}$} & \multicolumn{2}{|c|}{ LC-Chip/ESI-Q-TOF-MS } \\
\hline & & & $\mathrm{RT}(\min )$ & $\begin{array}{c}\mathrm{M}^{+} \text {area } \% \\
\text { Relative to } \mathrm{My} \text { monoglucoside }\end{array}$ \\
\hline Cyanidin-3-O-monoglucoside & 449 & 9 & 3.794 & 11 \\
\hline Peonidin-3-O-monoglucoside & 463 & 33 & 3.869 & 52 \\
\hline Delphinidin-3-O-monoglucoside & 465 & 35 & 3.744 & 38 \\
\hline Petudinin-3-O-monoglucoside & 479 & 44 & 3.794 & 39 \\
\hline Cyanidin-3-O-(6-O-acetyl)monoglucoside & 491 & 2 & 4.095 & $\operatorname{tr}$ \\
\hline Malvidin-3-O-monoglucoside & 493 & 100 & 3.869 & 100 \\
\hline Peonidin-3-O-(6-O-acetyl)monoglucoside & 505 & 10 & 4.070 & 6 \\
\hline Delphinidin-3-O-(6-O-acetyl)monoglucoside & 507 & 6 & 3.944 & 2 \\
\hline Petudinin-3-O-(6-O-acetyl)monoglucoside & 521 & $\underline{23}$ & 3.995 & 5 \\
\hline Malvidin-3-O-(6-O-acetyl)monoglucoside & 535 & 36 & 4.045 & 30 \\
\hline Cyanidin-3-(6-O-p-coumaryl)monoglucoside & 595 & 3 & 4.220 & 5 \\
\hline Peonidin-3-(6-O-p-coumaryl)monoglucoside & 609 & 6 & 4.295 & 18 \\
\hline Cyanidin-3,5-O-diglucoside & 611 & $19(m / z 611)$ & 3.644 & 3 \\
\hline Delphinidin-3-(6-O-p-coumaryl)monoglucoside & 611 & & 4.170 & 15 \\
\hline Peonidin-3,5-O-diglucoside & 625 & $14(m / z 625)$ & 3.719 & 3 \\
\hline Petudinin-3-(6-O-p-coumaryl)monoglucoside & 625 & & 4.220 & 3 \\
\hline Delphinidin-3,5-O-diglucoside & 627 & $\underline{35}$ & 3.594 & 2 \\
\hline Malvidin-3-(6-O-p-coumaryl)monoglucoside & 639 & 39 & 4.270 & 48 \\
\hline Petudinin-3,5-O-diglucoside & 641 & 16 & 3.669 & 14 \\
\hline Malvidin-3,5-O-diglucoside & 655 & $24(m / z 655)$ & 3.719 & 26 \\
\hline Malvidin-3-(6-O-caffeoyl)monoglucoside & 655 & & 4.170 & 1 \\
\hline Cyanidin-3-(6-O-p-coumaryl),5-O-diglucoside & 757 & 2 & 3.995 & 1 \\
\hline Delphinidin-3-(6-O-p-coumaryl),5-O-diglucoside & 773 & 2 & 3.944 & 2 \\
\hline Petudinin-3-(6-O-p-coumaryl),5-O-diglucoside & 787 & 2 & 3.995 & 3 \\
\hline Malvidin-3-(6-O- $p$-coumaryl),5-O-diglucoside & 801 & 2 & 4.045 & 3 \\
\hline
\end{tabular}

tr: trace [49].

for Pt-3-O-(6-O-acetyl)monoglucoside $(m / z 521)$ and Dp3,5-O-diglucoside $(\mathrm{m} / \mathrm{z} 627)$ for which the $\mathrm{M}^{+}$signal area resulted overestimated in the ESI/IT-MS analysis. CID of the species at $m / z 627$ in the ESI/MS spectrum, other than the ions at $\mathrm{m} / z 465$ and 303 corresponding to Dp-3,5-Odiglucoside, produced the ion at $m / z 317$ as the most intense signal probably corresponding to petunidin or protonated isorhamnetin revealing the overlapping of at least two compounds. CID spectrum of the ion at $m / z 521$, other than the aglycone base peak signal at $m / z 317$, showed two intense signals at $m / z 522$ and 488 with relative abundance of about $40 \%$ each. $\mathrm{MS}^{3}$ of the ion at $m / z 488$ showed that at least two isobaric compounds were present in the extract.

TOF/MS was not suitable to distinguish between isobaric pairs of compounds such as protonated isorhamnetin glucoside and petunidin glucoside $\left(\mathrm{C}_{22} \mathrm{H}_{23} \mathrm{O}_{12}\right.$, exact mass 479.1190), and protonated kaempferol monoglucoside and cyanidin monoglucoside $\left(\mathrm{C}_{21} \mathrm{H}_{21} \mathrm{O}_{11}\right.$, exact mass 449.1084). Intensities of the signals at $\mathrm{m} / z 449$ and $\mathrm{m} / z 479$ recorded by direct-ESI/IT-MS and LC-Chip/ESI-QTOF-MS are similar (Table 8 ), inferring that probably protonated flavonols present in the extract were not separated from the chromatographic chip used.

In grape skins, also the oligomeric anthocyanins listed in Table 9 were identified $[56,59]$. Figure 16 shows the fragmentation scheme proposed for two anthocyanin dimers.

In a recent work anthocyanins of 21 hybrid red grape varieties produced by crossing of different Vitis vinifera, riparia, labrusca, Lincecumii, and rupestris species were studied [58]. In general, hybrid grapes are characterized by peculiar contents of anthocyanins, often qualitatively and quantitatively different-and superior-to the $V$. vinifera varieties $[66,71-$ 77]. Also due to the increasing industrial demand for natural colorants, the knowledge of their composition may be useful for industrial purposes [78, 79].

The study was performed by using an ultraperformance liquid chromatography and triple quadrupole mass spectrometry system (UPLC/MS). Precursor-ion analysis of the anthocyanidin and monoglucoside-anthocyanin fragments produced by CID was performed. Twenty-four compounds were identified using two different experimental conditions: precursor-ions scan of the aglycone fragments produced at 
TABLE 9: Oligomeric anthocyanins identified in Shiraz grape skins.

\begin{tabular}{|c|c|}
\hline$m / z$ & Assignment \\
\hline $617^{\mathrm{F}}$ & $\mathrm{MvCy}$ \\
\hline $631^{\mathrm{F}}$ & $\mathrm{MvPn}$ \\
\hline $633^{\mathrm{F}}$ & $\mathrm{MvDp}$ \\
\hline $647^{\mathrm{F}}$ & $\mathrm{MvPt}$ \\
\hline $661^{\mathrm{F}}$ & $\mathrm{MvMv}$ \\
\hline $779^{\mathrm{F}}$ & $\mathrm{MvCy}+\mathrm{G}$ \\
\hline $793^{\mathrm{F}}$ & $\mathrm{MvPn}+\mathrm{G}$ \\
\hline $795^{\mathrm{F}}$ & $\mathrm{MvDp}+\mathrm{G}$ \\
\hline $809^{\mathrm{F}}$ & $\mathrm{MvPt}+\mathrm{G}$ \\
\hline $823^{\mathrm{F}}$ & $\mathrm{MvMv}+\mathrm{G}$ \\
\hline $941^{\mathrm{M}}$ & $\mathrm{MvCy}+2 \mathrm{G}$ \\
\hline $955^{\mathrm{M}}$ & $\mathrm{MvPn}+2 \mathrm{G}$ \\
\hline $957^{\mathrm{M}}$ & $\mathrm{MvDp}+2 \mathrm{G}$ \\
\hline $971^{\mathrm{M}}$ & $\mathrm{MvPt}+2 \mathrm{G}$ \\
\hline $985^{\mathrm{M}}$ & $\mathrm{MvMv}+2 \mathrm{G}$ \\
\hline $1087^{\mathrm{M}}$ & $\mathrm{MvCy}+\mathrm{G} \cdot \mathrm{pCG}$ \\
\hline $1101^{\mathrm{M}}$ & $\mathrm{MvPn}+\mathrm{G} \cdot \mathrm{pCG}$ \\
\hline $1103^{\mathrm{M}}$ & $\mathrm{MvDp}+\mathrm{G} \cdot \mathrm{pCG}$ \\
\hline $1117^{\mathrm{M}}$ & $\mathrm{MvPt}+\mathrm{G} \cdot \mathrm{pCG}$ \\
\hline $1131^{\mathrm{M}}$ & $\mathrm{MvMv}+\mathrm{G} \cdot \mathrm{pCG}$ \\
\hline $1271^{\mathrm{F}}$ & $\mathrm{MvMvCy}+2 \mathrm{G}$ \\
\hline $1285^{\mathrm{F}}$ & $\mathrm{MvMvPn}+2 \mathrm{G}$ \\
\hline $1287^{\mathrm{F}}$ & $\mathrm{MvMvDp}+2 \mathrm{G}$ \\
\hline $1301^{\mathrm{F}}$ & $\mathrm{MvMvPt}+2 \mathrm{G}$ \\
\hline $1315^{\mathrm{F}}$ & $\mathrm{MvMvMv}+2 \mathrm{G}$ \\
\hline $1417^{\mathrm{F}}$ & $\mathrm{MvMvCy}+\mathrm{G} \cdot \mathrm{pCG}$ \\
\hline $1431^{\mathrm{F}}$ & $\mathrm{MvMvPn}+\mathrm{G} \cdot \mathrm{pCG}$ \\
\hline $1433^{\mathrm{F}}$ & $\mathrm{MvMvDp}+\mathrm{G} \cdot \mathrm{pCG}$ \\
\hline $1433^{\mathrm{M}}$ & $\mathrm{MvMvCy}+3 \mathrm{G}$ \\
\hline $1447^{\mathrm{F}}$ & $\mathrm{MvMvPt}+\mathrm{G} \cdot \mathrm{pCG}$ \\
\hline $1447^{\mathrm{M}}$ & MvMvPn + 3G \\
\hline $1449^{\mathrm{M}}$ & $\mathrm{MvMvDp}+3 \mathrm{G}$ \\
\hline $1461^{\mathrm{F}}$ & $\mathrm{MvMvMv}+\mathrm{G} \cdot \mathrm{pCG}$ \\
\hline $1463^{\mathrm{M}}$ & $\mathrm{MvMvPt}+3 \mathrm{G}$ \\
\hline $1477^{\mathrm{M}}$ & $\mathrm{MvMvMv}+3 \mathrm{G}$ \\
\hline $1579^{\mathrm{M}}$ & $\mathrm{MvMvCy}+2 \mathrm{G} \cdot \mathrm{pCG}$ \\
\hline $1593^{\mathrm{M}}$ & $\operatorname{MvMvPn}+2 \mathrm{G} \cdot \mathrm{pCG}$ \\
\hline $1595^{\mathrm{M}}$ & $\mathrm{MvMvDp}+2 \mathrm{G} \cdot \mathrm{pCG}$ \\
\hline $1609^{\mathrm{M}}$ & $\mathrm{MvMvPt}+2 \mathrm{G} \cdot \mathrm{pCG}$ \\
\hline $1623^{\mathrm{M}}$ & $\mathrm{MvMvMv}+2 \mathrm{G} \cdot \mathrm{pCG}$ \\
\hline
\end{tabular}

F: fragment ion; M: molecular ion. Dp: delphinidin; Cy: cyanidin; Pt: petunidin; Pn: peonidin; Mv: malvidin; G: glucose, pCG: $p$-coumaroylglucoside [56].

a collision energy of $4 \mathrm{eV}$ and precursors scan of monoglucoside anthocyanin fragments produced at collision energy $25 \mathrm{eV}$. Analysis of precursor ions of these fragments was possible because usually no fragmentation occurs in the glucose and acyl group linkage, nor formation of acylglucoside anthocyanins was observed in neutral-loss analysis [80]. The samples were subdivided into two groups on the basis of their anthocyanin profiles which were characterized by the substantial presence or scarce presence of diglucoside compounds, respectively. Analysis of precursor ions showed to be a highly selective method: by monitoring each aglycone, the signals of all corresponding derivatives are detected. This approach can be used for selective study of particular anthocyanidin derivatives in the sample; for example, by monitoring the product ion at $\mathrm{m} / z 331$ (corresponding to $\mathrm{Mv}$ ), the signals of precursors at $\mathrm{m} / z 493$ (the monoglucoside derivative), $m / z 535$ (acetyl monoglucoside), $m / z 639$ ( $p$ coumaroylmonoglucoside), $\mathrm{m} / z 655$ (diglucoside), and $\mathrm{m} / z$ 801 ( $p$-coumaroyl diglucoside) were detected. In addition, precursor-ion analysis enhances the signal-to-noise ratio, allowing more sensitivity in analysis of anthocyanins in complex matrices [80].

Figure 17 shows the TIC and precursor-ion chromatograms of aglycone fragments from analysis of a hybrid grape sample (Bacò 30-12). Three precursor ions for $\mathrm{Dp}, \mathrm{Pn}$, and, Cy anthocyanidin fragments and five precursor ions for Mv and Pt were found, leading to identification of the 20 anthocyanins (13 monoglucosides and 7 diglucosides) reported in Table 10.

The precursors identified by precursor-ion analysis of monoglucoside anthocyanins are reported in Table 11. Identification of diglucoside compounds found in precursor-ion analysis of aglycone fragments was confirmed, and the signals of four additional diglucoside compounds were also found [Mv-3-O-(6-O-acetyl)diglucoside at $m / z 697, \mathrm{Dp}-3,5$-diglucoside at $m / z 627, \mathrm{Pn}-3-\mathrm{O}-(6-\mathrm{O}-$ $p$-coumaroyl)diglucoside at $\mathrm{m} / z$ 771, and Cy-3-O-(6-O-pcoumaroyl)diglucoside at $m / z$ 757], leading to identification of total 11 diglucoside anthocyanins. Therefore, the coupling of UPLC and precursor-ion analysis with monitoring of monoglucosides resulted a highly specific method for selective detection of diglucoside compounds.

\section{LC/MS of Anthocyanin Derivatives in Wine}

LC/MS analysis of anthocyanin derivatives in wine can be performed by direct injection of the sample without prior sample preparation, and several methods with different chromatographic conditions were proposed by this approach. Table 12 shows the compounds identified in Graciano, Tempranillo, Cabernet Sauvignon, and Primitivo wines. Alternatively, a previous sample purification can be performed on a $\mathrm{C}_{18}$ cartridge recovering anthocyanins with methanol [81].

Several methods for isolation and fractionation of oligomeric pigments in the analysis of pyranoanthocyanins and anthocyanin derivatives in wine were proposed [22, 33]. Anthocyanin-flavanol derivatives can be characterized by MS/MS experiments (Table 12). For example, Figure 18 shows the fragmentation schemes proposed for (epi)catechin-Mv-3-glu $\left(\mathrm{M}^{+}\right.$at $\mathrm{m} / z$ 781) and for Mv-3-glu(epi)catechin with A-type linkage $\left(\mathrm{M}^{+}\right.$at $m / z$ 783).

A list of anthocyanin derivatives identified in wines at different aging stages is reported in Table 13. As may be seen, 


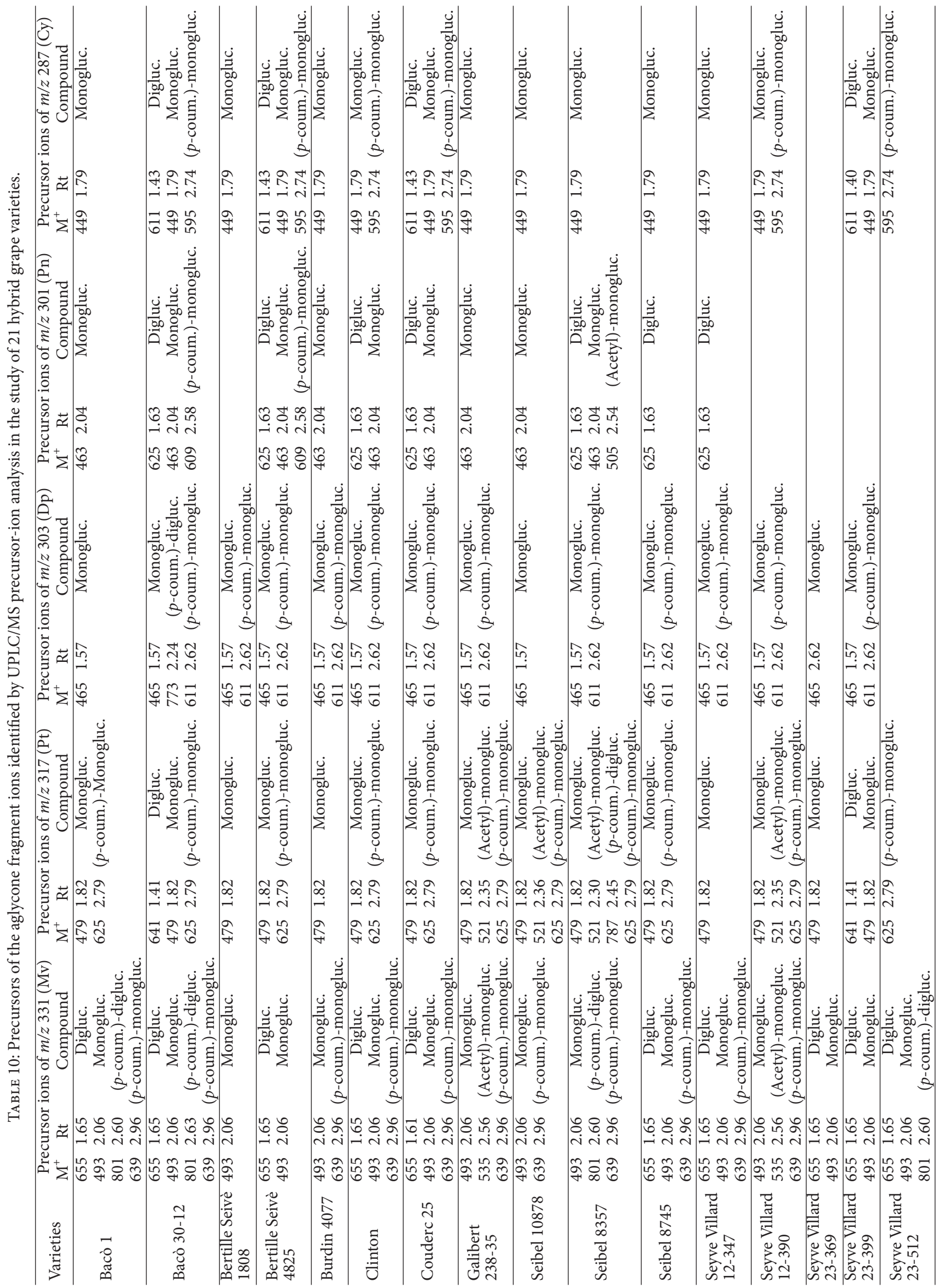




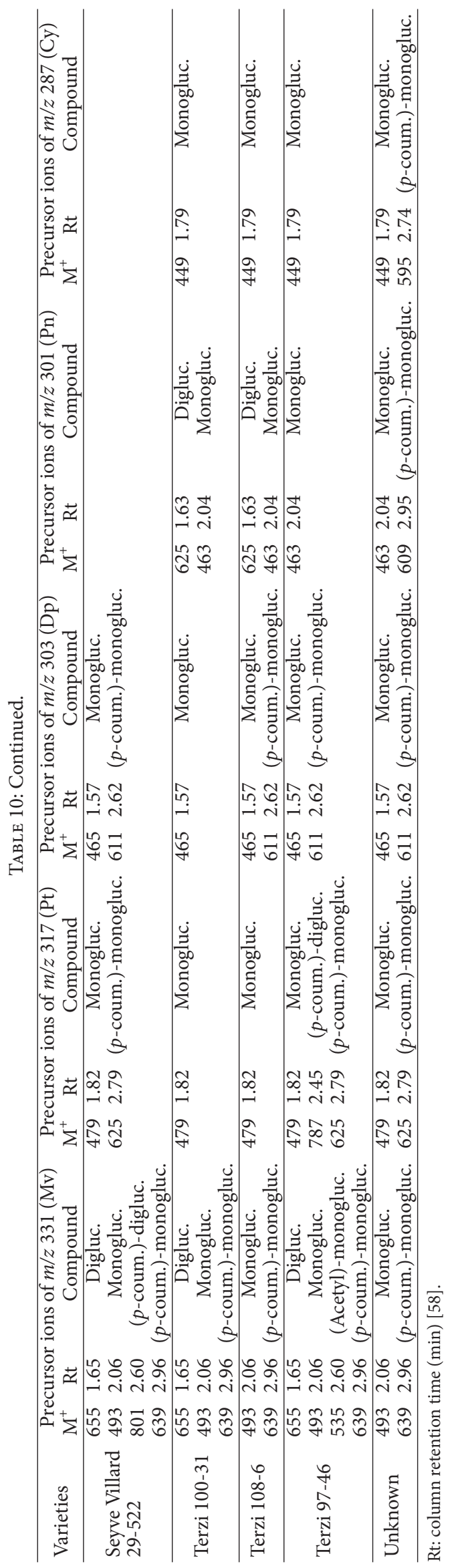




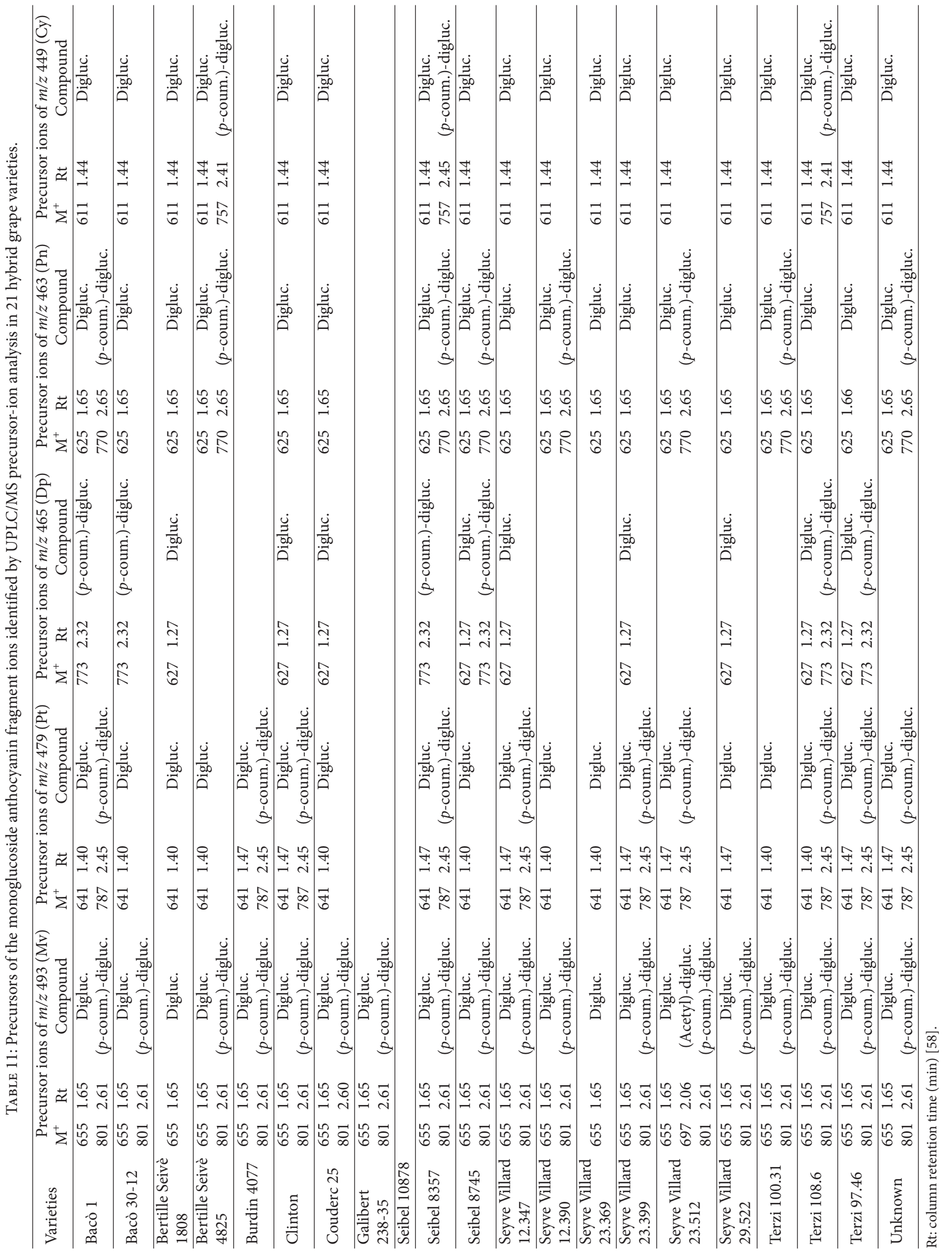


Table 12: Anthocyanin derivatives identified by positive-ion LC/ESI-MS analysis in Graciano, Tempranillo, Cabernet Sauvignon, and Primitivo wines [36, 82].

\begin{tabular}{|c|c|c|c|}
\hline \multirow{2}{*}{ Compound } & \multicolumn{3}{|c|}{$m / z$} \\
\hline & {$[\mathrm{M}]^{+}$} & Main MS $^{2}$ fragments & Main $\mathrm{MS}^{3}$ fragments \\
\hline (epi)catechin-peonidin-3-O-glucoside & 751 & 589 & $571,437,463$ \\
\hline (epi)catechin-malvidin-3-O-glucoside & 781 & 619 & $601,493,467$ \\
\hline Delphinidin-3-O-glucoside & 465 & 303 & 1 \\
\hline Di(epi)catechinMalvidin-3-O-glucoside & 1069 & $907,781,619$ & l \\
\hline Cyanidin-3-O-glucoside & 449 & 287 & l \\
\hline (epi)catechin-malvidin-3-O-glucoside & 781 & 619 & $601,493,467$ \\
\hline Di(epi)catechin-malvidin-3-O-glucoside & 1069 & $907,781,619$ & 1 \\
\hline Petunidin-3-O-glucoside & 479 & 317 & l \\
\hline Peonidin-3-O-glucoside & 463 & 301 & l \\
\hline Malvidin-3-O-glucoside & 493 & 331 & / \\
\hline Malvidin-3-O-glucoside pyruvate & 561 & 399 & I \\
\hline Malvidin-3-O-glucoside acetaldehyde & 517 & 355 & / \\
\hline Malvidin-3-O-glucoside-8-ethyl-(epi)catechin & 809 & $647,519,357$ & l \\
\hline Malvidin-3-O-glucoside-8-ethyl-(epi)catechin & 809 & $647,519,357$ & l \\
\hline Malvidin-3-O-glucoside-4-vinyl-di(epi)catechin & 1093 & 931,803 & 641 \\
\hline Malvidin-3-O-glucoside-8-ethyl-(epi)catechin & 809 & $647,519,357$ & / \\
\hline Malvidin-3-O-glucoside-4-vinyl-di(epi)catechin & 1093 & 931,803 & 641 \\
\hline Malvidin-3-O-glucoside-8-ethyl-(epi)catechin & 809 & $647,519,357$ & / \\
\hline Malvidin-3-(6-O-p-coumaroylglucoside)-(epi)catechin & 927 & 619 & $601,493,467$ \\
\hline Malvidin-3-(6-O-p-coumaroylglucoside) pyruvate & 707 & 399 & 1 \\
\hline Peonidin-3-(6-O-acetylglucoside) & 505 & 301 & I \\
\hline Malvidin-3-(6-O-acetylglucoside) & 535 & 331 & l \\
\hline Delphinidin-3-(6-O-p-coumaroylglucoside) & 611 & 303 & l \\
\hline Malvidin-3-(6-O-acetylglucoside)-4-vinyl-(epi)catechin & 847 & 643 & 491 \\
\hline Malvidin-3-(6-O-caffeoylglucoside) & 655 & 331 & / \\
\hline Cyanidin-3-(6-O-p-coumaroylglucoside) & 595 & 287 & I \\
\hline Petunidin-3-(6-O-p-coumaroylglucoside) & 625 & 317 & / \\
\hline Malvidin-3-(6-O-p-coumaroylglucoside) & 639 & 331 & l \\
\hline Malvidin-3-(6-O-p-coumaroylglucoside)-4-vinyl-di(epi)catechin & 1239 & 931,641 & 641 \\
\hline Malvidin-3-O-glucoside-4-vinyl-(epi)catechin & 805 & 643 & 491 \\
\hline Peonidin-3-(6-O-p-coumaroylglucoside)-8-ethyl-(epi)catechin & 925 & $635,617,327$ & l \\
\hline Malvidin-3-(6-O-p-coumaroylglucoside)-8-ethyl-(epi)catechin & 955 & 665,357 & / \\
\hline Peonidin-3-(6-O-p-coumaroylglucoside) & 609 & 301 & I \\
\hline Malvidin-3-(6-O-p-coumaroylglucoside) & 639 & 331 & / \\
\hline Malvidin-3-O-glucoside-4-vinylcatechol & 625 & 463 & l \\
\hline Malvidin-3-O-glucoside-4-vinyl-(epi)catechin & 805 & 643 & 491 \\
\hline Malvidin-3-(6-O-p-coumaroylglucoside)-4-vinyl-(epi)catechin & 951 & 643 & 491 \\
\hline Malvidin-3-(6-O-p-coumaroylglucoside)-4-vinyl-(epi)catechin & 951 & 643 & 491 \\
\hline Malvidin-3-O-glucoside-4-vinylphenol & 609 & 447 & l \\
\hline Malvidin-3-O-glucoside-4-vinylguaiacol & 639 & 477 & l \\
\hline Malvidin-3-(6-O-p-coumaroylglucoside)-8-ethyl-(epi)catechin & 955 & 665,357 & l \\
\hline Malvidin-3-O-glucoside-(epi)catechin & 781 & 619 & \\
\hline Delphinidin-3-O-glucoside & 465 & 303 & \\
\hline Peonidin-3-O-glucoside pyruvate & 531 & 369 & \\
\hline Malvidin-3-O-glucoside pyruvate & 561 & 399 & \\
\hline Malvidin-3-(6-O-acetylglucoside) pyruvate & 603 & 399 & \\
\hline Malvidin-3-O-glucoside-8-ethyl-(epi)catechin & 809 & $647,519,357$ & \\
\hline Malvidin-3-(6-O-p-coumaroylglucoside) pyruvate & 707 & 399 & \\
\hline Peonidin-3-(6-O-caffeoylglucoside) & 625 & 301 & \\
\hline
\end{tabular}


TABle 12: Continued.

\begin{tabular}{|c|c|c|c|}
\hline \multirow{2}{*}{ Compound } & \multicolumn{3}{|c|}{$m / z$} \\
\hline & {$[\mathrm{M}]^{+}$} & Main $\mathrm{MS}^{2}$ fragments & Main $\mathrm{MS}^{3}$ fragments \\
\hline Malvidin-3-(6-O-caffeoylglucoside) & 655 & 331 & \\
\hline Malvidin-3-O-glucoside-4-vinyl-catechin & 805 & 643 & \\
\hline Malvidin-3-(6-O-p-coumaroylglucoside)-8-ethyl-(epi)catechin & 955 & 665,357 & \\
\hline Malvidin-3-(6-O-acetylglucoside)-4-vinyl-catechin & 847 & 643 & \\
\hline Malvidin-3-O-glucoside-4-vinylcatechol & 625 & 463 & \\
\hline Malvidin-3-(6-O-acetylglucoside)-4-vinyl-epicatechin & 847 & 643 & \\
\hline Malvidin-3-O-glucoside-4-vinyl-epicatechin & 805 & 643 & \\
\hline Malvidin-3-O-glucoside-4-vinylphenol & 609 & 447 & \\
\hline Malvidin-3-O-glucoside-4-vinylguaiacol & 639 & 477 & \\
\hline Malvidin-3-(6-O-acetylglucoside)-4-vinylphenol & 651 & 447 & \\
\hline Malvidin-3-(6-O-p-coumaroylglucoside)-4-vinylphenol & 755 & 447 & \\
\hline
\end{tabular}

ethyl-bridge derivatives, pyranoanthocyanins, and pigments formed by anthocyanin-flavanol linkage are included. Some of these compounds are already present in wine in the first aging stage and disappear in the time, and others are formed with long time aging.

Also, oligomeric pigments $\mathrm{F}-\mathrm{A}-\mathrm{A}^{+}$type (F, flavanol; A, anthocyanin) were identified in wines and characterized by ESI/MS ${ }^{n}$. Table 14 reports the compounds identified in Tempranillo aged wines. Possible structures proposed for the $\mathrm{M}^{+}$species at $m / z 1273$ are shown in Figure 19, [60].

A fast and selective method for screening of the anthocyanic composition of wine was recently proposed [70]. Analysis of wine extract was performed by direct-infusion ESI-MS/MS operating in positive-ion mode with application of a low spray capillary voltage $(0.5 \mathrm{kV})$. The high selectivity of the method towards anthocyanins is due to the following: by operating far from ESI conditions, any process related to electrospray ionization occurs (these processes taking place with capillary voltages up $3 \mathrm{kV}$ [83]), and only the species already present in ionic form in the sprayed solution can be detected [84]. In ESI conditions, simultaneous detection of anthocyanins, their derivatives, and protonated ions of other wine components can lead to a quite complex panorama, with possible occurrence of matrix effects, favouring the detection of nonanthocyanic compounds. Operating with a low spraying capillary voltage, the protonation of these molecules is strongly reduced, or avoided, so allowing to obtain directly a fingerprint of the cations already present in the sample. As a matter of fact, by decreasing the spray capillary voltage, a dramatic increase of selectivity toward anthocyanins was observed and their peaks become the most abundant (Figure 20). In these conditions, the electrospray phenomena are practically inhibited and the solution spray is generated only by pneumatic effects, so that the method was called direct-infusion pneumatic spray (DIPS) mass spectrometry. The previous spectrum was obtained by application of an usual capillary voltage of $3 \mathrm{kV}$ and the most abundant signals at $m / z$ 977, 949, 739, and 711 are of unknown compounds. By decreasing the spray capillary voltage to $0.5 \mathrm{kV}$, signals of the main anthocyanins in the sample at $m / z 331,479,493,535$, and 609 increase (marked peaks in the spectrum in the following).

The anthocyanic profiles of several red wines at different aging stages were studied by DIPS, and a great number of anthocyanins and anthocyanin-derivatives were detected. Sample preparation for analysis was performed by extraction of anthocyanins using a reverse-phase $\mathrm{C}_{18}$ cartridge and recovering the analytes with methanol. In order to verify the structural assignment of the ionic species detected in the DIPS spectra, MS/MS was performed. The product ions found confirmed the presence of 15 anthocyaninflavanol derivatives, including 11 pyranoanthocyanins, 3 vitisin A-type compounds (at $m / z$ 531, 533, and 561, resp.) and malvin-vinyl(epi)catechin $(\mathrm{m} / z$ 805) (in particular in aged wines), and other several anthocyanin derivatives. The list of compounds identified is reported in Table 15.

Of course, the absolute intensity of anthocyanin signals is lower than that observed using spraying capillary voltage of $3 \mathrm{kV}$ due to the lack of the ion focusing effect originating by the high voltage. This aspect reflects negatively in higher values of limit of detection (LOD) and of limit of quantification (LOQ) but positively in higher specificity of the data. DIPS fingerprint of a several years aged wine shows profound transformations of anthocyanin composition, as shown in the spectrum in Figure 21. Signals of pyranoanthocyanin and anthocyanin-flavanol derivatives arise in two $m / z$ ranges of the spectrum, the first at $m / z 579-771$ and the second at $m / z$ 751-929, respectively.

For a semiquantitative analysis, Mv-3,5-diglucoside (compound usually not present in $V$. vinifera grapes and wines) was added to the sample as internal standard (IS), and two indexes, of wine color and of wine color evolution, were calculated. The first is a total anthocyanin index of the sample. It was calculated as the sum of intensity of all anthocyanin and anthocyanin derivative signals in the TIC and was expressed as $\mathrm{mg} / \mathrm{L}$ of IS. As expected, higher values of this parameter were found for nonaged wines (between 40 and $100 \mathrm{mg} / \mathrm{L}$ ), instead the aged samples had anthocyanin content between 4 and $80 \mathrm{mg} / \mathrm{L}$. In particular, very low contents were found in the two oldest samples aged in barrels 
TABLE 13: Anthocyanin derivatives identified in 4-23 months aged wines.

\begin{tabular}{|c|c|c|c|c|c|c|c|c|c|}
\hline \multirow{2}{*}{$\mathrm{RT}(\min )$} & \multirow{2}{*}{ Compound } & \multirow{2}{*}[\mathrm{M}]{$^{+}(m / z)$} & \multirow{2}{*}{$\begin{array}{c}\mathrm{MS}^{n} \text { fragment ions } \\
(\mathrm{m} / \mathrm{z})\end{array}$} & \multirow{2}{*}{$\lambda_{\max }(\mathrm{nm})$} & \multicolumn{5}{|c|}{ Aged wine (months) } \\
\hline & & & & & 4 & 8 & 13 & 16 & 23 \\
\hline 21.7 & Dp-3-glc & 465 & 303 & $277,342,524$ & * & * & $*$ & $*$ & $*$ \\
\hline 26.1 & Cy-3-glc & 449 & 287 & 279,516 & * & * & $*$ & $*$ & * \\
\hline 28.1 & Pt-3-glc & 479 & 317 & $277,347,525$ & * & * & * & * & $*$ \\
\hline 34.1 & Pn-3-glc & 463 & 301 & 280,517 & $*$ & * & $*$ & $*$ & * \\
\hline 35.5 & Mv-3-glc & 493 & 331 & $277,348,527$ & * & $*$ & * & * & * \\
\hline 38.3 & Dp-3-acetylglc & 507 & 303 & $276,346,527$ & $*$ & * & * & $*$ & * \\
\hline 41.0 & Cy-3-acetylglc & 491 & 287 & 280,523 & * & * & * & * & * \\
\hline 41.6 & Pt-3-acetylglc & 521 & 317 & 270,529 & $*$ & * & $*$ & $*$ & * \\
\hline 43.6 & Pn-3-acetylglc & 505 & 301 & 280,522 & $*$ & * & * & $*$ & $*$ \\
\hline 44.3 & Mv-3-acetylglc & 535 & 331 & $278,350,530$ & * & * & * & $*$ & * \\
\hline 43.1 & Dp-3-p-coumglc cis & 611 & 303 & $280,301,534$ & $*$ & * & $*$ & $*$ & * \\
\hline 44.3 & Dp-3-p-coumglc trans & 611 & 303 & $282,313,531$ & * & * & $*$ & * & * \\
\hline 45.1 & Cy-3-p-coumglc cis & 595 & 287 & $280,301,533$ & $*$ & * & * & * & * \\
\hline 46.3 & Cy-3-p-coumglc trans & 595 & 287 & $284,314,524$ & $*$ & * & * & * & $*$ \\
\hline 45.3 & Pt-3-p-coumglc cis & 625 & 317 & $281,301,536$ & $*$ & * & * & * & $*$ \\
\hline 46.6 & Pt-3-p-coumglc trans & 625 & 317 & $282,313,532$ & $*$ & $*$ & $*$ & $*$ & $*$ \\
\hline 47.5 & Pn-3-p-coumglc cis & 609 & 301 & $283,300,535$ & * & * & * & * & * \\
\hline 48.6 & Pn-3-p-coumglc trans & 609 & 301 & $283,313,526$ & * & * & * & * & * \\
\hline 47.5 & Mv-3-p-coumglc cis & 639 & 331 & $280,301,535$ & $*$ & $*$ & * & $*$ & $*$ \\
\hline 48.7 & Mv-3-p-coumglc trans & 639 & 331 & $282,313,532$ & * & $*$ & $*$ & $*$ & $*$ \\
\hline 41.1 & Dp-3-cafglc trans & 627 & 303 & $283,331,532$ & $*$ & n.d. & n.d. & n.d. & n.d. \\
\hline 43.6 & Pt-3-cafglc trans & 641 & 317 & $283,328,531$ & $*$ & $*$ & n.d. & n.d. & n.d. \\
\hline 45.6 & Pn-3-cafglc trans & 625 & 301 & $283,328,525$ & $*$ & n.d. & n.d. & n.d. & n.d. \\
\hline 44.8 & Mv-3-cafglc cis & 655 & 331 & & * & $*$ & n.d. & n.d. & n.d. \\
\hline 45.7 & Mv-3-cafglc trans & 655 & 331 & $282,328,534$ & ${ }^{*}$ & ${ }^{*}$ & ${ }^{*}$ & ${ }^{*}$ & $*$ \\
\hline 16.7 & Dp-3,7-diglc & 627 & 303 & 279,523 & $*$ & n.d. & n.d. & n.d. & n.d. \\
\hline 20.4 & Pt-3,5-diglc & 641 & 317 & 275,521 & $*$ & n.d. & n.d. & n.d. & n.d. \\
\hline 24.6 & Pt-3,7-diglc & 641 & 317 & $275,349,522$ & $*$ & * & $*$ & $*$ & $*$ \\
\hline 28.7 & Pn-3,7-diglc & 625 & 301 & & $*$ & * & n.d. & n.d. & n.d. \\
\hline 23.5 & Mv-3,5-diglc & 655 & 331 & 275,524 & $*$ & * & n.d. & n.d. & n.d. \\
\hline 30.8 & Mv-3,7-diglc & 655 & 331 & $278,350,526$ & * & * & ${ }^{*}$ & ${ }^{*}$ & ${ }^{*}$ \\
\hline 34.7 & Dp-3-glc $+\mathrm{L}(+)$ lactic acid & 537 & & & * & * & * & ${ }^{*}$ & $*$ \\
\hline 37.5 & Pt-3-glc $+\mathrm{D}(-)$ lactic acid & 551 & & & $*$ & * & * & $*$ & n.d. \\
\hline 39.2 & Pt-3-glc $+\mathrm{L}(+)$ lactic acid & 551 & 317 & 278,526 & * & * & $*$ & $*$ & $*$ \\
\hline 40.5 & Pn-3-glc $+D(-)$ lactic acid & 535 & & & * & * & n.d. & n.d. & n.d. \\
\hline 41.7 & Pn-3-glc $+\mathrm{L}(+)$ lactic acid & 535 & 301 & 281,525 & $*$ & $*$ & * & * & $*$ \\
\hline 40.8 & Mv-3-glc $+D(-)$ lactic acid & 565 & 331 & $278,350,530$ & * & * & * & * & * \\
\hline 42.1 & Mv-3-glc $+\mathrm{L}(+)$ lactic acid & 565 & 331 & $278,348,531$ & * & * & * & $*$ & * \\
\hline 5.7 & Dp-3-glc-GC & 769 & 607,439 & 531 & * & * & * & $*$ & * \\
\hline 7.1 & Cy-3-glc-GC & 753 & 591,453 & 282,524 & * & * & * & $*$ & * \\
\hline 7.2 & Pt-3-glc-GC & 783 & 621,453 & 279,532 & $*$ & * & * & * & * \\
\hline 10.8 & Pn-3-glc-GC & 767 & 605,437 & & $*$ & * & * & * & * \\
\hline 10.6 & Mv-3-glc-GC & 797 & 635,467 & 281,531 & $*$ & * & $*$ & $*$ & * \\
\hline 22.3 & Mv-3-glc-EGC & 797 & 635,467 & & $*$ & * & * & $*$ & $*$ \\
\hline 24.4 & Mv-3-acetylglc-GC & 839 & & & n.d. & * & * & ${ }^{*}$ & n.d. \\
\hline 30.9 & Dp-3-p-coumglc-GC & 915 & 607,439 & & n.d. & * & * & ${ }^{*}$ & n.d. \\
\hline 35.1 & Cy-3-p-coumglc-GC & 899 & & & n.d. & ${ }^{*}$ & * & n.d. & n.d. \\
\hline 35.4 & Pt-3-p-coumglc-GC & 929 & & & n.d. & * & * & ${ }^{*}$ & n.d. \\
\hline 38.5 & Pn-3-p-coumglc-GC & 913 & 605,437 & & n.d. & * & $*$ & $*$ & $*$ \\
\hline 38.3 & Mv-3-p-coumglc-GC & 943 & 635,467 & & n.d. & $*$ & $*$ & $*$ & $*$ \\
\hline
\end{tabular}


TABle 13: Continued.

\begin{tabular}{|c|c|c|c|c|c|c|c|c|c|}
\hline \multirow{2}{*}{$\mathrm{RT}(\min )$} & \multirow{2}{*}{ Compound } & \multirow{2}{*}[\mathrm{M}]{$^{+}(m / z)$} & \multirow{2}{*}{$\begin{array}{l}\mathrm{MS}^{n} \text { fragment ions } \\
\qquad(\mathrm{m} / z)\end{array}$} & \multirow{2}{*}{$\lambda_{\max }(\mathrm{nm})$} & \multicolumn{5}{|c|}{ Aged wine (months) } \\
\hline & & & & & 4 & 8 & 13 & 16 & 23 \\
\hline 41.1 & Mv-3-p-coumglc-EGC & 943 & & & n.d. & ${ }^{*}$ & ${ }^{*}$ & ${ }^{*}$ & ${ }^{*}$ \\
\hline 10.8 & Dp-3-glc-C & 753 & 591,439 & 282,534 & $*$ & $*$ & $*$ & * & $*$ \\
\hline 14.8 & Dp-3-glc-EC & 753 & 591,439 & & * & $*$ & $*$ & $*$ & $*$ \\
\hline 14.9 & $\mathrm{Cy}-3-\mathrm{glc}-\mathrm{C}$ & 737 & 575,423 & 286,526 & * & $*$ & * & * & $*$ \\
\hline 18,0 & Cy-3-glc-EC & 737 & 575,423 & & $*$ & $*$ & $*$ & * & $*$ \\
\hline 16.2 & Pt-3-glc-C & 767 & 605,453 & 279,532 & $*$ & $*$ & $*$ & * & $*$ \\
\hline 21.6 & Pt-3-glc-EC & 767 & 605,453 & & $*$ & * & * & $*$ & $*$ \\
\hline 20.3 & Pn-3-glc-C & 751 & 589,437 & 283,524 & * & $*$ & * & $*$ & * \\
\hline 24.3 & Pn-3-glc-EC & 751 & 589,437 & & $*$ & $*$ & $*$ & * & $*$ \\
\hline 21.0 & Mv-3-glc-C & 781 & 619,467 & 280,532 & * & * & * & $*$ & * \\
\hline 29.9 & Mv-3-glc-EC & 781 & 619,467 & 279,533 & * & $*$ & * & * & * \\
\hline 35.9 & Mv-3-acetylglc-C & 823 & 619,467 & & n.d. & $*$ & $*$ & * & $*$ \\
\hline 39.0 & Dp-3-p-coumglc-C & 899 & 591,439 & & n.d. & $*$ & $*$ & $*$ & $*$ \\
\hline 40.5 & Dp-3-p-coumglc-EC & 899 & & & n.d. & $*$ & n.d. & n.d. & n.d. \\
\hline 39.5 & Cy-3-p-coumglc-C & 883 & & & n.d. & * & ${ }^{*}$ & ${ }^{*}$ & n.d. \\
\hline 41.4 & Cy-3-p-coumglc-EC & 883 & & & n.d. & * & n.d. & n.d. & n.d. \\
\hline 41.0 & Pt-3-p-coumglc-C & 913 & 605,453 & & n.d. & * & ${ }^{*}$ & ${ }^{*}$ & ${ }^{*}$ \\
\hline 42.6 & Pt-3-p-coumglc-EC & 913 & & & n.d. & * & n.d. & n.d. & n.d. \\
\hline 41.8 & Pn-3-p-coumglc-C & 897 & 589,437 & & n.d. & $*$ & * & * & ${ }^{*}$ \\
\hline 43.8 & Pn-3-p-coumglc-EC & 897 & & & n.d. & * & n.d. & n.d. & n.d. \\
\hline 43.4 & Mv-3-p-coumglc-C & 927 & 619,467 & 290,538 & * & $*$ & * & * & $*$ \\
\hline 46.0 & Mv-3-p-coumglc-EC & 927 & & & n.d. & ${ }^{*}$ & n.d. & n.d. & n.d. \\
\hline 35.8 & Dp-3-glc-ethyl-C & 781 & 329,329 & & * & n.d. & n.d. & $*$ & n.d. \\
\hline 36.7 & Dp-3-glc-ethyl-EC & 781 & & & * & n.d. & n.d. & $*$ & n.d. \\
\hline 39.5 & Cy-3-glc-ethyl-C & 765 & & & * & n.d. & n.d. & n.d. & n.d. \\
\hline 39.6 & Pt-3-glc-ethyl-C & 795 & 343 & & $*$ & n.d. & n.d. & * & ${ }^{*}$ \\
\hline 42.0 & Pn-3-glc-ethyl-C & 779 & 327 & & $*$ & * & n.d. & * & $*$ \\
\hline 43.1 & Pn-3-glc-ethyl-EC & 779 & & & * & n.d. & n.d. & * & * \\
\hline 41.1 & Mv-3-glc-ethyl-C & 809 & 357 & & $*$ & * & $*$ & * & $*$ \\
\hline 42.2 & Mv-3-glc-ethyl-C & 809 & 357 & 282,539 & $*$ & $*$ & $*$ & * & $*$ \\
\hline 43.1 & Mv-3-glc-ethyl-C & 809 & 357 & 276,537 & $*$ & $*$ & * & ${ }^{*}$ & ${ }^{*}$ \\
\hline 45.8 & Mv-3-acetylglc-ethyl-C & 851 & 357 & & $*$ & $*$ & n.d. & n.d. & n.d. \\
\hline 47.4 & Mv-3-p-coumglc-ethyl-C & 955 & 357 & & * & * & * & ${ }^{*}$ & n.d. \\
\hline 34.7 & Dp-3-glc-ethyl-GC & 797 & 329 & & $*$ & n.d. & n.d. & n.d. & $*$ \\
\hline 38.6 & Cy-3-glc-ethyl-GC & 781 & & & * & n.d. & n.d. & n.d. & n.d. \\
\hline 38.7 & Pt-3-glc-ethyl-GC & 811 & 343 & & $*$ & n.d. & n.d. & * & ${ }^{*}$ \\
\hline 40.9 & Pn-3-glc-ethyl-GC & 795 & & & * & n.d. & n.d. & n.d. & n.d. \\
\hline 40.6 & Mv-3-glc-ethyl-GC & 825 & 357 & & * & n.d. & * & * & * \\
\hline 41.1 & Mv-3-glc-ethyl-GC & 825 & 357 & 539 & $*$ & * & $*$ & $*$ & * \\
\hline 41.8 & Mv-3-glc-ethyl-GC & 825 & 357 & & * & n.d. & $*$ & $*$ & $*$ \\
\hline 45.0 & Mv-3-acetylglc-ethyl-GC & 867 & & & $*$ & n.d. & n.d. & n.d. & n.d. \\
\hline 21.0 & A-type vitisin of Dp-3-glc & 533 & 371 & $297,368,507$ & n.d. & ${ }^{*}$ & ${ }^{*}$ & ${ }^{*}$ & ${ }^{*}$ \\
\hline 27.0 & A-type vitisin of Cy-3-glc & 517 & & & n.d. & n.d. & n.d. & $*$ & n.d. \\
\hline 28.7 & A-type vitisin of Pt-3-glc & 547 & 385 & $299,371,508$ & n.d. & $*$ & ${ }^{*}$ & $*$ & * \\
\hline 35.0 & A-type vitisin of Pn-3-glc & 531 & 369 & 503 & n.d. & n.d. & n.d. & $*$ & * \\
\hline 36.0 & Vitisin A & 561 & 399 & $299,372,510$ & n.d. & $*$ & $*$ & $*$ & $*$ \\
\hline 40.7 & A-type vitisin of Pt-3-p-coumglc & 693 & & & n.d. & n.d. & $*$ & $*$ & n.d. \\
\hline 43.8 & A-type vitisin of Pn-3-p-coumglc & 677 & 369 & 284,508 & n.d. & * & * & * & * \\
\hline 44.1 & A-type vitisin of Mv-3-p-coumglc & 707 & 399 & 271,514 & n.d. & $*$ & * & $*$ & $*$ \\
\hline 24.4 & B-type vitisin of Dp-3-glc & 489 & 327 & & n.d. & $*$ & * & $*$ & * \\
\hline
\end{tabular}


TABle 13: Continued.

\begin{tabular}{|c|c|c|c|c|c|c|c|c|c|}
\hline \multirow{2}{*}{$\mathrm{RT}(\min )$} & \multirow{2}{*}{ Compound } & \multirow{2}{*}[\mathrm{M}]{$^{+}(m / z)$} & \multirow{2}{*}{$\begin{array}{c}\mathrm{MS}^{n} \text { fragment ions } \\
(\mathrm{m} / \mathrm{z})\end{array}$} & \multirow{2}{*}{$\lambda_{\max }(\mathrm{nm})$} & \multicolumn{5}{|c|}{ Aged wine (months) } \\
\hline & & & & & 4 & 8 & 13 & 16 & 23 \\
\hline 33.5 & B-type vitisin of Pt-3-glc & 503 & 341 & 492 & n.d. & * & $*$ & $*$ & $*$ \\
\hline 38.5 & B-type vitisin of Pn-3-glc & 487 & 325 & & $*$ & * & * & * & n.d. \\
\hline 39.5 & Vitisin B & 517 & 355 & $294,358,490$ & * & * & $*$ & $*$ & $*$ \\
\hline 41.4 & B-type vitisin of Pn-3-acetylglc & 529 & 325 & & * & * & n.d. & n.d. & n.d. \\
\hline 42.4 & B-type vitisin of Mv-3-acetylglc & 559 & 355 & $298,361,494$ & $*$ & * & $*$ & * & n.d. \\
\hline 41.1 & Acetone derivative of $\mathrm{Pn}-3$-glc & 501 & 339 & 475 & n.d. & * & * & * & n.d. \\
\hline 42.1 & Acetone derivative of $\mathrm{Mv}$-3-glc & 531 & 369 & 480 & n.d. & * & * & * & $*$ \\
\hline 45.5 & Dp-3-glc 4-vinylphenol adduct & 581 & 419 & $264,412,503$ & $*$ & * & * & * & * \\
\hline 47.5 & Cy-3-glc 4-vinylphenol adduct & 565 & & & n.d. & * & * & * & * \\
\hline 48.3 & Pt-3-glc 4-vinylphenol adduct & 595 & 433 & $264,413,502$ & $*$ & * & * & * & * \\
\hline 50.5 & Pn-3-glc 4-vinylphenol adduct & 579 & 417 & $278,406,500$ & * & * & * & * & * \\
\hline 51.0 & Mv-3-glc 4-vinylphenol adduct & 609 & 447 & $263,412,504$ & * & * & * & * & * \\
\hline 53.2 & Mv-3-acetylglc 4-vinylphenol adduct & 651 & 447 & $298,416,505$ & $*$ & $*$ & $*$ & * & * \\
\hline 49.9 & Dp-3-p-coumglc 4-vinylphenol adduct & 727 & 419 & & n.d. & n.d. & n.d. & * & * \\
\hline 52.4 & Pt-3-p-coumglc 4-vinylphenol adduct & 741 & 433 & 314,504 & n.d. & n.d. & n.d. & * & * \\
\hline 54.6 & Pn-3-p-coumglc 4-vinylphenol adduct & 725 & 417 & 314,501 & n.d. & n.d. & n.d. & * & * \\
\hline 55.2 & Mv-3-p-coumglc 4-vinylphenol adduct & 755 & 447 & $264,313,416,505$ & n.d. & * & * & * & * \\
\hline 43.5 & Dp-3-glc 4-vinylcatechol adduct & 597 & 435 & 509 & * & * & * & * & * \\
\hline 46.5 & Pt-3-glc 4-vinylcatechol adduct & 611 & 449 & 510 & * & * & * & * & * \\
\hline 48.6 & Pn-3-glc 4-vinylcatechol adduct & 595 & 433 & 506 & * & * & * & * & * \\
\hline 49.2 & Mv-3-glc 4-vinylcatechol adduct & 625 & 463 & 510 & $*$ & $*$ & * & * & * \\
\hline 50.9 & Mv-3-acetylglc 4-vinylcatechol adduct & 667 & 463 & 513 & n.d. & n.d. & * & * & * \\
\hline 47.6 & Dp-3-p-coumglc 4-vinylcatechol adduct & 743 & 435 & & * & * & * & * & * \\
\hline 50.5 & Pt-3-p-coumglc 4-vinylcatechol adduct & 757 & 449 & & n.d. & * & * & * & * \\
\hline 53.2 & Mv-3-p-coumglc 4-vinylcatechol adduct & 771 & 463 & 312,511 & $*$ & * & * & * & * \\
\hline 52.0 & Mv-3-glc 4-vinylguaiacol adduct & 639 & 477 & 511 & * & * & * & * & * \\
\hline 54.0 & Mv-3-acetylglc 4-vinylguaiacol adduct & 681 & 477 & 514 & n.d. & * & * & * & * \\
\hline 55.7 & Mv-3-p-coumglc 4-vinylguaiacol adduct & 785 & 477 & 514 & n.d. & * & * & $*$ & $*$ \\
\hline 49.0 & Mv-3-glc 4-vinylepicatechin adduct & 805 & & & $*$ & $*$ & $*$ & $*$ & $*$ \\
\hline
\end{tabular}

Dp: delphinidin; Cy: cyanidin; Pt: petunidin; Pn: peonidin; Mv: malvidin; glc: glucose; p-coumglc: p-coumaroylglucoside; cafglc: caffeoylglucoside; acetylglc: acetylglucoside; catechin; GC: gallocatechin; EC: epicatechin; ECG: epigallocatechin; ${ }^{*}$ detected; n.d.: not detected [30].

(between 3 and $10 \mathrm{mg} / \mathrm{L}$ ), inferring that anthocyanins and derivatives are undergone to severe degradation processes in barrel ageing for long time.

During aging, the chemical composition of anthocyanins (i.e., color) changes as well. Index of wine color evolution was calculated as the ratio $\Sigma$ anthocyanin-derived signals intensity/total anthocyanin index and represents these chemical changes. All the nonaged wines had a value lower than $20 \%$, while it was higher in all aged samples. As a consequence, a wine color evolution index of $20 \%$ was proposed as the limit for distinguishing between aged and nonaged wines. This index can be also correlated to the wine aging conditions, such as presence of oxidative or reductive environment (barrel or bottle), oxygen level in wine, and air exchange through the barrel staves. Moreover, because pyranoanthocyanins remain colored over a wide $\mathrm{pH}$ range and in the presence of sulphites $[32,85]$, the study of the ratio between pyranoanthocyanins and the other anthocyaninflavanol derivatives was proposed to predict the wine color stability.

\section{Study of Grape Procyanidins by MALDI-TOF MS}

Matrix-assisted laser desorption-ionization and time of flight (MALDI-TOF) mass spectrometry is a technique in which an acidic solution containing an energy-absorbing molecule (matrix) is mixed with the analyte and a highly focused laser pulses are directed to the mixture [86]. Molecules are desorbed, ionized, and accelerated by a high electrical potential, and the ions arrive to the detector in the order of their increasing $\mathrm{m} / z$ ratio. Due to robustness, tolerance to salt- and detergent-related impurities, and ability to be 
TABLE 14: Molecular and fragment ions of the flavanol-anthocyanin-anthocyanin (F-A-A $\left.{ }^{+}\right)$trimers identified in Tempranillo aged wines. The fragment ions are reported in order of abundance.

\begin{tabular}{|c|c|c|c|c|}
\hline \multirow{3}{*}{ Proposed identity } & \multirow{3}{*}[\mathrm{M}]{$^{+}$} & \multicolumn{3}{|c|}{$m / z$} \\
\hline & & & Fragment ions & \\
\hline & & $\mathrm{MS}^{2}$ & $\mathrm{MS}^{3}$ & $\mathrm{MS}^{4}$ \\
\hline \multirow[t]{5}{*}{ (E)C-DpG-MvG } & 1245 & $1083\left[\mathrm{M}^{+}-162\right]$ & $921\left[\mathrm{MS}^{+}-162\right]$ & \\
\hline & & $795\left[\mathrm{M}^{+}-450\right]$ & $903\left[\mathrm{MS}^{+}-180\right]$ & \\
\hline & & $921\left[\mathrm{M}^{+}-324\right]$ & $657\left[\mathrm{MS}^{+}-426\right]$ & \\
\hline & & $903\left[\mathrm{M}^{+}-342\right]$ & $633\left[\mathrm{MS}^{+}-450\right]$ & \\
\hline & & & $837\left[\mathrm{MS}^{+}-246\right]$ & \\
\hline \multirow[t]{2}{*}{ (E)C-CyG-MvG } & 1229 & $1067\left[\mathrm{M}^{+}-162\right]$ & $905\left[\mathrm{MS}^{+}-162\right]$ & \\
\hline & & $904\left[\mathrm{M}^{+}-324\right]$ & $917\left[\mathrm{MS}^{+}-150\right]$ & \\
\hline \multirow[t]{6}{*}{ (E)C-PtG-MvG } & 1259 & $1097\left[\mathrm{M}^{+}-162\right]$ & $935\left[\mathrm{MS}^{+}-162\right]$ & $629\left[\mathrm{MS}^{+}-306\right]$ \\
\hline & & $971\left[\mathrm{M}^{+}-288\right]$ & $917\left[\mathrm{MS}^{+}-180\right]$ & \\
\hline & & $935\left[\mathrm{M}^{+}-324\right]$ & $899\left[\mathrm{MS}^{+}-198\right]$ & \\
\hline & & $809\left[\mathrm{M}^{+}-450\right]$ & $671\left[\mathrm{MS}^{+}-426\right]$ & \\
\hline & & $1079\left[\mathrm{M}^{+}-180\right]$ & $747\left[\mathrm{MS}^{+}-350\right]$ & \\
\hline & & & $971\left[\mathrm{MS}^{+}-126\right]$ & \\
\hline \multirow[t]{2}{*}{ (E)C-PnG-MvG } & 1243 & $1081\left[\mathrm{M}^{+}-162\right]$ & $919\left[\mathrm{MS}^{+}-162\right]$ & \\
\hline & & $1063\left[\mathrm{M}^{+}-180\right]$ & & \\
\hline \multirow[t]{9}{*}{ (E)C-MvG-MvG } & 1273 & $1111\left[\mathrm{M}^{+}-162\right]$ & $949\left[\mathrm{MS}^{+}-162\right]$ & \\
\hline & & $949\left[\mathrm{M}^{+}-324\right]$ & $931\left[\mathrm{MS}^{+}-180\right]$ & \\
\hline & & $661\left[\mathrm{M}^{+}-612\right]$ & $823\left[\mathrm{MS}^{+}-288\right]$ & \\
\hline & & $931\left[\mathrm{M}^{+}-342\right]$ & $685\left[\mathrm{MS}^{+}-426\right]$ & \\
\hline & & $823\left[\mathrm{M}^{+}-450\right]$ & $661\left[\mathrm{MS}^{+}-450\right]$ & \\
\hline & & & $737\left[\mathrm{MS}^{+}-374\right]$ & \\
\hline & & & $913\left[\mathrm{MS}^{+}-198\right]$ & \\
\hline & & & $535\left[\mathrm{MS}^{+}-576\right]$ & \\
\hline & & & $331\left[\mathrm{MS}^{+}-780\right]$ & \\
\hline (E)GC-DpG-MvG & 1261 & $1099\left[\mathrm{M}^{+}-162\right]$ & $937\left[\mathrm{MS}^{+}-162\right]$ & \\
\hline \multirow[t]{2}{*}{ (E)GC-PtG -MvG } & 1275 & $1113\left[\mathrm{M}^{+}-162\right]$ & $951\left[\mathrm{MS}^{+}-162\right]$ & \\
\hline & & & $647\left[\mathrm{MS}^{+}-466\right]$ & \\
\hline \multirow[t]{10}{*}{ (E)GC-MvG-MvG } & 1289 & $1127\left[\mathrm{M}^{+}-162\right]$ & $965\left[\mathrm{MS}^{+}-162\right]$ & \\
\hline & & $965\left[\mathrm{M}^{+}-324\right]$ & $929\left[\mathrm{MS}^{+}-198\right]$ & \\
\hline & & $661\left[\mathrm{M}^{+}-628\right]$ & $947\left[\mathrm{MS}^{+}-180\right]$ & \\
\hline & & $823\left[\mathrm{M}^{+}-466\right]$ & $823\left[\mathrm{MS}^{+}-304\right]$ & \\
\hline & & & $865\left[\mathrm{MS}^{+}-262\right]$ & \\
\hline & & & $661\left[\mathrm{MS}^{+}-466\right]$ & \\
\hline & & & $535\left[\mathrm{MS}^{+}-592\right]$ & \\
\hline & & & $839\left[\mathrm{MS}^{+}-288\right]$ & \\
\hline & & & $467\left[\mathrm{MS}^{+}-660\right]$ & \\
\hline & & & $331\left[\mathrm{MS}^{+}-796\right]$ & \\
\hline
\end{tabular}

$\mathrm{MS2}^{+}$: major fragment ion obtained in $\mathrm{MS}^{2}$ analysis; $\mathrm{MS}^{+}$: major fragment ion obtained in $\mathrm{MS}^{3}$ analysis; Dp: delphinidin; Cy: cyanidin; Pt: petunidin; Pn: peonidin; Mv: malvidin; G: glucose; (E)C: (epi)catechin; (E)GC: (epi)gallocatechin [60].

automated, MALDI-TOF is used to perform generation of mass map of proteins after enzymatic digestion [87]. $\alpha$ cyano-4-hydroxycinnamic acid (CHCA) is the matrix commonly used for analysis of peptides and small proteins and sinapinic acid (SA) of higher molecular weight (MW) proteins (10-100 kDa). Advantages of MALDI-TOF are good mass accuracy $(0.01 \%)$ and sensitivity to require very little sample for analysis.
MALDI-TOF has been used also for characterization of grape procyanidins [88-92]. LC/MS does not allow separation and identification of oligomers higher than pentamers because the separation of a large number of diastereoisomers is not possible. By operating positive-ion MALDI-TOF in the reflectron mode, flavan-3-ol oligomers and their galloylated derivatives in grape seeds extracts were studied [88]. Oligomers were detected up to heptamer as sodium adducts 
TABLE 15: Compounds identified by DIPS and MS/MS in 12 wines at different aging stages.

\begin{tabular}{|c|c|c|c|}
\hline \multirow{2}{*}{ Compound } & \multicolumn{2}{|c|}{$m / z$} & \multirow{2}{*}{ Loss $\mathrm{Da}$} \\
\hline & $\mathrm{M}^{+}$ & MS/MS ions & \\
\hline Cy-glu & 449 & 287 & -162 \\
\hline Pn-glu & 463 & 301 & -162 \\
\hline Dp-glu & 465 & 303 & -162 \\
\hline Pt-glu & 479 & 317 & -162 \\
\hline Vitisin B-Pn-glu & 487 & 325 & -162 \\
\hline Vitisin B-Dp-glu & 489 & 327 & -162 \\
\hline Mv-glu & 493 & 331 & -162 \\
\hline Vitisin B-Pt-glu & 503 & 341 & -162 \\
\hline Pn-glu-Ac & 505 & 301 & -204 \\
\hline Dp-glu-Ac & 507 & 303 & -204 \\
\hline Pt-glu-Ac & 521 & 317 & -204 \\
\hline Vitisin A-Pn-glu & 531 & 369 & -162 \\
\hline Vitisin A-Dp-glu & 533 & 371 & -162 \\
\hline Mv-glu-Ac & 535 & 331 & -204 \\
\hline Vitisin A-Pt-glu & 547 & 385 & -162 \\
\hline Vitisin B-Mv-glu-Ac & 559 & 355 & -204 \\
\hline Vitisin A & 561 & 399 & -162 \\
\hline 4-Vinylphenol-Pn-glu & 579 & 417 & -162 \\
\hline 4-Vinylphenol-Dp-glu & 581 & 419 & -162 \\
\hline Cy-glu-pcoum & 595 & 287 & -308 \\
\hline 4-Vinylphenol-Pt-glu & 595 & 433 & -162 \\
\hline 4-Vinylcatechol-Dp-glu & 597 & 435,303 & -162 \\
\hline 4-Vinylphenol-Mv-glu & 609 & 447 & -162 \\
\hline Pn-glu-pcoum & 609 & 301 & -308 \\
\hline Dp-glu-pcoum & 611 & 303 & -308 \\
\hline 4-Vinylcatechol-Mv-glu (Pinotin A) & 625 & 463 & -162 \\
\hline Mv-glu-pcoum & 639 & 331 & -308 \\
\hline 4-Vinylguaiacol-Mv-glu & 639 & 477 & -162 \\
\hline 4-Vinylphenol-Mv-glu-Ac & 651 & 447 & -204 \\
\hline Mv-diglu (IS) & 655 & 493,331 & -162 \\
\hline 4-Vinylcatechol-Mv-glu-Ac & 667 & 463 & -204 \\
\hline Vitisin A-Pt-glu-pcoum & 693 & 385 & -308 \\
\hline Vitisin A-Mv-glu-pcoum & 707 & 399 & -308 \\
\hline 4-Vinylphenol-Pt-glu-pcoum & 741 & 433 & -308 \\
\hline Cat-Pn-glu & 751 & 589 & -162 \\
\hline Cat-Dp-glu & 753 & 591 & -162 \\
\hline 4-Vinylphenol-Mv-glu-pcoum & 755 & 447 & -308 \\
\hline 4-Vinylcatechol-Pt-glu-pcoum & 757 & 449 & -308 \\
\hline Cat-Et-Cy-glu & 765 & 603 & -162 \\
\hline GCat-Pn-glu or Cat-Pt-glu & 767 & 605 & -162 \\
\hline 4-Vinylcatechol-Mv-glu-pcoum & 771 & 463,331 & -308 \\
\hline Cat-Mv-glu & 781 & $619,467,331$ & -162 \\
\hline GCat-Pt-glu & 783 & 621 & -162 \\
\hline Cat-Dp-glu-Ac & 795 & 591,507 & -204 \\
\hline Cat-Et-Pt-glu & 795 & $633,507,343,317$ & -162 \\
\hline GCat-Mv-glu & 797 & 635,331 & -162 \\
\hline 4-VinylCat-Mv-glu & 805 & 643 & -162 \\
\hline
\end{tabular}


TABle 15: Continued.

\begin{tabular}{lccc}
\hline Compound & & $m / z$ & MS/MS ions \\
\hline Cat-Et-Mv-glu & $\mathrm{M}^{+}$ & $657,647,357,331$ & Loss Da \\
Cat-Pt-glu-Ac & 809 & $605,519,317$ & -162 \\
GCat-Et-Pt-glu & 809 & 649,343 & -204 \\
Cat-Mv-glu-Ac & 811 & $619,535,331$ & -468 \\
GCat-Et-Mv-glu & 823 & 663,331 & -204 \\
GCat-Mv-glu-Ac & 825 & 635 & -162 \\
GCat-Et-Mv-glu-Ac & 839 & 663 & -204 \\
Cat-Pn-glu-pcoum & 867 & 589,301 & -204 \\
GCat-Dp-glu-pcoum & 897 & 607 & -308 \\
Cat-Mv-glu-pcoum & 915 & 619 & -308 \\
GCat-Pt-glu-pcoum & 927 & 621 & -308 \\
GCat-Mv-glu-pcoum & 929 & 635 \\
Cat-Et-Mv-glu-pcoum & 943 & 647 & -308 \\
\hline
\end{tabular}

$\mathrm{M}^{+}$: molecular ion; Cat: (epi)catechin; GCat: gallo(epi)catechin; Ac: acetyl; pcoum: p-coumaroyl; Et: ethyl; Dp: delphinidin; Cy: cyanidin; Pt: petunidin; Pn: peonidin; Mv: malvidin; glu: glucoside [70].

$[\mathrm{M}+\mathrm{Na}]^{+}$using 2,5-dihydroxybenzoic acid (DHB) as matrix with a resolution higher than 3000 , allowing to separate individual ions of different isotope composition (e.g., the ion at $m / z 1177.46$ was further resolved into a group of four peaks). In another study, to perform analysis of seed extracts in positive-ion reflectron mode using trans-3-indoleacrylic acid ( $t$-IAA) as matrix allowed the identification of a series of compounds with MW $2 \mathrm{Da}$ lower, which correspond to Atype polycatechins. Linear mode analysis provided detection of PAs oligomers sodium adducts up to nonamers [89]. The lower sensitivity of the reflectron mode for the large ions is reasonably due to their collisionally induced decomposition occurring in the flight path [88, 89]. Masses of PAs determined in both reflectron and liner modes are reported in Table 16. On the basis of the galloylated structures, the equation $290+288 c+152 g+23$ used to predict the mass distribution of PGPF in grape seeds was calculated (290 is the MW of the terminal catechin/epicatechin unit, $c$ degree of polymerization, $g$ number of galloyl esters, $23 \mathrm{Na}$ atomic mass) [89].

Extraction of PAs from grape seeds for MALDI-TOF analysis was carried out with acetone/water, ethanol, or methanol/water mixtures, then a purification by extraction with ethyl acetate or chloroform which can be performed $[88,89,91,93]$.

Among the matrices tested for MALDI, DHB and $t$-IAA showed to be highly suited for PAs analysis. The experiments performed by Yang and Chien showed that DHB provides the broadest mass range and the least background noise. The dry grape seed extract was dissolved in acetone or methanol at $2 \mathrm{mg} / \mathrm{mL}$, and a DHB matrix solution $20 \mathrm{mg} / \mathrm{mL}$ in tetrahydrofuran was prepared (the sample and matrix solutions were mixed at $1: 1 \mathrm{v} / \mathrm{v}$ ) [88]. Sodium apparently arises from the seeds themselves, and only a minute amount of sodium was needed. The use of DHB and water-free solvents such as anhydrous tetrahydrofuran, acetone, or methanol for the sample and matrix preparation showed the best analytical conditions in reflectron mode.

In general tannins containing A-type bonds showed lower signal intensity with respect to the corresponding compounds with B-type bonds (between 10\% and 50\%). By the formula in Table 16 and the data from the literature, PAs with DP from 2 up to 11 were identified [52, 57, 89, 92].

A study of PAs in grape seeds of 35 hybrid and V. vinifera grape varieties is now in progress. PAs are extracted with a methanol/water $70: 30 \mathrm{v} / \mathrm{v}$ solution and analyzed by MALDITOF in positive-ion mode using matrix DHB. PAs showed $[\mathrm{M}+\mathrm{Na}]^{+}$adducts as main signal, and some of $[\mathrm{M}+\mathrm{K}]^{+}$and $[\mathrm{M}+\mathrm{H}]^{+}$adducts (Table 17). Signals of tannins containing Btype bonds and one or more A-type bonds were found in the mass spectra (Figure 22). For example, the protonated trimer was present in different forms: with two B-type bonds and MW $867 \mathrm{Da}$, with one A-type and one B-type bond and MW $865 \mathrm{Da}$, and with two A-type bonds with MW $863 \mathrm{Da}$.

\section{Polyphenols and Grape Metabolomics}

"Metabolomics" is the comprehensive quantitative and qualitative study of all the metabolites within a cell, tissue, or organism. The major limitation of this approach is its current inability to exhaustively describe the whole "metabolome" profile. This is due to its chemical complexity and the dynamic range limitations of most instrumental approaches. Because a single analytical technique does not provide sufficient description of whole metabolome, more methods are needed for a comprehensive view. LC/MS, direct-injection MS, and electrospray ionization (ESI) are powerful tools that offer high selectivity and sensitivity, allowing detection of nonvolatile and labile components in the extract. The coupling of the techniques with GC/MS analysis of volatile compounds, in general, provides a sufficiently wide panorama of the sample metabolomics. The selection of the 
TABLE 16: Masses observed by MALDI-TOF analysis calculated using the equation $290+288 c+152 g+23$ (290: MW of the terminal catechin unit; $c$ : degree of polymerization; $g$ : number of galloyl ester; 23 : Na atomic mass). n.d.: not observed [88].

\begin{tabular}{|c|c|c|c|c|}
\hline \multirow{2}{*}{ Polymer } & \multirow{2}{*}{ no. galloyl ester } & \multirow{2}{*}{ Calculated $[\mathrm{M}+\mathrm{Na}]^{+}$} & \multicolumn{2}{|c|}{ Observed $[\mathrm{M}+\mathrm{Na}]^{+}$} \\
\hline & & & Positive linear & Positive reflectron \\
\hline \multirow{3}{*}{ Dimer } & 0 & 601 & 600 & 601 \\
\hline & 1 & 753 & 752 & 753 \\
\hline & 2 & 905 & 905 & 905 \\
\hline \multirow{4}{*}{ Trimer } & 0 & 889 & 889 & 889 \\
\hline & 1 & 1041 & 1041 & 1041 \\
\hline & 2 & 1193 & 1193 & 1193 \\
\hline & 3 & 1345 & 1346 & 1345 \\
\hline \multirow{5}{*}{ Tetramer } & 0 & 1177 & 1177 & 1177 \\
\hline & 1 & 1329 & 1329 & 1329 \\
\hline & 2 & 1481 & 1482 & 1482 \\
\hline & 3 & 1634 & 1634 & 1634 \\
\hline & 4 & 1786 & 1785 & 1786 \\
\hline \multirow{6}{*}{ Pentamer } & 0 & 1466 & 1465 & 1466 \\
\hline & 1 & 1618 & 1618 & 1618 \\
\hline & 2 & 1770 & 1770 & 1770 \\
\hline & 3 & 1922 & 1922 & 1922 \\
\hline & 4 & 2074 & 2074 & 2074 \\
\hline & 5 & 2226 & n.d. & n.d. \\
\hline \multirow{7}{*}{ Hexamer } & 0 & 1754 & 1754 & 1754 \\
\hline & 1 & 1906 & 1907 & 1906 \\
\hline & 2 & 2058 & 2059 & 2058 \\
\hline & 3 & 2210 & 2211 & n.d. \\
\hline & 4 & 2362 & 2362 & 2362 \\
\hline & 5 & 2514 & 2513 & n.d. \\
\hline & 6 & 2666 & 2667 & n.d. \\
\hline \multirow{8}{*}{ Heptamer } & 0 & 2042 & 2043 & 2042 \\
\hline & 1 & 2194 & 2195 & 2194 \\
\hline & 2 & 2346 & 2346 & 2346 \\
\hline & 3 & 2398 & 2499 & 2499 \\
\hline & 4 & 2651 & 2651 & n.d. \\
\hline & 5 & 2803 & 2800 & n.d. \\
\hline & 6 & 2955 & 2954 & n.d. \\
\hline & 7 & 3107 & n.d. & n.d. \\
\hline \multirow{7}{*}{ Octamer } & 0 & 2330 & 2330 & 2330 \\
\hline & 1 & 2483 & 2483 & 2483 \\
\hline & 2 & 2635 & 2635 & n.d. \\
\hline & 3 & 2787 & 2787 & n.d. \\
\hline & 4 & 2939 & 2938 & n.d. \\
\hline & 5 & 3091 & 3090 & n.d. \\
\hline & 6 & 3243 & n.d. & n.d. \\
\hline \multirow{5}{*}{ Nonamer } & 0 & 2619 & 2618 & 2618 \\
\hline & 1 & 2771 & 2770 & n.d. \\
\hline & 2 & 2923 & 2923 & n.d. \\
\hline & 3 & 3075 & 3075 & n.d. \\
\hline & 4 & 3227 & n.d. & n.d. \\
\hline \multirow{4}{*}{ Decamer } & 0 & 2907 & 2907 & n.d. \\
\hline & 1 & 3059 & 3060 & n.d. \\
\hline & 2 & 3211 & 3212 & n.d. \\
\hline & 3 & 3363 & n.d. & n.d. \\
\hline \multirow{2}{*}{ Undecamer } & 0 & 3195 & 3194 & n.d. \\
\hline & 1 & 3347 & 3349 & n.d. \\
\hline
\end{tabular}


TABle 17: Main PAs identified in the MALDI-TOF positive-ion spectra of seeds extracts of 35 hybrid and $V$. vinifera grape varieties. Signals were divided in A and B series in reference to the interflavanic bond type: series B only B-type interflavanic bonds, and also A-type bonds are included in series A. Signals of sodium and protonated ions are reported. G: galloyl ester.

\begin{tabular}{|c|c|c|c|c|}
\hline \multirow{2}{*}{ Procyanidin } & \multicolumn{2}{|c|}{ Series B } & \multicolumn{2}{|c|}{ Series A } \\
\hline & {$[\mathrm{M}+\mathrm{H}]^{+}$} & {$[\mathrm{M}+\mathrm{Na}]^{+}$} & {$[\mathrm{M}+\mathrm{H}]^{+}$} & {$[\mathrm{M}+\mathrm{Na}]^{+}$} \\
\hline Dimer A-type & & & 577 & \\
\hline Dimer B-type & & 601 & & \\
\hline Dimer, $1 \mathrm{G}$ & & 753 & & \\
\hline Trimer & 867 & & & 863,865 \\
\hline Trimer & & 889 & & 887 \\
\hline Dimer, 2G & & 905 & & 903 \\
\hline Trimer, 1G & & 1041 & & 1039 \\
\hline Tetramer & & 1177 & & 1175 \\
\hline Trimer, 2G & & 1193 & & 1191 \\
\hline Tetramer, $1 \mathrm{G}$ & 1305 & 1329 & 1303 & 1327 \\
\hline Trimer, 3G & & 1345 & & 1343 \\
\hline Pentamer & & 1465 & & 1463 \\
\hline Tetramer, 2G & & 1481 & & 1629,1631 \\
\hline Pentamer, $1 G$ & & 1617 & & 1613,1615 \\
\hline Tetramer, 3G & & 1633 & & 1629,1631 \\
\hline Hexamer & & 1753 & & 1751 \\
\hline Pentamer, 2G & & 1769 & & 1765,1767 \\
\hline Tetramer, 4G & & 1785 & & 1781,1783 \\
\hline Hexamer, $1 G$ & & 1905 & & 1903 \\
\hline Pentamer, 3G & & 1921 & & 1917,1919 \\
\hline Heptamer & & 2041 & & \\
\hline Hexamer, $2 \mathrm{G}$ & & 2057 & & 2053,2055 \\
\hline Pentamer, 4G & & 2073 & & 2069,2071 \\
\hline Heptamer, $1 G$ & & 2193 & & 2189,2191 \\
\hline Hexamer, 3G & & 2209 & & 2205,2207 \\
\hline Pentamer, 5G & & 2225 & & 2221,2223 \\
\hline Heptamer, 2G & & 2345 & & 2341,2343 \\
\hline Hexamer, 4G & & 2361 & & 2357,2359 \\
\hline Heptamer, 3G & & 2497 & & 2495 \\
\hline Hexamer, 5G & & 2513 & & 2511 \\
\hline Octamer, $2 \mathrm{G}$ & & 2633 & & 2631 \\
\hline Heptamer, 4G & & 2649 & & 2647 \\
\hline Hexamer, 6G & & 2665 & & 2663 \\
\hline Octamer, 3G & & 2785 & & 2783 \\
\hline Heptamer 5G & & 2802 & & \\
\hline Nonamer, $2 \mathrm{G}$ & & 2922 & & 2919 \\
\hline Octamer, 4G & & 2937 & & 2935 \\
\hline Heptamer, 6G & & 2953 & & 2951 \\
\hline Nonamer, 3G & & 3073 & & 3071 \\
\hline Octamer, 5G & & 3089 & & 3087 \\
\hline Decamer, 2G & & 3209 & & 3207 \\
\hline Nonamer, 4G & & 3225 & & 3223 \\
\hline Octamer, 6G & & 3241 & & \\
\hline Decamer, 3G & & 3361 & & \\
\hline Nonamer, 5G & & 3377 & & 3376 \\
\hline Undecamer, 2G & & 3496 & & \\
\hline
\end{tabular}

most suitable techniques is generally a compromise between speed, selectivity, and sensitivity. Due to the complexity of plant extracts, statistical multivariate analysis of data (principal component analysis and cluster analysis) has to be performed to ensure good analytical rigorousness and define both similarities and differences among samples [94].

In general, an "untargeted" metabolomics approach provides sensitivity, resolution, and high-throughput capacity and identification of thousands compounds in a single run [95]. Several studies reported that by performing a "targeted" analysis of specific metabolites, large part of the molecular information regarding the metabolome of complex samples (e.g., the wine) is missed [96, 97]. On the other hand, other several studies performed in target analysis provided interesting results in the wine study [98-100]. For example, in targeted analysis of red wines, anthocyanins and the pigments formed during wine ageing were reported as main biomarkers [95].

A middle-way method between these two approaches is the "suspects screening analysis." In this study the identification of metabolites relies on available specific information on compounds such as their molecular formula and structure [101]. This approach is applied in our laboratories to the study of metabolomics of grape varieties. Grape berries are powered using liquid nitrogen (in order to minimize possible artifacts) and extracted with methanol. An internal standard is added, and the extract is analyzed with a LC/QTOF system with nominal resolution 40.000 which provides accurate mass measurements.

A library called Grape Metabolomics is actually under construction. This database includes the information available in the literature and found in electronic databases on the potential grape metabolites. Partial confirmation of the library hits was achieved by performing the identification of metabolites in extracts of some grape varieties taken as models for the peculiar chemical characteristics previously studied (e.g., Raboso Piave for the study of anthocyanins and polyphenols and Moscato Bianco for aroma precursors) [102, 103]. Currently, this library contains around 1000 putative compounds of grape with MW between 100 and $1700 \mathrm{Da}$. When data processing of a sample provides identification of a new compound with score sufficiently confident, it is added to the library. As a consequence, a further increase of the library will be possible. Compounds are identified on the basis of accurate mass measurements and their isotope patterns, and the identification is confirmed by MS/MS (multiple mass spectrometry).

With this approach, between 260 and 450 signals were assigned to putative phenolic compounds in grapes (the number depending on the grape variety), mainly including nutraceutical and antioxidant compounds such as anthocyanins, flavones and flavanones, flavanols and procyanidins, phytoalexins, and phenolic acids. Average 30-60 hits had an identification score higher than $99 \%$ and a hundred higher 95\% (Table 18). For example, in analysis of Raboso Piave grape extract, 17 stilbenes and derivatives were identified, among them trans-resveratrol, piceatannol, cis- and transpiceid, several viniferins, and resveratrol dimers, trimers, and tetramers. Moreover, tentative of identification of a number of aroma precursors (mono- and diterpenols glycoside, norisoprenoids), primary metabolites and peptides, is now in progress. 
TABLE 18: Phenolic compounds identified by LC/QTOF mass spectrometry and "suspects screening" analysis using the library GrapeMetabolomics in the study of metabolomics of Raboso Piave grape extract. The compounds identified with identification score (id.) higher than $95 \%$ are reported.

\begin{tabular}{|c|c|c|c|}
\hline Phenolic compound & Id. score & Exact mass & Formula \\
\hline Vanillic acid & 99.9 & 168.0423 & $\mathrm{C}_{8} \mathrm{H}_{8} \mathrm{O}_{4}$ \\
\hline cis-piceid & 99.9 & 390.1315 & $\mathrm{C}_{20} \mathrm{H}_{22} \mathrm{O}_{8}$ \\
\hline Pentahydroxyflavone A & 99.8 & 302.0427 & $\mathrm{C}_{15} \mathrm{H}_{10} \mathrm{O}_{7}$ \\
\hline Myricetin-3-O-rhamnoside & 99.8 & 464.0955 & $\mathrm{C}_{21} \mathrm{H}_{20} \mathrm{O}_{12}$ \\
\hline (epi)catechin gallate & 99.8 & 442.0900 & $\mathrm{C}_{22} \mathrm{H}_{18} \mathrm{O}_{10}$ \\
\hline Hydroxycoumarin & 99.8 & 162.0317 & $\mathrm{C}_{9} \mathrm{H}_{6} \mathrm{O}_{3}$ \\
\hline Rhamnetin & 99.8 & 316.0583 & $\mathrm{C}_{16} \mathrm{H}_{12} \mathrm{O}_{7}$ \\
\hline trans-resveratrol & 99.8 & 228.0786 & $\mathrm{C}_{14} \mathrm{H}_{12} \mathrm{O}_{3}$ \\
\hline Myricetin & 99.8 & 318.0376 & $\mathrm{C}_{15} \mathrm{H}_{10} \mathrm{O}_{8}$ \\
\hline Coumarin & 99.8 & 146.0368 & $\mathrm{C}_{9} \mathrm{H}_{6} \mathrm{O}_{2}$ \\
\hline Resveratrol tetramer 3 & 99.8 & 906.2676 & $\mathrm{C}_{56} \mathrm{H}_{42} \mathrm{O}_{12}$ \\
\hline Pentahydroxyflavone B & 99.7 & 302.0427 & $\mathrm{C}_{15} \mathrm{H}_{10} \mathrm{O}_{7}$ \\
\hline Pyrogallol & 99.7 & 126.0317 & $\mathrm{C}_{6} \mathrm{H}_{6} \mathrm{O}_{3}$ \\
\hline Syringetin & 99.7 & 346.0689 & $\mathrm{C}_{17} \mathrm{H}_{14} \mathrm{O}_{8}$ \\
\hline Taxifolin-deoxy hexoside B & 99.7 & 450.1162 & $\mathrm{C}_{21} \mathrm{H}_{22} \mathrm{O}_{11}$ \\
\hline Gingerol & 99.7 & 294.1831 & $\mathrm{C}_{17} \mathrm{H}_{26} \mathrm{O}_{4}$ \\
\hline Dimethoxyphenol & 99.6 & 154.0630 & $\mathrm{C}_{8} \mathrm{H}_{10} \mathrm{O}_{3}$ \\
\hline Barbaloin & 99.6 & 418.1264 & $\mathrm{C}_{21} \mathrm{H}_{22} \mathrm{O}_{9}$ \\
\hline trans-caffeoyl-tartaric acid & 99.6 & 312.0481 & $\mathrm{C}_{13} \mathrm{H}_{12} \mathrm{O}_{9}$ \\
\hline Ferulic acid & 99.6 & 194.0579 & $\mathrm{C}_{10} \mathrm{H}_{10} \mathrm{O}_{4}$ \\
\hline Delphinidin p-coumarylmonoglucoside & 99.6 & 611.1401 & $\mathrm{C}_{30} \mathrm{H}_{27} \mathrm{O}_{14}$ \\
\hline Laricitrin-3-O-glucoside & 99.6 & 494.1060 & $\mathrm{C}_{22} \mathrm{H}_{22} \mathrm{O}_{13}$ \\
\hline Emodin 8-glucoside & 99.5 & 432.1057 & $\mathrm{C}_{21} \mathrm{H}_{20} \mathrm{O}_{10}$ \\
\hline$E$ - $\varepsilon$-viniferin & 99.5 & 454.1416 & $\mathrm{C}_{28} \mathrm{H}_{22} \mathrm{O} 6$ \\
\hline Isorhamnetin-3-O-glucoside & 99.5 & 478.1111 & $\mathrm{C}_{22} \mathrm{H}_{22} \mathrm{O}_{12}$ \\
\hline Laricitrin & 99.4 & 332.0532 & $\mathrm{C}_{16} \mathrm{H}_{12} \mathrm{O}_{8}$ \\
\hline Cyanidin p-coumarylmonoglucoside & 99.4 & 595.1452 & $\mathrm{C}_{30} \mathrm{H}_{27} \mathrm{O}_{13}$ \\
\hline Esahydroxyflavanone-C-deoxy hexoside & 99.4 & 466.1111 & $\mathrm{C}_{21} \mathrm{H}_{22} \mathrm{O}_{12}$ \\
\hline Pentahydroxyflavanone-C-hexoside & 99.4 & 466.1111 & $\mathrm{C}_{21} \mathrm{H}_{22} \mathrm{O}_{12}$ \\
\hline Kaempferol-deoxy hexoside & 99.4 & 432.1056 & $\mathrm{C}_{21} \mathrm{H}_{20} \mathrm{O}_{10}$ \\
\hline$Z$ - $\varepsilon$-viniferin & 99.4 & 454.1416 & $\mathrm{C}_{28} \mathrm{H}_{22} \mathrm{O}_{6}$ \\
\hline (epi)gallocatechin-catechin & 99.3 & 594.1373 & $\mathrm{C}_{30} \mathrm{H}_{26} \mathrm{O}_{13}$ \\
\hline Caffeic acid & 99.3 & 180.0423 & $\mathrm{C}_{9} \mathrm{H}_{8} \mathrm{O}_{4}$ \\
\hline Taxifolin-deoxy hexoside A & 99.3 & 450.1162 & $\mathrm{C}_{21} \mathrm{H}_{22} \mathrm{O}_{11}$ \\
\hline Taxifolin-pentoside B & 99.3 & 436.1006 & $\mathrm{C}_{20} \mathrm{H}_{20} \mathrm{O}_{11}$ \\
\hline Guaiacol & 99.2 & 124.0524 & $\mathrm{C}_{7} \mathrm{H}_{8} \mathrm{O}_{2}$ \\
\hline Resveratrol dimer 4 & 99.2 & 454.1416 & $\mathrm{C}_{28} \mathrm{H}_{22} \mathrm{O}_{6}$ \\
\hline Methylnaringenin & 99.2 & 286.0841 & $\mathrm{C}_{16} \mathrm{H}_{14} \mathrm{O}_{5}$ \\
\hline Petunidin-3-O-monoglucoside & 99.2 & 479.1190 & $\mathrm{C}_{22} \mathrm{H}_{23} \mathrm{O}_{12}$ \\
\hline Tamarixetin & 99.2 & 316.0583 & $\mathrm{C}_{16} \mathrm{H}_{12} \mathrm{O}_{7}$ \\
\hline Peonidin acetylmonoglucoside & 99.2 & 505.1346 & $\mathrm{C}_{24} \mathrm{H}_{25} \mathrm{O}_{12}$ \\
\hline Dihydroquercetin & 99.2 & 304.0583 & $\mathrm{C}_{15} \mathrm{H}_{12} \mathrm{O}_{7}$ \\
\hline Syringetin-3-O-glucoside & 99.1 & 508.1217 & $\mathrm{C}_{23} \mathrm{H}_{24} \mathrm{O}_{13}$ \\
\hline Quercetin-3-O-rhamnoside & 99.1 & 448.1006 & $\mathrm{C}_{21} \mathrm{H}_{20} \mathrm{O}_{11}$ \\
\hline Fisetin & 99.1 & 286.0477 & $\mathrm{C}_{15} \mathrm{H}_{10} \mathrm{O}_{6}$ \\
\hline Luteolin & 99.1 & 286.0477 & $\mathrm{C}_{15} \mathrm{H}_{10} \mathrm{O}_{6}$ \\
\hline Vanillic acid beta-D-glucopyranoside & 98.9 & 330.0951 & $\mathrm{C}_{14} \mathrm{H}_{18} \mathrm{O}_{9}$ \\
\hline Peonidin p-coumaroylmonoglucoside & 98.9 & 609.1608 & $\mathrm{C}_{31} \mathrm{H}_{29} \mathrm{O}_{13}$ \\
\hline
\end{tabular}


TABle 18: Continued.

\begin{tabular}{|c|c|c|c|}
\hline Phenolic compound & Id. score & Exact mass & Formula \\
\hline Piceatannol & 98.7 & 244.0736 & $\mathrm{C}_{14} \mathrm{H}_{12} \mathrm{O}_{4}$ \\
\hline Petunidin acetylmonoglucoside & 98.6 & 521.1295 & $\mathrm{C}_{24} \mathrm{H}_{25} \mathrm{O}_{13}$ \\
\hline Myricetin-3-O-glucoside & 98.5 & 480.0904 & $\mathrm{C}_{21} \mathrm{H}_{20} \mathrm{O}_{13}$ \\
\hline p-hydroxybenzoic acid & 98.4 & 138.0317 & $\mathrm{C}_{7} \mathrm{H}_{6} \mathrm{O}_{3}$ \\
\hline Methylsyringate beta-D-glucopyranoside & 98.3 & 374.1213 & $\mathrm{C}_{16} \mathrm{H}_{22} \mathrm{O}_{10}$ \\
\hline Quercetin-3-O-glucoside & 98.0 & 464.0955 & $\mathrm{C}_{21} \mathrm{H}_{20} \mathrm{O}_{12}$ \\
\hline Resveratrol dimer 3 & 98.0 & 454.1416 & $\mathrm{C}_{28} \mathrm{H}_{22} \mathrm{O}_{6}$ \\
\hline Silybin & 97.9 & 482.1213 & $\mathrm{C}_{25} \mathrm{H}_{22} \mathrm{O}_{10}$ \\
\hline Methylvanillate beta-D-glucopyranoside & 97.9 & 344.1107 & $\mathrm{C}_{15} \mathrm{H}_{20} \mathrm{O}_{9}$ \\
\hline Syringaldehyde 4-O-beta-D-glucopyranoside & 97.9 & 344.1107 & $\mathrm{C}_{15} \mathrm{H}_{20} \mathrm{O}_{9}$ \\
\hline Procyanidin (B1, B2, B3, B4, B5) & 97.8 & 578.1424 & $\mathrm{C}_{30} \mathrm{H}_{26} \mathrm{O}_{12}$ \\
\hline Tetrahydroxy-dimethoxyflavanone-hexoside & 97.8 & 510.1373 & $\mathrm{C}_{23} \mathrm{H}_{26} \mathrm{O}_{13}$ \\
\hline Malvidin-3-O-monoglucoside & 97.7 & 493.1346 & $\mathrm{C}_{23} \mathrm{H}_{25} \mathrm{O}_{12}$ \\
\hline Resveratrol trimer 1 & 97.7 & 680.2046 & $\mathrm{C}_{42} \mathrm{H}_{32} \mathrm{O}_{9}$ \\
\hline Pelargonidin p-coumaroylmonoglucoside & 97.6 & 579.1503 & $\mathrm{C}_{30} \mathrm{H}_{27} \mathrm{O}_{12}$ \\
\hline Cyanidin-3-O-monoglucoside & 97.6 & 449.1084 & $\mathrm{C}_{21} \mathrm{H}_{21} \mathrm{O}_{11}$ \\
\hline Resveratrol trimer 2 & 97.5 & 680.2046 & $\mathrm{C}_{42} \mathrm{H}_{32} \mathrm{O}_{9}$ \\
\hline Di-O-methylquercetin B & 97.5 & 330.0740 & $\mathrm{C}_{17} \mathrm{H}_{14} \mathrm{O}_{7}$ \\
\hline p-cumaric acid beta-D-glucopyranoside & 97.5 & 326.1002 & $\mathrm{C}_{15} \mathrm{H}_{18} \mathrm{O}_{8}$ \\
\hline Delphinidin-3-O-monoglucoside & 97.4 & 465.1033 & $\mathrm{C}_{21} \mathrm{H}_{21} \mathrm{O}_{12}$ \\
\hline Quercetin-3-O-glucuronide & 97.4 & 478.0747 & $\mathrm{C}_{21} \mathrm{H}_{18} \mathrm{O}_{13}$ \\
\hline p-cumaric acid & 97.2 & 164.0473 & $\mathrm{C}_{9} \mathrm{H}_{8} \mathrm{O}_{3}$ \\
\hline Delphinidin acetylmonoglucoside & 97.2 & 507.1139 & $\mathrm{C}_{23} \mathrm{H}_{23} \mathrm{O}_{13}$ \\
\hline Procyanidin (T2, T3, T4) & 97.0 & 866.2058 & $\mathrm{C}_{45} \mathrm{H}_{38} \mathrm{O}_{18}$ \\
\hline Petunidin p-coumaroylmonoglucoside & 96.8 & 625.1557 & $\mathrm{C}_{31} \mathrm{H}_{29} \mathrm{O}_{14}$ \\
\hline Malvidin acetylmonoglucoside & 96.7 & 535.1452 & $\mathrm{C}_{25} \mathrm{H}_{27} \mathrm{O}_{13}$ \\
\hline Di-O-methylquercetin A & 96.5 & 330.0740 & $\mathrm{C}_{17} \mathrm{H}_{14} \mathrm{O}_{7}$ \\
\hline Malvidin p-coumaroylmonoglucoside & 96.3 & 639.1714 & $\mathrm{C}_{32} \mathrm{H}_{31} \mathrm{O}_{14}$ \\
\hline Methylgallic acid isomer 2 & 96.0 & 184.0372 & $\mathrm{C}_{8} \mathrm{H}_{8} \mathrm{O}_{5}$ \\
\hline Resveratrol dimer 5 & 95.5 & 454.1416 & $\mathrm{C}_{28} \mathrm{H}_{22} \mathrm{O}_{6}$ \\
\hline Coniferaldehyde 4-O-beta-D-glucopyranoside & 95.3 & 340.1158 & $\mathrm{C}_{16} \mathrm{H}_{20} \mathrm{O}_{8}$ \\
\hline Myricetin-3-O-glucuronide & 95.0 & 494.0697 & $\mathrm{C}_{21} \mathrm{H}_{18} \mathrm{O}_{14}$ \\
\hline
\end{tabular}

\section{Conclusions}

Mass spectrometry plays a very important role for research and quality control in the viticulture and oenology field. The soft ionization conditions of LC/MS and the minor sample purification usually needed make these techniques more suitable to study the structures of polyphenols and anthocyanins in grape extracts and for the study of structures correlated to the color changing of red wines. These methods also allow to characterize the high-MW compounds of grape, such as procyanidins, proanthocyanidins, prodelphinidins, and tannins. The important role of LC/MS in the structural study of polyphenols is also confirmed by the considerable number of papers appeared in the literature in the last years.

Complementary use of different MS techniques can be highly effective to characterize the large panorama of compounds of grape and wine. For example, the use of LC/MS, MALDI-TOF and MS/MS techniques allowed the characterization of procyanidin oligomers up to dodecamers; the coupling of LC/MS with MS/MS techniques is very effective in particular for characterization of glycoside compounds, and GC/MS and LC/MS analyses allow the characterization of hundreds volatile and nonvolatile compounds providing practically the whole metabolome of grape. Further development of these metabolomic approaches will provide effective tools for identification of a high number of important compounds in grape with few analyses and minimal sample preparation, providing useful information on the compounds involved in the metabolisms of cells and tissues.

\section{Acknowledgments}

The author would like to thank Dr. Laura Molin and Dr. Roberta Seraglia for the MALDI-TOF data of PAs and for the spectrum of Cabernet Sauvignon grape seeds extract kindly provided. 


\section{References}

[1] S. Renaud and M. De Lorgeril, "Wine, alcohol, platelets, and the French paradox for coronary heart disease," The Lancet, vol. 339, no. 8808, pp. 1523-1526, 1992.

[2] V. Cheynier and J. Rigaud, "HPLC separation and characterization of flavonols in the skin of Vitis vinifera var. Cinsault," American Journal of Enology and Viticulture, vol. 37, no. 4, pp. 248-252, 1986.

[3] S. Vidal, L. Francis, S. Guyot et al., "The mouth-feel properties of grape and apple proanthocyanidins in a wine-like medium," Journal of the Science of Food and Agriculture, vol. 83, no. 6, pp. 564-573, 2003.

[4] R. Flamini, "Mass spectrometry in grape and wine chemistry. Part I: polyphenols," Mass Spectrometry Reviews, vol. 22, no. 4, pp. 218-250, 2003.

[5] N. Castillo-Muñoz, S. Gómez-Alonso, E. García-Romero, and I. Hermosn-Gutiérrez, "Flavonol profiles of Vitis vinifera red grapes and their single-cultivar wines," Journal of Agricultural and Food Chemistry, vol. 55, no. 3, pp. 992-1002, 2007.

[6] N. Castillo-Muñoz, S. Gómez-Alonso, E. García-Romero, M. V. Gómez, A. H. Velders, and I. Hermosín-Gutiérrez, "Flavonol 3$\mathrm{O}$-glycosides series of Vitis vinifera $\mathrm{Cv}$. Petit Verdot red wine grapes," Journal of Agricultural and Food Chemistry, vol. 57, no. 1, pp. 209-219, 2009.

[7] M. Jang, L. Cai, G. O. Udeani et al., "Cancer chemopreventive activity of resveratrol, a natural product derived from grapes," Science, vol. 275, no. 5297, pp. 218-220, 1997.

[8] L. M. Hung, J. K. Chen, S. S. Huang, R. S. Lee, and M. J. Su, "Cardioprotective effect of resveratrol, a natural antioxidant derived from grapes," Cardiovascular Research, vol. 47, no. 3, pp. 549-555, 2000.

[9] E. N. Frankel, A. L. Waterhouse, and J. E. Kinsella, "Inhibition of human LDL oxidation by resveratrol," The Lancet, vol. 341, no. 8852, pp. 1103-1104, 1993.

[10] L. Frémont, L. Belguendouz, and S. Delpal, "Antioxidant activity of resveratrol and alcohol-free wine polyphenols related to LDL oxidation and polyunsaturated fatty acids," Life Sciences, vol. 64, no. 26, pp. 2511-2521, 1999.

[11] A. A. E. Bertelli, L. Giovannini, D. Giannessi et al., "Antiplatelet activity of synthetic and natural resveratrol in red wine," International Journal of Tissue Reactions, vol. 17, no. 1, pp. 1-3, 1995.

[12] C. R. Pace-Asciak, S. Hahn, E. P. Diamandis, G. Soleas, and D. M. Goldberg, "The red wine phenolics trans-resveratrol and quercetin block human platelet aggregation and eicosanoid synthesis: implications for protection against coronary heart disease," Clinica Chimica Acta, vol. 235, no. 2, pp. 207-219, 1995.

[13] L. Bavaresco, F. Mattivi, M. De Rosso, and R. Flamini, "Effects of elicitors, viticultural factors, and enological practices on resveratrol and stilbenes in grapevine and wine," Mini-Reviews in Medicinal Chemistry, vol. 12, no. 13, pp. 1366-1381, 2012.

[14] L. Bavaresco, E. Cantù, M. Fregoni, and M. Trevisan, "Constitutive stilbene contents of grapevine cluster stems as potential source of resveratrol in wine," Vitis, vol. 36, no. 3, pp. 115-118, 1997.

[15] P. Waffo-Teguo, D. Lee, M. Cuendet, J. M. Mërillon, J. M. Pezzuto, and A. Douglas Kinghorn, "Two new stilbene dimer glucosides from grape (Vitis vinifera) cell cultures," Journal of Natural Products, vol. 64, no. 1, pp. 136-138, 2001.
[16] R. H. Cichewicz, S. A. Kouzi, and M. T. Hamann, "Dimerization of resveratrol by the grapevine pathogen Botrytis cinerea," Journal of Natural Products, vol. 63, no. 1, pp. 29-33, 2000.

[17] M. Sbaghi, P. Jeandet, R. Bessis, and P. Leroux, "Degradation of stilbene-type phytoalexins in relation to the pathogenicity of Botrytis cinerea to grapevines," Plant Pathology, vol. 45, no. 1, pp. 139-144, 1996.

[18] T. C. Somers, “The polymeric nature of wine pigments," Phytochemistry, vol. 10, no. 9, pp. 2175-2186, 1971.

[19] C. F. Timberlake and P. Bridle, "Interactions between anthocyanins, phenolic compounds, and acetaldehyde and their significance in red wines," American Journal of Enology and Viticulture, vol. 27, no. 3, pp. 97-105, 1976.

[20] H. Fulcrand, C. Benabdeljalil, J. Rigaud, V. Cheynier, and M. Moutounet, "A new class of wine pigments generated by reaction between pyruvic acid and grape anthocyanins," Phytochemistry, vol. 47, no. 7, pp. 1401-1407, 1998.

[21] Y. Hayasaka and R. E. Asenstorfer, "Screening for potential pigments derived from anthocyanins in red wine using nanoelectrospray tandem mass spectrometry," Journal of Agricultural and Food Chemistry, vol. 50, no. 4, pp. 756-761, 2002.

[22] C. Alcalde-Eon, M. T. Escribano-Bailón, C. Santos-Buelga, and J. C. Rivas-Gonzalo, "Separation of pyranoanthocyanins from red wine by column chromatography," Analytica Chimica Acta, vol. 513, no. 1, pp. 305-318, 2004.

[23] J. L. Gómez-Ariza, T. García-Barrera, and F. Lorenzo, "Anthocyanins profile as fingerprint of wines using atmospheric pressure photoionisation coupled to quadrupole time-of-flight mass spectrometry," Analytica Chimica Acta, vol. 570, no. 1, pp. 101-108, 2006.

[24] H. Wang, E. J. Race, and A. J. Shrikhande, "Characterization of anthocyanins in grape juices by ion trap liquid chromatography-mass spectrometry," Journal of Agricultural and Food Chemistry, vol. 51, no. 7, pp. 1839-1844, 2003.

[25] L. Stella, M. De Rosso, A. Panighel, A. Dalla Vedova, R. Flamini, and P. Traldi, "Collisionally induced fragmentation of $[\mathrm{M}-\mathrm{H}]^{-}$species of resveratrol and piceatannol investigated by deuterium labelling and accurate mass measurements," Rapid Communications in Mass Spectrometry, vol. 22, no. 23, pp. 3867-3872, 2008.

[26] M. E. Camire, A. Chaovanalikit, M. P. Dougherty, and J. Briggs, "Blueberry and grape anthocyanins as breakfast cereal colorants," Journal of Food Science, vol. 67, no. 1, pp. 438-441, 2002.

[27] J. He and M. M. Giusti, "Anthocyanins: natural colorants with health-promoting properties," Annual Review of Food Science and Technology, vol. 1, pp. 163-187, 2010.

[28] V. Hong and R. E. Wrolstad, "Characterization of anthocyanincontaining colorants and fruit juices by HPLC/photodiode array detection," Journal of Agricultural and Food Chemistry, vol. 38, no. 3, pp. 698-708, 1990.

[29] A. Versari, R. B. Boulton, and G. P. Parpinello, "A comparison of analytical methods for measuring the color components of red wines," Food Chemistry, vol. 106, no. 1, pp. 397-402, 2008.

[30] C. Alcalde-Eon, M. T. Escribano-Bailón, C. Santos-Buelga, and J. C. Rivas-Gonzalo, "Changes in the detailed pigment composition of red wine during maturity and ageing: a comprehensive study," Analytica Chimica Acta, vol. 563, no. 1-2, pp. 238-254, 2006.

[31] C. Boido, F. Alcalde-Eon, E. Carrau, E. Dellacassa, and J. C. Rivas-Gonzalo, "Aging effect on the pigment composition and 
color of Vitis vinifera L. cv. Tannat wines. Contribution of the main pigment families to wine color," Journal of Agricultural and Food Chemistry, vol. 54, pp. 6692-6704, 2006.

[32] J. Bakker and C. F. Timberlake, "Isolation, identification, and characterization of new color-stable anthocyanins occurring in some red wines," Journal of Agricultural and Food Chemistry, vol. 45, no. 1, pp. 35-43, 1997.

[33] R. E. Asenstorfer, Y. Hayasaka, and G. P. Jones, "Isolation and structures of oligomeric wine pigments by bisulfite-mediated ion-exchange chromatography," Journal of Agricultural and Food Chemistry, vol. 49, no. 12, pp. 5957-5963, 2001.

[34] M. Schwarz, T. C. Wabnitz, and P. Winterhalter, "Pathway leading to the formation of anthocyanin-vinylphenol adducts and related pigments in red wines," Journal of Agricultural and Food Chemistry, vol. 51, no. 12, pp. 3682-3687, 2003.

[35] A. Morata, F. Calderón, M. C. González, M. C. GómezCordovés, and J. A. Suárez, "Formation of the highly stable pyranoanthocyanins (vitisins A and B) in red wines by the addition of pyruvic acid and acetaldehyde," Food Chemistry, vol. 100, no. 3, pp. 1144-1152, 2007.

[36] S. Pati, I. Losito, G. Gambacorta, E. La Notte, F. Palmisano, and P. G. Zambonin, "Simultaneous separation and identification of oligomeric procyanidins and anthocyanin-derived pigments in raw red wine by HPLC-UV-ESI-MSn," Journal of Mass Spectrometry, vol. 41, no. 7, pp. 861-871, 2006.

[37] W. M. A. Niessen and A. P. Tinke, "Liquid chromatographymass spectrometry. General principles and instrumentation," Journal of Chromatography A, vol. 703, no. 1-2, pp. 37-57, 1995.

[38] E. de Hoffmann, "Tandem mass spectrometry: a primer," Journal of Mass Spectrometry, vol. 31, no. 2, pp. 125-137, 1996.

[39] J. Abian, "The coupling of gas and liquid chromatography with mass spectrometry," Journal of Mass Spectrometry, vol. 34, no. 3, pp. 157-168, 1999.

[40] R. Flamini, A. Dalla Vedova, D. Cancian, A. Panighel, and M. De Rosso, "GC/MS-positive ion chemical ionization and MS/MS study of volatile benzene compounds in five different woods used in barrel making," Journal of Mass Spectrometry, vol. 42, no. 5, pp. 641-646, 2007.

[41] H. J. Li and M. L. Deinzer, "Tandem mass spectrometry for sequencing proanthocyanidins," Analytical Chemistry, vol. 79, no. 4, pp. 1739-1748, 2007.

[42] M. D. Rosso, A. Panighel, A. D. Vedova, L. Stella, and R. Flamini, "Changes in chemical composition of a red wine aged in acacia, cherry, chestnut, mulberry, and oak wood barrels," Journal of Agricultural and Food Chemistry, vol. 57, no. 5, pp. 1915-1920, 2009.

[43] B. Sun, M. C. Leandro, V. de Freitas, and M. I. Spranger, "Fractionation of red wine polyphenols by solid-phase extraction and liquid chromatography," Journal of Chromatography A, vol. 1128, no. 1-2, pp. 27-38, 2006.

[44] S. González-Manzano, C. Santos-Buelga, J. J. Pérez-Alonso, J. C. Rivas-Gonzalo, and M. T. Escribano-Bailón, "Characterization of the mean degree of polymerization of proanthocyanidins in red wines using liquid chromatography-mass spectrometry (LC-MS)," Journal of Agricultural and Food Chemistry, vol. 54, no. 12, pp. 4326-4332, 2006.

[45] B. Gabetta, N. Fuzzati, A. Griffini et al., "Characterization of proanthocyanidins from grape seeds," Fitoterapia, vol. 71, no. 2, pp. 162-175, 2000.

[46] S. A. Lazarus, G. E. Adamson, J. F. Hammerstone, and H. H. Schmitz, "High-performance liquid chromatography/mass spectrometry analysis of proanthocyanidins in foods and beverages," Journal of Agricultural and Food Chemistry, vol. 47, no. 9, pp. 3693-3701, 1999.

[47] V. Núñez, C. Gómez-Cordovés, B. Bartolomé, Y. J. Hong, and A. E. Mitchell, "Non-galloylated and galloylated proanthocyanidin oligomers in grape seeds from Vitus vinifera L. cv. Graciano, Tempranillo and Cabernet Sauvignon," Journal of the Science of Food and Agriculture, vol. 86, no. 6, pp. 915-921, 2006.

[48] Q. Wu, M. Wang, and J. E. Simon, "Determination of proanthocyanidins in fresh grapes and grape products using liquid chromatography with mass spectrometric detection," Rapid Communications in Mass Spectrometry, vol. 19, no. 14, pp. 2062-2068, 2005.

[49] R. Flamini, M. Rosso De, A. Smaniotto et al., "Fast analysis of isobaric grape anthocyanins by chip-liquid chromatography/mass spectrometry," Rapid Communications in Mass Spectrometry, vol. 23, no. 18, pp. 2891-2896, 2009.

[50] Y. Hayasaka, E. J. Waters, V. Cheynier, M. J. Herderich, and S. Vidal, "Characterization of proanthocyanidins in grape seeds using electrospray mass spectrometry," Rapid Communications in Mass Spectrometry, vol. 17, no. 1, pp. 9-16, 2003.

[51] V. Cheynier, T. Doco, H. Fulcrand et al., "ESI-MS analysis of polyphenolic oligomers and polymers," Analusis, vol. 25, no. 8, pp. M32-M37, 1997.

[52] C. P. Passos, S. M. Cardoso, M. R. M. Domingues, P. Domingues, C. M. Silva, and M. A. Coimbra, "Evidence for galloylated typeA procyanidins in grape seeds," Food Chemistry, vol. 105, no. 4, pp. 1457-1467, 2007.

[53] A. Delcambre and C. Saucier, "Identification of new flavan-3-ol monoglycosides by UHPLC-ESI-Q-TOF in grapes and wine," Journal of Mass Spectrometry, vol. 47, no. 6, pp. 727-736, 2012.

[54] M. Monagas, R. Suárez, C. Gómez-Cordovés, and B. Bartolomé, "Simultaneous determination of nonanthocyanin phenolic compounds in red wines by HPLC-DAD/ESI-MS," American Journal of Enology and Viticulture, vol. 56, no. 2, pp. 139-147, 2005.

[55] H. Fulcrand, S. Remy, J. M. Souquet, V. Cheynier, and M. Moutounet, "Study of wine tannin oligomers by on-line liquid chromatography electrospray ionization mass spectrometry," Journal of Agricultural and Food Chemistry, vol. 47, no. 3, pp. 1023-1028, 1999.

[56] S. Vidal, E. Meudec, V. Cheynier, G. Skouroumounis, and Y. Hayasaka, "Mass spectrometric evidence for the existence of oligomeric anthocyanins in grape skins," Journal of Agricultural and Food Chemistry, vol. 52, no. 23, pp. 7144-7151, 2004.

[57] I. I. Rockenbach, E. Junfer, C. Ritter et al., "Characterization of flavan-3-ols in seeds of grape pomace by CE, HPLC-DAD-MSn and LC-ESI-FTICR-MS," Food Research International, vol. 48, no. 2, pp. 845-855, 2012.

[58] M. De Rosso, L. Tonidandel, R. Larcher et al., "Study of anthocyanic profiles of twenty-one hybrid grape varieties by liquid chromatography and precursor-Ion mass spectrometry," Analytica Chimica Acta, vol. 732, pp. 120-129, 2012.

[59] S. Pati, M. T. Liberatore, G. Gambacorta, D. Antonacci, and E. La Notte, "Rapid screening for anthocyanins and anthocyanin dimers in crude grape extracts by high performance liquid chromatography coupled with diode array detection and tandem mass spectrometry," Journal of Chromatography A, vol. 1216, no. 18, pp. 3864-3868, 2009.

[60] C. Alcalde-Eon, M. T. Escribano-Bailón, C. Santos-Buelga, and J. C. Rivas-Gonzalo, "Identification of dimeric anthocyanins 
and new oligomeric pigments in red wine by means of HPLCDAD-ESI/MSn," Journal of Mass Spectrometry, vol. 42, no. 6, pp. 735-748, 2007.

[61] L. Hartmanova, V. Ranc, B. Papouskova, P. Bednar, V. Havlicek, and K. Lemr, "Fast profiling of anthocyanins in wine by desorption nano-electrospray ionization mass spectrometry," Journal of Chromatography A, vol. 1217, no. 25, pp. 4223-4228, 2010.

[62] B. Sun, T. A. Fernandes, and M. I. Spranger, "A new class of anthocyanin-procyanidin condensation products detected in red wine by electrospray ionization multi-stage mass spectrometry analysis," Rapid Communications in Mass Spectrometry, vol. 24, no. 3, pp. 254-260, 2010.

[63] B. Papoušková, P. Bednář, K. Hron et al., "Advanced liquid chromatography/mass spectrometry profiling of anthocyanins in relation to set of red wine varieties certified in Czech Republic," Journal of Chromatography A, vol. 1218, no. 42, pp. 7581-7591, 2011.

[64] E. Revilla, J. M. Ryan, and G. Martín-Ortega, "Comparison of several procedures used for the extraction of anthocyanins from red grapes," Journal of Agricultural and Food Chemistry, vol. 46, no. 11, pp. 4592-4597, 1998.

[65] L. Gao, B. Girard, G. Mazza, and A. G. Reynolds, "Changes in anthocyanins and color characteristics of Pinot Noir during different vinification processes," Journal of Agricultural and Food Chemistry, vol. 45, no. 6, pp. 2003-2008, 1997.

[66] D. Favretto and R. Flamini, "Application of electrospray ionization mass spectrometry to the study of grape anthocyanins," American Journal of Enology and Viticulture, vol. 51, no. 1, pp. 55-64, 2000.

[67] E. Salas, V. Atanasova, C. Poncet-Legrand, E. Meudec, J. P. Mazauric, and V. Cheynier, "Demonstration of the occurrence of flavanol-anthocyanin adducts in wine and in model solutions," Analytica Chimica Acta, vol. 513, no. 1, pp. 325-332, 2004.

[68] B. Sun, C. P. Reis Santos, M. C. Leandro, V. De Freitas, and M. I. Spranger, "High-performance liquid chromatography/electrospray ionization mass spectrometric characterization of new products formed by the reaction between flavanols and malvidin 3-glucoside in the presence of acetaldehyde," Rapid Communications in Mass Spectrometry, vol. 21, no. 14, pp. 2227-2236, 2007.

[69] P. Mazzuca, P. Ferranti, G. Picariello, L. Chianese, and F. Addeo, "Mass spectrometry in the study of anthocyanins and their derivatives: differentiation of Vitis vinifera and hybrid grapes by liquid chromatography/electrospray ionization mass spectrometry and tandem mass spectrometry," Journal of Mass Spectrometry, vol. 40, no. 1, pp. 83-90, 2005.

[70] R. Flamini, F. Agnolin, R. Seraglia et al., "A fast and selective method for anthocyanic profiling of red wines by directinfusion pneumatic spray mass spectrometry," Rapid Communications in Mass Spectrometry, vol. 26, no. 3, pp. 355-362, 2012.

[71] S. Vidal, L. Francis, A. Noble, M. Kwiatkowski, V. Cheynier, and E. Waters, "Taste and mouth-feel properties of different types of tannin-like polyphenolic compounds and anthocyanins in wine," Analytica Chimica Acta, vol. 513, no. 1, pp. 57-65, 2004.

[72] C. Dufour and I. Sauvaitre, "Interactions between anthocyanins and aroma substances in a model system. Effect on the flavor of grape-derived beverages," Journal of Agricultural and Food Chemistry, vol. 48, no. 5, pp. 1784-1788, 2000.

[73] M. Garcia-Alonso, G. Rimbach, M. Sasai et al., "Electron spin resonance spectroscopy studies on the free radical scavenging activity of wine anthocyanins and pyranoanthocyanins," Molecular Nutrition and Food Research, vol. 49, no. 12, pp. 1112-1119, 2005.

[74] I. Tedesco, G. Luigi Russo, F. Nazzaro, M. Russo, and R. Palumbo, "Antioxidant effect of red wine anthocyanins in normal and catalase-inactive human erythrocytes," Journal of Nutritional Biochemistry, vol. 12, no. 9, pp. 505-511, 2001.

[75] R. Flamini and D. Tomasi, "The anthocyanin content in berries of the hybrid grape cultivars Clinton and Isabella," Vitis, vol. 39, no. 2, pp. 79-81, 2000.

[76] E. Hebrero, C. Garcia-Rodriguez, C. Santos-Buelga, and J. C. Rivas-Gonzalo, "Analysis of anthocyanins by high performance liquid chromatography-diode array spectroscopy in a hybrid grape variety (vitis vinifera $\mathrm{x}$ vitis berlandieri 41b)," American Journal of Enology and Viticulture, vol. 40, pp. 283-291, 1989.

[77] S. L. Nixdorf and I. Hermosín-Gutiérrez, "Brazilian red wines made from the hybrid grape cultivar Isabel: phenolic composition and antioxidant capacity," Analytica Chimica Acta, vol. 659, no. 1-2, pp. 208-215, 2010.

[78] F. Mattivi, R. Guzzon, U. Vrhovsek, M. Stefanini, and R. Velasco, "Metabolite profiling of grape: flavonols and anthocyanins," Journal of Agricultural and Food Chemistry, vol. 54, no. 20, pp. 7692-7702, 2006.

[79] R. Di Stefano, "Metodichimici nella caratterizzazione varietale," Rivista di Viticoltura e di Enologia, vol. 1, pp. 51-56, 1996.

[80] Q. Tian, M. M. Giusti, G. D. Stoner, and S. J. Schwartz, "Screening for anthocyanins using high-performance liquid chromatography coupled to electrospray ionization tandem mass spectrometry with precursor-ion analysis, product-ion analysis, common-neutral-loss analysis, and selected reaction monitoring," Journal of Chromatography A, vol. 1091, no. 1-2, pp. 72-82, 2005.

[81] I. J. Košir, B. Lapornik, S. Andrenšek, A. G. Wondra, U. Vrhovšek, and J. Kidrič, "Identification of anthocyanins in wines by liquid chromatography, liquid chromatographymass spectrometry and nuclear magnetic resonance," Analytica Chimica Acta, vol. 513, no. 1, pp. 277-282, 2004.

[82] M. Monagas, V. Núñez, B. Bartolomé, and C. Gómez-Cordovés, "Anthocyanin-derived pigments in Graciano, Tempranillo, and Cabernet Sauvignon wines produced in Spain," American Journal of Enology and Viticulture, vol. 54, no. 3, pp. 163-169, 2003.

[83] P. Kebarle and U. H. Verkcerk, "Electrospray: from Ions in solution to Ions in the gas phase, what we know now," Mass Spectrometry Reviews, vol. 28, no. 6, pp. 898-917, 2009.

[84] S. Crotti, R. Seraglia, and P. Traldi, "Some thoughts on electrospray ionization mechanisms," European Journal of Mass Spectrometry, vol. 17, no. 2, pp. 85-100, 2011.

[85] P. Sarni-Manchado, H. Fulcrand, J. M. Souquet, V. Cheynier, and M. Moutounet, "Stability and color of unreported wine anthocyanin-derived pigments," Journal of Food Science, vol. 61, no. 5, pp. 938-941, 1996.

[86] M. Karas, U. Bahr, and U. Gießmann, "Matrix-assisted laser desorption ionization mass spectrometry," Mass Spectrometry Reviews, vol. 10, no. 5, pp. 335-357, 1991.

[87] A. E. Ashcroft, "Protein and peptide identification: the rôle of mass spectrometry in proteomics," Natural Product Reports, vol. 20, no. 2, pp. 202-215, 2003.

[88] Y. Yang and M. Chien, "Characterization of grape procyanidins using high-performance liquid chromatography/mass spectrometry and matrix-assisted laser desorption/ionization timeof-flight mass spectrometry," Journal of Agricultural and Food Chemistry, vol. 48, no. 9, pp. 3990-3996, 2000. 
[89] C. G. Krueger, N. C. Dopke, P. M. Treichel, J. Folts, and J. D. Reed, "Matrix-assisted laser desorption/ionization timeof-flight mass spectrometry of polygalloyl polyflavan-3-ols in grape seed extract," Journal of Agricultural and Food Chemistry, vol. 48, no. 5, pp. 1663-1667, 2000.

[90] N. Vivas, M. F. Nonier, and N. Vivas De Gaulejac, "Structural characterization and analytical differentiation of grape seeds, skins, steams and Quebracho tannins," Bulletin de L'OIV, vol. 77, no. 883-884, pp. 643-659, 2004.

[91] N. Vivas, M. F. Nonier, N. V ivas De Gaulejac, C. Absalon, A. Bertrand, and M. Mirabel, "Differentiation of proanthocyanidin tannins from seeds, skins and stems of grapes (Vitis vinifera) and heartwood of Quebracho (Schinopsis balansae) by matrix-assisted laser desorption/ionization time-offlight mass spectrometry and thioacidolysis/liquid chromatography/electrospray ionization mass spectrometry," Analytica Chimica Acta, vol. 513, no. 1, pp. 247-256, 2004.

[92] H. A. Weber, A. E. Hodges, J. R. Guthrie et al., "Comparison of proanthocyanidins in commercial antioxidants: grape seed and pine bark extracts," Journal of Agricultural and Food Chemistry, vol. 55, no. 1, pp. 148-156, 2007.

[93] M. F. Nonier, C. Absalon, N. Vivas, and N. Vivas De Gaulejac, "Application of off-line size-exclusion chromatographic fractionation-matrix assisted laser desorption ionization time of flight mass spectrometry for proanthocyanidin characterization," Journal of Chromatography A, vol. 1033, no. 2, pp. 291-297, 2004.

[94] L. Mattoli, F. Cangi, A. Maidecchi et al., "Metabolomic fingerprinting of plant extracts," Journal of Mass Spectrometry, vol. 41, no. 12, pp. 1534-1545, 2006.

[95] P. Arapitsas, M. Scholz, U. Vrhovsek et al., "A metabolomic approach to the study of wine micro-oxygenation," PLOS ONE, vol. 7, no. 5, Article ID e37783, 2012.

[96] A. Cuadros-Inostroza, P. Giavalisco, J. Hummel, A. Eckardt, L. Willmitzer, and H. Peña-Cortés, "Discrimination of wine attributes by metabolome analysis," Analytical Chemistry, vol. 82, no. 9, pp. 3573-3580, 2010.

[97] L. Vaclavik, O. Lacina, J. Hajslova, and J. Zweigenbaum, “The use of high performance liquid chromatography-quadrupole time-of-flight mass spectrometry coupled to advanced data mining and chemometric tools for discrimination and classification of red wines according to their variety," Analytica Chimica Acta, vol. 685, no. 1, pp. 45-51, 2011.

[98] A. Carpentieri, G. Marino, and A. Amoresano, "Rapid fingerprinting of red wines by MALDI mass spectrometry," Analytical and Bioanalytical Chemistry, vol. 389, no. 3, pp. 969-982, 2007.

[99] H. Fulcrand, C. Mané, S. Preys et al., "Direct mass spectrometry approaches to characterize polyphenol composition of complex samples," Phytochemistry, vol. 69, no. 18, pp. 3131-3138, 2008.

[100] G. Mazerolles, S. Preys, C. Bouchut et al., "Combination of several mass spectrometry ionization modes: a multiblock analysis for a rapid characterization of the red wine polyphenolic composition," Analytica Chimica Acta, vol. 678, no. 2, pp. 195-202, 2010.

[101] M. Krauss, H. Singer, and J. Hollender, "LC-high resolution MS in environmental analysis: from target screening to the identification of unknowns," Analytical and Bioanalytical Chemistry, vol. 397, no. 3, pp. 943-951, 2010.

[102] M. De Rosso, A. Panighel, R. Carraro et al., "Chemical characterization and enological potential of Raboso varieties by study of secondary grape metabolites," Journal of Agricultural and Food Chemistry, vol. 58, no. 21, pp. 11364-11371, 2010.
[103] R. Flamini, A. Dalla Vedova, and A. Calò, "Studio sui contenuti monoterpenici di 23 accessioni di uve Moscato: correlazione tra profilo aromatico e varietà," Rivista Di Viticoltura E Di Enologia, vol. 54, no. 2-3, pp. 35-49, 2001. 

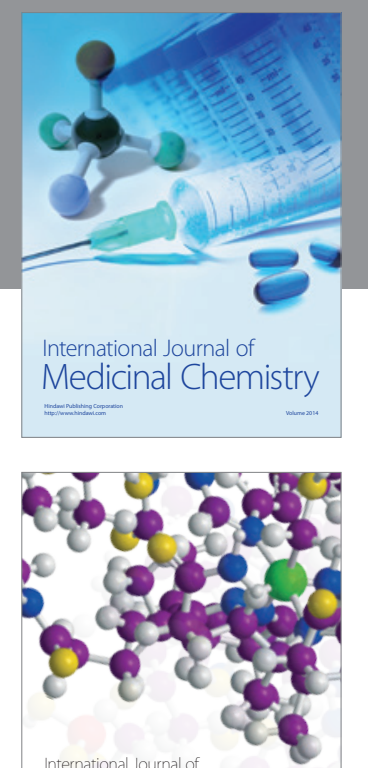

\section{Carbohydrate} Chemistry

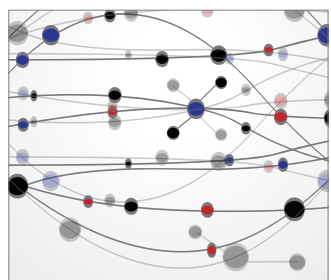

The Scientific World Journal
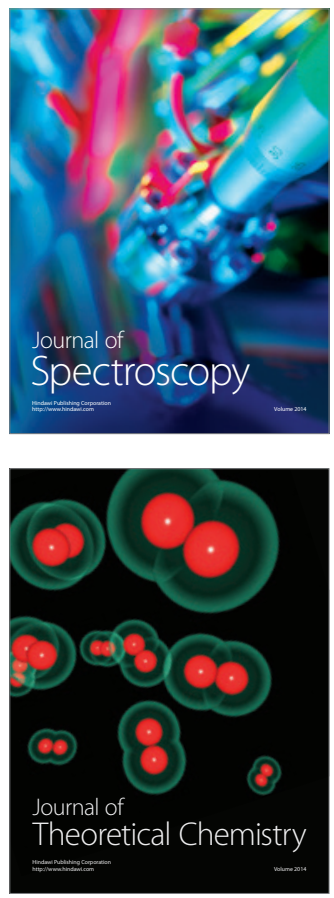
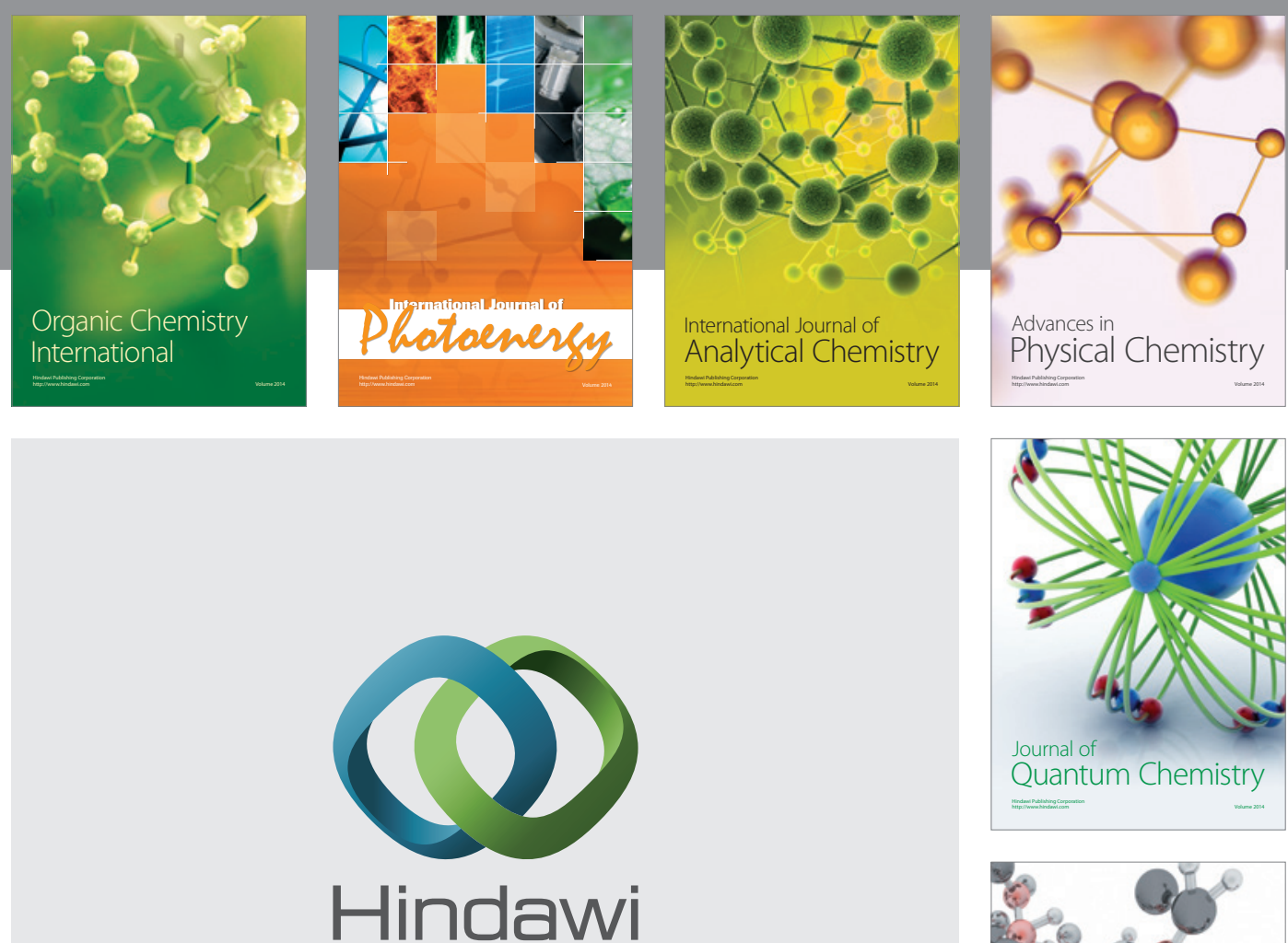

Submit your manuscripts at

http://www.hindawi.com

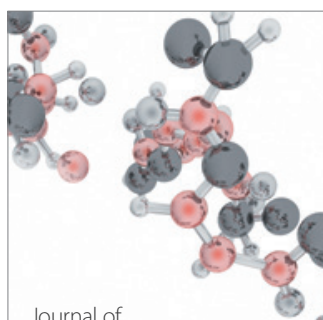

Analytical Methods

in Chemistry

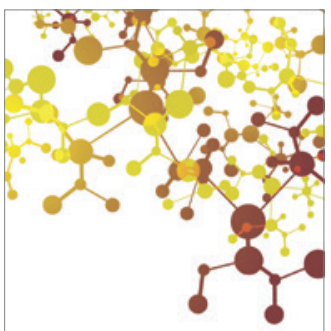

Journal of

Applied Chemistry

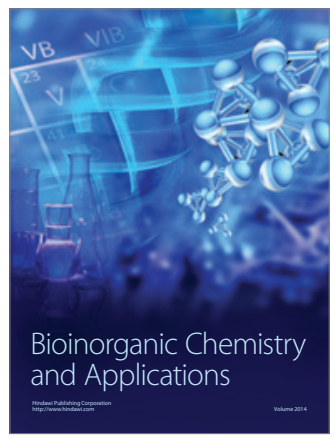

Inorganic Chemistry
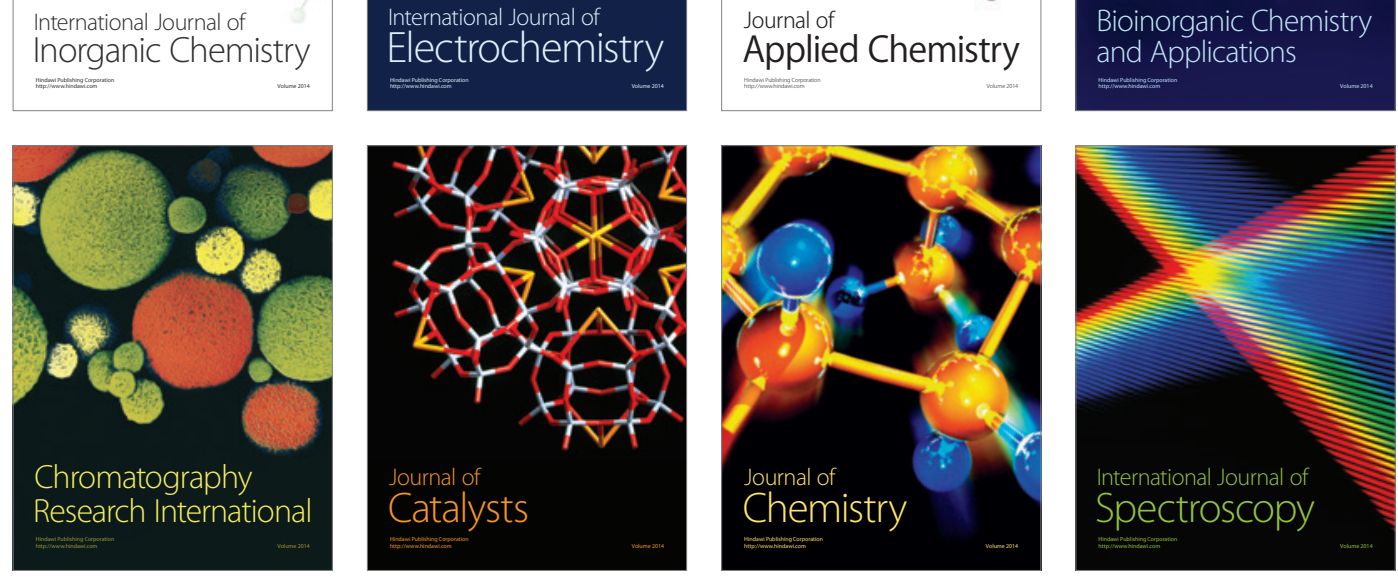